BNL - 28073 - 99/05 - REV

Informal Report

\title{
REQUIREMENTS AND GUIDELINES FOR NSLS EXPERIMENTAL BEAM LINE VACUUM SYSTEMS - REVISION B
}

\author{
C. Foerster \\ National Synchrotron Light Source, Brookhaven National Laboratory \\ P.O. Box 5000, Upton, NY, USA 11973-5000
}

May 1999

National Synchrotron Light Source

Brookhaven National Laboratory

Operated by

$\therefore$ Brookhaven Science Associates

Upton, NY 11973

Under Contract with the United States Department of Energy

Contract Number DE-AC02-98CH10886 


\section{DISCLAIMER}

This report was prepäred as an account of work sponsored by an agency of the United States Government. Neither the United States Government nor any agency thereof, nor any of their employees, nor any of their contractors, subcontractors or their employees, makes any warranty, express or implied, or assumes any legal liability or responsibility for the accuracy, completeness, or any third party's use or the results of such use of any information, apparatus, product, or process disclosed, or represents that its use would not infringe privately owned rights. Reference herein to any specific commercial product, process, or service by trade name, trademark, manufacturer, or otherwise, does not necessarily constitute or imply its endorsement, recommendation, or favoring by the United States Government or any agency thereof or its contractors or subcontractors. The views and opinions of authors expressed herein do not necessarily state or reflect those of the United States Government or any agency thereof. 
BNL

Revision B

Informal Report

Requirements and Guidelines for NSLS Experimental Beam Line Vacuum Systems - Revision B

C. Foerster

May 1999

Original Document - BNL 28073

J.B. Godel and J.C. Schuchman

July 1980 
BNL

Revision B

Informal Report

\title{
REQUIREMENTS AND GUIDELINES FOR NSLS EXPERIMENTAL BEAM LINE VACUUM SYSTEMS \\ Revision B
}

\author{
May 1999 \\ C. Foerster
}

Research Supported by the OFFICE OF BASIC ENERGY SCIENCES

U.S. DEPARTMENT OF ENERGY

WASHINGTON, D.C,

\section{NATIONAL SYNCHROTRON LIGHT SOURCE BROOKHAVEN NATIONAL LABORATORY \\ Brookhaven Science Associates}




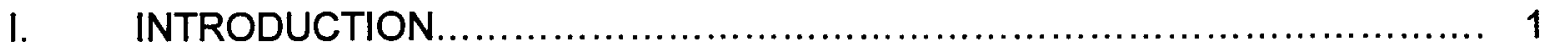

II. BEAM LINE FRONT ENDS ..................................................... 2

II.A UHV Gate Valve...................................................... 2

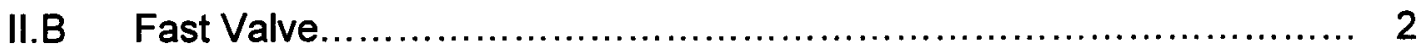

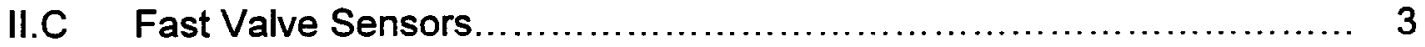

III. VACUUM INTERLOCKS............................................................. 3

IV. GUIDELINES FOR UHV BEAM LINE VACUUM SYSTEMS .................... 4

IV.A Materials................................................................. 4

IV.B Vacuum Hardware - Pumps, Valves, Flanges.......................... 6

IV.C Acoustic Delay Lines and Beam Line Fast Valves....................... 6

IV.D Instrumentation........................................................ 7

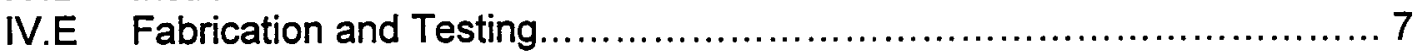

IV.F Central Shops Cleaning Facility ...................................... 8

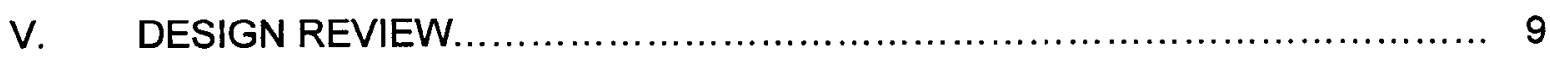

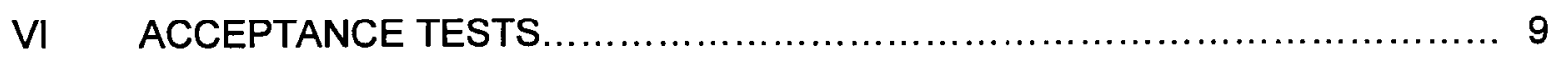

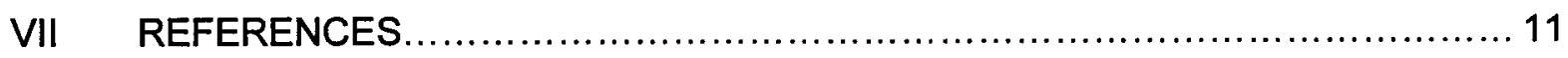

\section{APPENDICES}

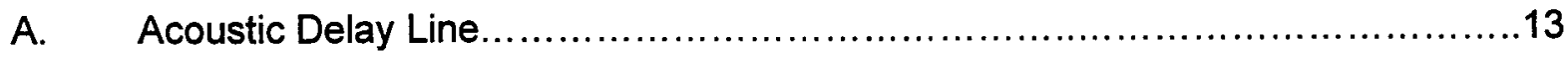

B. NSLS Vacuum Standards

SLS-07.10-6-1 Tentative Standards of the American Vacuum Society (Only Table of Contents Provided) …............................................................17

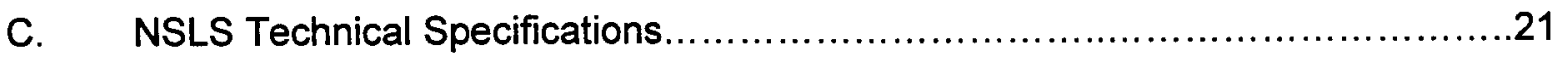

SLS-07.11-7-1 Fast Valve Sensor

SLS-07.12-1-1 Cleaning Procedures for Vacuum Components and Hardware

SLS-07.12-2-1 Cleaning and Fabrication of Welded Bellows Assemblies

SLS-07.13-1-1 Thermister Gauge, Atmosphere to 1 Micron

SLS-07.13-2-1 Thermister Gauge, Atmosphere to 1 Micron

SLS-07.13-3-1 Ion Gauge, Cold Cathode, $10^{-3}$ to $10^{-8}$ Torr

SLS-07.13-4-1 Ion Gauge, Hot Filament, $10^{-4}$ to $10^{-11}$ Torr

SLS-07.14-1-1 UHV Bakeable Flanges (Conflat)

SLS-07.14-4-1 · Copper Gaskets for Conflat Flanges

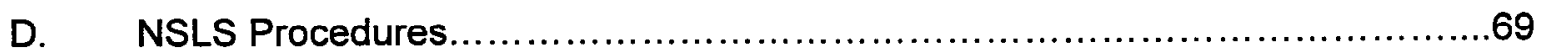

LS-M-0108 (SLS-07.19-12-1) Vacuum Procedure to Open VUV or X-ray Beam Line Front End Valve

LS-M-0103 (SLS-07.19-4-1) Baking Out VUV or X-ray Storage Ring 


\section{INTRODUCTION}

Typical beam lines, shown in Figures $1 \mathrm{a}$ and $1 \mathrm{~b}$, are comprised of an assembly of vacuum valves and shutters referred to as a "front end", optical elements to monochromatize, focus and split the photon beam, and an experimental area where a target sample is placed into the photon beam and data from the interaction is detected and recorded. Windows are used to separate sections of beam lines that are not compatible with storage ring ultra high vacuum.

Some experimental beam lines share a common vacuum with storage rings. Sections of beam lines are only allowed to vent up to atmospheric pressure using pure nitrogen gas after a vacuum barrier is established to protect ring vacuum. The front end may only be bled up when there is no current in the machine. This is especially true on the VUV storage ring where for most experiments, windows are not used. For the shorter wavelength, more energetic photons of the $x$-ray ring, beryllium windows are used at various beam line locations so that the monochromator, mirror box or sample chamber may be used in a helium atmosphere or rough vacuum. The window separates ring vacuum from the environment of the downstream beam line components.

The stored beam lifetime in the storage rings and the maintenance of desirable reflection properties of optical surfaces depend upon hydrocarbon-free, ultra-high vacuum systems. Storage ring vacuum systems will operate at pressures of $\sim 1 \times 10^{-10}$ Torr without beam and $\sim 1$ $\times 10^{-9}$ Torr with beam. Systems are free of hydrocarbons in the sense that no pumps, valves, etc. containing organics are used. Components are all-metal, chemically cleaned and bakeable. To the extent that beam lines share a common vacuum with the storage ring, the same criteria will hold for beam line components. The design philosophy for NSLS beam lines is to use allmetal, hydrocarbon-free front end components and recommend that experimenters use this approach for common vacuum hardware downstream of front ends. O-ring-sealed valves, if used, are not permitted upstream of the monochromator exit aperture. It will be the responsibility of users to demonstrate that their experiment will not degrade the pressure or quality of the storage ring vacuum. As a matter of operating policy, all beam lines will be monitored for prescribed pressure and the contribution of high mass gases to this pressure each time a beam line has been opened to ring vacuum. 


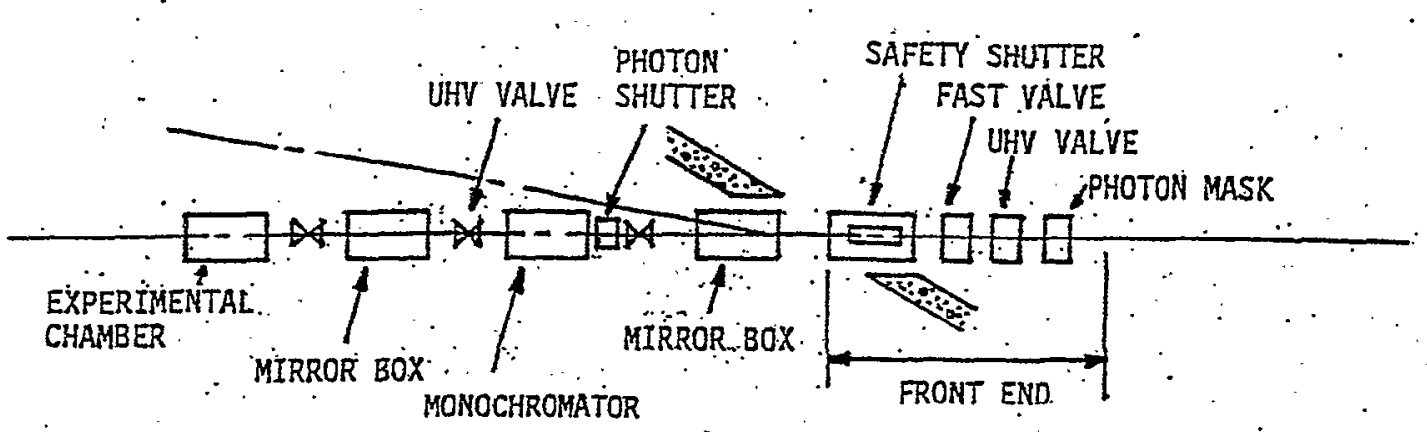

TYPICAL VUY BEAM LINE FIGURE IA:

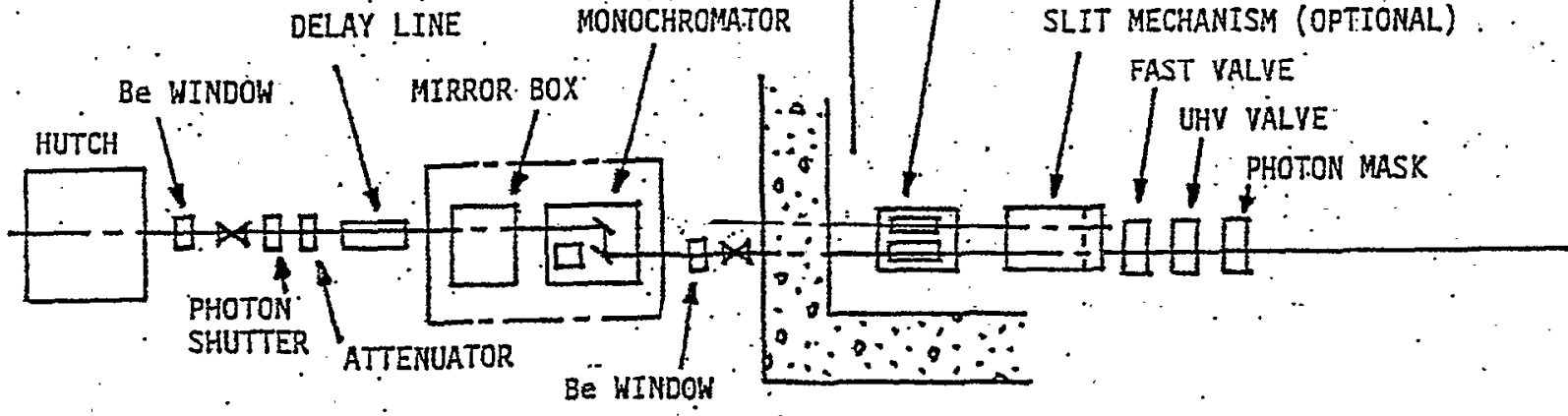

TYPICAL-X-RAY BEAM LINE

FTEURE 18. 


\section{FRONT ENDS}

Each beam port front end contains a $150 \mathrm{~mm}$ (6 in.) diameter Granville-Phillips (G-P) or VAT, all-metal gate valve and a BNL-designed fast valve. The gate valve is the primary vacuum isolation valve between the storage ring and the beam line. The fast-acting valve, which seals to a conductance of approximately 0.1 torr-liter second ${ }^{-1}$ in less than 8 milliseconds is used to intercept a pressure wave of atmospheric air from an accidental break in the beam line vacuum envelope. The gate valve is pneumatically closed and sealed in approximately two to three seconds.

All front ends will be designed, fabricated, installed and maintained by the NSLS. All vacuum interlocks on beam line components supplied by experimenters will use NSLS designs or a NSLS approved design. Electrical connections between vacuum interlocks and front end components will be made and tested by NSLS staff members.

Front ends will be fitted with a hot filament ionization gauge, to measure pressure, and a residual gas analyzer (RGA) head on a flanged valve connection. Spectrographic analysis of the residual gas will be done for each new experiment before the UHV valve is opened and then either continuously or intermittently during operation. The frequency will be determined by the Beamline Vacuum Committee or the Vacuum Group in order to monitor changes in the partial pressure of the gas constituents.

\section{II.A UHV Gate Valve (Graneville-Phillips or VAT Valve)}

The GRANEVILLE-PHILLIPS (GP) valve is no longer manufactured, therefore VAT valves must be used for replacements. The GP valve has a lifetime of approximately 2000 closures, after which the valve must be removed and replaced. The VAT valve is larger and heavier than the G-P valve and has a lifetime of 10,000 cycles. Valve replacement requires that the storage ring be let up to boil-off $\mathrm{N}_{2}$.

By adding UHV valves on beam lines as shown in Figure 1, monochromators, mirror boxes, and experimental chambers can be vacuum isolated and a vacuum barrier can be established to protect ring vacuum. The front end UHV valve will be closed and sealed when working on internal front end components or on the first VUV mirror box. The valve will also be closed and sealed to isolate a beam line when the ring must be vented up to boil-off $N_{2}$. GP front end valves will be closed, but do not have to be sealed, prior to closing isolating UHV valves on the beam line. Approved NSLS beam line vacuum procedures will be followed for valve and boil off $\mathrm{N}_{2}$ operations.

The front end UHV valve cannot be closed without also closing the photon mask to protect the valve from overheating. Located between the UHV valve and the storage ring, the photon mask is automatically closed whenever the UHV valve is closed. However, controls are provided to close the mask independently of the UHV valve. Controls to close the front end valve and valve position displays are located at each experimental station. Opening the sealed UHV valve can only take place after beam line pressure and residual gas analysis have met NSLS standards.

\section{II.B Fast Valve}

The NSLS fast valve closes in less than eight milliseconds and has a leak rate less than one Torr liter per second when closed. The NSLS valve fast apertures are $14 \times 140 \mathrm{~mm}, 19 \times 146$ 
$\mathrm{mm}$, and $30 \times 146 \mathrm{~mm}$. Commercial fast valves (i.e., shutters) may be used if approved by the NSLS Vacuum Group and the NSLS Beam Line Vacuum Committee.

There are no manual controls for fast valves. They close automatically when the sensor pressure reaches a prescribed limit. Position indication will be provided from the fast valve actuator.

\section{II.C Fast Valve Sensors}

The NSLS has evaluated four types of cold discharge sensors:
a. Spark gap
b. Coaxial Discharge Switch
c. Penning Gauge (2 liters per sec ion pump)
d. Varian miniature appendage pump (see Appendix A)

The Varian miniature appendage pump was selected as a standard sensor and its use is mandatory on all front ends and beam lines. The design of the NSLS fast valve sensor will be found in Appendix A. Design of the fast valve sensor firing circuits is based on the standard sensor selected.

Sensors are located to suit each type of beam line set-up or experimental condition. In general, one should be placed in the front end and one should be placed at least five meters downstream from the fast valve. Additional sensors and sensor circuits should be placed near potential breaks in the vacuum envelope. For the VUV experiment in Figure 1a, sensors should be located as follows:
a. Front end
b. Monochromator or mirror box, or (exit-slit housing) or adjacent to ring vacuum side of beryllium window

For the x-ray experiment in Figure $1 b$, where the monochromator and mirror box are UHVcompatible, sensors should be placed as follows:

a. Front end

b. Monochromator-mirror box or

Adjacent to ring vacuum side of beryllium window,

A beryllium window will be used between the safety shutter and the monochromator when the monochromator and mirror box operate in helium. For this case, sensors will be installed in two places:

a. Front end, downstream end of the safety shutter

b. Adjacent to the ring vacuum side of the beryllium window

\section{VACUUM INTERLOCKS}

Fast valve sensors will protect the storage ring in the event of a beam line vacuum failure. There are interlocks in the storage ring to protect beam lines from a storage ring vacuum failure:

If the pressure at any beam line sensor increases to $1 \times 10^{-5} \mathrm{Torr}$, the fast valve will be triggered. Triggering the fast valve simultaneously closes the photon mask and UHV valve. The safety interlock system will also dump the electron beam. If the pressure in the front_end exceeds $7 \times 10^{-6}$ Torr, the UHV valve in the front end will close and seal via high pressure 
interlock with the ion gauge. The photon shutter will automatically close at this time. The fast valve will remain open.

Either the experimenter or the Operations Coordinator can close, or close and seal, the front end UHV valve. Only an authorized NSLS staff member can open the closed and sealed valve after he or she is assured that the beam line pressure is $2 \times 10^{-9}$ Torr or less and a residual gas scan indicates acceptable gas composition with no offending hydrocarbons. Exceptions to these requirements must be authorized by The Beam Line Vacuum Committee or the Vacuum Group. Under normal operating conditions the UHV valve will remain open. During injection it may be necessary for the Control Room operator to close the valve.

When venting part of a beam line to atmospheric pressure with boil-off $\mathrm{N}_{2}$ the fast valve sensors which serve the portion being vented must be bypassed. An interlock or approved procedure must prevent the sensors from remaining being locked out when the entire beam line is once again under vacuum.

In order not to seal the front end UHV valve more than necessary, UHV valves will be used whenever possible on beam lines to isolate monochromators and mirror boxes. Before closing the isolating valves, the experimenter will close the front end mask. Isolation valves should not be opened unless the pressure in this section is under hard vacuum, the pressure in the front end is $2 \times 10^{-9}$ Torr, and the residual gas specification is met. Vacuum gauges will be installed in each vacuum separable portion of a beam line. Should an isolation valve be opened accidentally, the front end valve will protect the storage ring and the fast valve will be actuated. The "bleeding-up" and "returning to operation" procedures for each beam line in the "NSLS Beam Line Vacuum Procedures" book should be followed. The beam line spokes person develops the procedures, which must be approved by the NSLS prior to beam line operation. Copies are posted at each beam line.

For some windowless experiments where a particularly noxious sample or environment is used, the NSLS Beamline Vacuum Committee may require additional fast and UHV valves and triggers on the beam line. If the valves are placed at a point where the photon beam is focused, small diameter commercial valves can be used.

\section{GUIDELINES FOR UHV VACUUM SYSTEMS .}

The standards cited below are used for all NSLS beam line hardware that is not separated from the storage ring vacuum system by a window. It is the NSLS policy that all front ends must operate at or below $2 \times 10^{-9}$ Torr and be hydrocarbon-free. (See Section VI, Acceptance Tests). Users may deviate from the standards that follow as long as the performance requirements are approved by the NSLS Vacuum Committee. However, we strongly recommend that these guidelines be followed to ensure that NSLS UHV criteria are met, that optical surfaces will have reasonably long lifetimes without contamination, and that there will be interchangeability with NSLS vacuum hardware.

IV.A Materials

IV.A.1 The following materials are UHV-compatible: Stainless Steel - Austenitic, 300 Series

Preferred types are 304L, 316L, 321 and 347. The "L" signifies low carbon content which reduces carbide precipitation in the heat affected weld areas. Carbide precipitation can lead to corrosion and reduced strength. 
Aluminum-6061-T6 is high-strength, easily weldable alloy. If the material is to be bent, use 5454, 5058, etc. for. crack-free bends but at a somewhat reduced strength.

Copper-Oxygen-free high conductivity, OFHC

Titanium - Commercially pure, aircraft quality, type 50A

Ceramics, Refectories

Alumina and similar oxide ceramics

Sapphire

Glass

Metals, Inorganic Materials

Noble metals

Inconel, Monel

Kovar

Beryllium Copper

Mu. Metal

Lithium Fluoride

Magnesium Fluoride

Aluminum-to-stainless transition material, as noted in Section IV.A.2.

\section{IV.A:2 Aluminum-to-Stainless Steel Transition Material}

The following transition materials have been successfully used on UHV systems. However, before they can be used with confidence numerous inspections, bakeout cycles and leak tests must be made before and after fabrication. Since these materials can vary from lot to lot, all pieces should be $100 \%$ inspected and tested.

It is desirable to make tests for porosity and inclusions by means of radiography, ultrasonics and vacuum leak testing, depending upon the geometry of the transition material. However, thermal cycling the material is a must. Sources of supply are listed below:

Roll-Bonded Plate and Shells:

- Clad Metals, Inc., Cannonsburg, Pa. 15317 .

Roll-Bonded Plate

- Kaiser Aluminum and Chemical Sales 300 Lakeside Dr. Oakland, California 94612.

Friction-Welded Bars

- Coatings, Inc. 6623 West Mitchell St. Milwaukee, WI 53214 
Explosion-Bonded Plate

- Aerospace Materials, Inc, 249 Fornof Road, Columbus, OH 43207

- Explosive Fabricators, Inc, Louisville, CO 80027

- E.I. duPont de Nemours and Co.

Wilmington, DE 19898

IV.A.3 The following materials are not UHV compatible:

Zinc - Bearing metals and alloys

Cadmium - Bearing metals and alloys

Elastomers - O-ring-sealed flanges and valves

Organics - Oil-bearing pumps

\section{IV.B Vacuum Hardware}

IV.B.1 Pumps

The following types of pumps are hydrocarbon-free and are the only pumps permitted upstream of the first monochromator apertures:

- Sputter-ion pumps

- Titanium sublimation pumps

- NEG pumps

The following types of pumps may be used for rough pumping the beam line or during bake out. They must be interlock protected through an interconnecting valve in case of pressure failure.

- Turbopumps

- Cryopumps

- Sorption pumps

\section{IV.B.2 Valves}

Commercial, all-metal, bakeable UHV valves available in various styles and sizes from a number of manufacturers have been found acceptable. The NSLS Vacuum Group can advise beam lines concerning valves. Valve flanges must be in accordance with Sec. IV.B.3 below.

IV.B.3 Flanges

The "Conflat" type flange is standard on NSLS beam lines. Varian, the inventor of this flange, has licensed a number of manufacturers to produce them. The flange must be machined from cross-forged blanks or from vacuum remelted bar stock. This flange is described in Specification SLS-07.14-1-1 in Appendix B.

The cōpper sealing gaskets and the high strength clamping bolts are described in NSLS specifications SLS-07.14-4-1 and SLS-07.14-5-1, respectively. 


\section{IV.C Acoustic Delay Lines and Beam Line Fast Valves}

It was stated above that the storage ring is protected from an accidental inrush of air from a break in beam line vacuum. This is done through thefront end fast valve which is closed by the action of the fast valve sensor. Such protection is possible only if there is enough time for the fast valve to close before the arrival of the wave front. It was reported ${ }^{1}$ that the velocity of a pressure front in a vacuum beam tube in the range of $10^{-6}$ to $10^{-3}$ millibars is about one meter per millisecond for air and twice that for helium. The NSLS fast valve requires 5 to 7 meters between the trigger and the fast valve to intercept the wave front. Since this space is not always available, especially for VUV experiments, it may be recommended by the Beam Line Vacuum Committee that an acoustic delay line similar to that shown in Appendix $B$, be used. It should be located as close as practicable to the potential break in the beam line.

Where space restrictions prohibit the use of an acoustic delay line; it has been showr ${ }^{2}$ that the combination of a small aperture in a monochromator exit slit and a conical disc with a small hole that is located 25 to $30 \mathrm{~cm}$ upstream of the exit slit (with respect tothe shock wave), can substantially delay the shock wave. See Appendix B.

IV.D Instrumentation

Gauges - The following gauges are used at the NSLS and are recommended for use on beam line vacuum systems. Each gauge is described in the NSLS specifications listed below:

SLS-07.13-4-1.

SLS-07.13-3-1

SLS-07.13-1-1

SLS-07.13-2-1
Hot Filament Ionization Gauge, for $10^{-4}$ to $10^{-11}$ Torr. Cold Cathode lonization Gauge, for pressures $10^{-3}$ to $10^{-8}$. It must be modified for UHV (remove "O" ring and weld).

Thermistor Gauge (convectron guage), for pressures from atmosphere to one micron.

Thermistor Gauge, for pressures from atmosphere to one micron. It may be convenient to use this gauge with the cold cathode gauge above, as they are both packaged in one relatively small unit)

\section{IV.E Fabrication and Testing}

\section{IV.E.1 Machining}

a. The use of sulphur-bearing oils and abrasives is prohibited. Use CIMCOOL, KOOLMIST No. 77, MOBIL CUT MAX, or MISSLE LUB No. 5 or NSLS appróved equal.

b. All blind holes to be vented.

c. Avoid high impedance connections between parts

\footnotetext{
${ }^{1}$ Measurements on the Efficiency of Acoustic Delay Lines in View of Beamlines for Synchrotron Radiation, H. Betz, P. Hofbauer, and A. Henberger, J. Vac. Sci. Tech Note, 16 (3) May/June 1979.

${ }^{2}$ Measurement of Shock Wave Flight Times in Long Pipes, W. Peatman and E.W. Weiner, BESSY, Technischen Bericht 18/79, November 1979
} 


\section{IV.E.2 Welding}

a. No vacuum-to-water joints are permitted.

b. Weld to be on vacuum side of joint if possible. If not, full penetration welds to be used to eliminate virtual leaks.

c. Where high strength requires welding on both sides of thick sections, the side facing the vacuum is to be continuous and the opposite side intermittent. At no time should there be continuous welds on both sides of the joint.

d. Tungsten Inert Gas (TIG) and Electron Beam welding are recommended for UHV vacuum applications.

e. Hydrogen brazed joints are acceptable.

f. No silver soldered or soft soldered joints are permitted.

\section{IV.E.3 Leak Test}

The total leak rate of individual parts and assemblies must not exceed $2 \times 10^{-10}$ std $\mathrm{cc} / \mathrm{sec} \mathrm{He}$. A vacuum bakeout prior to leak checking is recommended to drive out any cleaning solutions or machining fluids that might otherwise plug a leak. It is recommended that all parts be chemically cleaned or vacuum baked prior to assembly on the NSLS.* After cleaning, the vacuum surfaces should not be touched with bare hands. (The outgassing rate of a fingerprint is reported to be $10^{-5}$ Torr liter/sec $\mathrm{cm}^{2}$ ).

\section{IV.E.4 References}

The following references are included for more comprehensive data:

\begin{tabular}{cl} 
Subject & References \\
\hline Design & \\
General Vacuum Technology & all \\
Conductances & $1,7,12,20$ \\
Differential Pumping & 19 \\
Outgassing & $2,7,12,20$ \\
Materials & $4,9,16$ \\
Welding Design & 9,21
\end{tabular}

\section{IV.F Central Shops Cleaning Facilitv}

A Central Shops cleaning facility was established to clean UHV components and hardware. This facility was set up primarily to clean aluminum, stainless steel, and copper. However, glass and ceramic parts can also be processed. The facility is located in building 498 on the West side of machine shop building 479 .

Experimental beam line components for Participating Research Teams and General Users may be processed through this facility after receiving necessary accounting and scheduling approval.

*See Section IV.F, NSLS Cleaning facility 


\section{Cleaning Process Summary}

The cleaning process developed to clean parts for the Brookhaven National Laboaratory is a multistep, batch type operation consisting of eight distinct steps in separate tanks. The process was set-up to clean stainless steel, aluminum, and copper. The equipment used in the cleaning process includes the washing tanks with ultrasonics, rinsing tanks, an air oven dryer, an automated material handling hoist, and an exhaust venting system to remove odor, water, and alcohol vapor from the top surface areas of the tanks.

1. Process steps

- ALMECO 18 (or equivalent) solution at $170^{\circ} \mathrm{F}\left(77^{\circ} \mathrm{C}\right)$.

- Deionized (DI) water immersion rinse at $140^{\circ} \mathrm{F}\left(60^{\circ} \mathrm{C}\right)$.

- Buff off 16000 solution at $170^{\circ} \mathrm{F}\left(77^{\circ} \mathrm{C}\right)$

- DI water immersion rinse at $140^{\circ} \mathrm{F}\left(60^{\circ} \mathrm{C}\right)$

- CITRANOX solution at $170^{\circ} \mathrm{F}\left(77^{\circ} \mathrm{C}\right)$

- DI water immersion rinse at $140^{\circ} \mathrm{F}\left(60^{\circ} \mathrm{C}\right)$

- Nondenatured ethanol rinse at $77^{\circ} \mathrm{F}\left(25^{\circ} \mathrm{C}\right)$

- Air oven dry at $212^{\circ} \mathrm{F}\left(100^{\circ} \mathrm{C}\right)$ at atmospheric pressure.

Original Cleaning Procedure for Reference see NSLS specification SLS-07.12-1-1 in Appendix $\mathrm{B}$ for details.

\section{DESIGN REVIEW}

In addition to a mandatory Design Review by the NSLS Beam Line Review Committee, experimenters are required to submit plans of their equipment to the NSLS Beam Line Vacuum Committee for a review of the vacuum design. Included shall be:

- Beam line assembly drawings to scale

- A list of materials of construction

- Gas burden expected from target samples

- A list of pumps and guages

- Details of any gas phase experiments

It is expected that experimenters will adhere to NSLS guidelines and standards for material and component selections, cleaning, and fabrication. Where guidelines and standards are not followed, the user shall demonstrate how his design will not compromise the vacuum requirements of the storage ring,

It is recommended that the:vacuum design review shall take place before beam line fabrication begins or major vacuum components ordered. NSLS approval of a PRT design does not relieve the PRT from satisfying the requirements as stated in the acceptance test below.

\section{VI.: ACCEPTANCE TESTS}

Before a beam line is connected to ring vacuum for the first time (Ref: SLS 07-19-12-1, Procedure to Open Front End Valve), the following tests will be made: 
a. Pressure: The system will maintain a base Pressure of no more than $2 \times 10^{-9}$ Torr as measured at the front end ionization gauge

b. A Residual Gas Analysis: The predominant gas component should be hydrogen and be at least $60 \%$ of the total pressure. There should be no evidence of air or other leaks in the system and masses greater than 28 amu shall be less than $10 \%$ of the total pressure. The sum of components at mass locations $39,41,43,45$ and greater shall total less than $1 \times 10^{-11}$ (N2 equivalent).

Thereafter, each time a beam line is opened to ring vacuum, steps $a$ and $b$ above must be satisfactorily completed if the front end G-P valve has been closed and sealed.

The following vacuum interlocks on users' apparatus will be approved by the NSLS prior to the initial start up of an experiment:

- Fast valve sensors location and hookup.

- Rising pressure from slow leak will close the UHV front end valve

- High system pressure in beam line prevents opening of UHV front end valve

- Auxiliary fast valves, on beam lines, where required

When a part of an existing beam line is brought up to air or conditions are otherwise changed that would affect the vacuum, the beam line can be returned to service only when steps $a$ and $b$ of Section VI. are satisfactorily completed. See NSLS Beam Line Vacuum Procedures Book in the control room.

It will be the responsibility of the experimenter to demonstrate, in collaboration with NSLS staff, that adequate means have been provided to impede a pressure wave front from an accidental break in his vacuum system so that it can be effectively stopped by the fast valve (see Section II.C). For purposes of design, use a fast valve closing time of 8 milliseconds. 


\section{REFERENCES}

1. A. Guthrie and R.K. Wakerling, Vacuum Equipment and Techniques, McGraw Hill, 1949.

2. P.A. Redhead, J/P/ Hobson, and E.V. Kornelson, The Physical Basis of Ultrahigh Vacuum, Chapman and Hall, 1968.

3. A.E. Barrington, High Vacuum Engineering, Prentice-Hall, 1964.

4. A.H. Beck (Ed.) Handbook of Vacuum Physics, Pergamon, 1965-1968.

5. W.F. Brunner and T.H. Batzer, Practical Vacuum Techniques, Krieger, 1974.

6. L.G. Carpenter, Vacuum Technology - An Introduction, Elsevier, 1970.

7. S. Dushman, Scientific Foundations of Vacuum Technique, 2nd Edition, (J.M. Lafferty, Ed.) Wiley, 1962.

8. N.W. Robinson, Physical Principles of Ultrahigh Vacuum Systems and Equipment, Chapman and Hall, 1968.

9. F. Rosebury, Handbook of Electron Tube and Vacuum Techniques, Addison-Wesley, 1965.

10. A. Roth, Vacuum Sealing Techniques, Pergamon, 1966.

11. H.A. Steinherz, Handbook of High Vacuum Engineering, Reinhold, 1963.

12. C.M. Van Atta Vacuum Science and Engineering, McGraw-Hill, 1965.

13. J. Yarwood, High Vacuum Technique, 4th Edition, Chapman and Hall, 1967.

14. J. Yarwood, et al., Vacuum Manual, Halsted Press. 1973.

15. K. Diels and R. Jaekel, Leybold Vacuum Handbook, (H. Adam and J. Edwards, trans.), Pergamon, 1966.

16. W. Espe, Materials of High Vacuum Technology, 3 Vols., Pergamon, 1968.

17. A. Guthrie, Vacuum Technology, Wiley, 1963.

18. J.H. Leck, Pressure Mèasurement in Vacuum Systems, Chapman and Hall, 1964.

19. J.A.R. Samson, Techiniques of Ultraviolet Spectroscopy, John Wiley and Sons, 1967, pg. 92.

20. A. Roth, Vacuum Technology, North-Holland, 1983. 


\section{Appendix A}

A. Acoustic Delay Line 


\section{APPENDIX A}

\section{Acoustic Delay Line}

Experiments and calculations ${ }^{1-4}$ show that the efficiency of an acoustic delay line is dependent upon such factors as:

1. Overall length, (L)

2. Ratio of diameter of chamber to aperture, D/d

3. Distance between segments

4. Number of segments

5. Shape of segments

Each delay line must be designed to suit its particular application. The aperture of each segment must clear the diverging photon beam. Ideally, the delay line would be located near the source of the vacuum leak and at a point where the beam was focused. The ratio of the diameter of the chamber to the equivalent diameter of the aperture affects the efficiency. Jean and Rauss found a $D / d$ of 10 to be four times as efficient as a $D / d$ of 5 . Betz, et al. 3 reported that conical segments doubled the efficiency of flat segments for an acoustic delay line with a $D / d=5_{\text {; }}$

Betz, et al., also demonstrated that the efficiency improved sharply with increasing distance between segments up to 10 or $15 \mathrm{~cm}$, and reached a maximum at $30 \mathrm{~cm}$. The most effective total length of the delay line is said to be 4 to 5 times the segment distance.

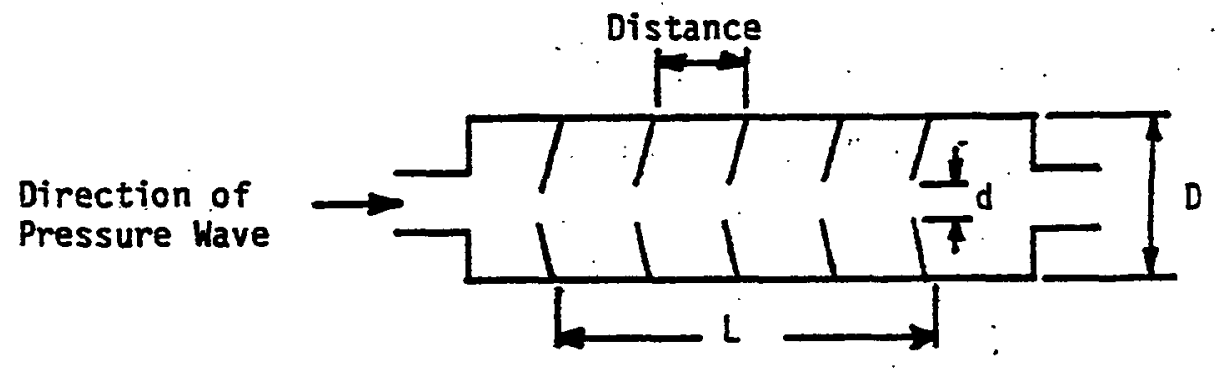

Peatman and Weiner ${ }^{4}$, using the apparatus shown below, showed that considerable delay times could be achieved using a limited number of baffles in conjunction with the exit slit of a monochromator.

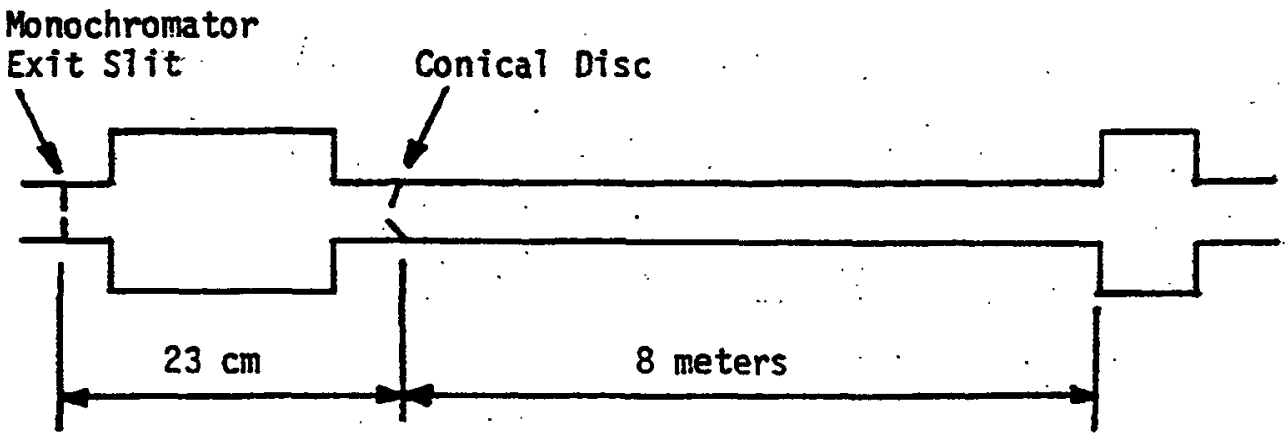


The data associated with their experiments are noted below:

\begin{tabular}{|c|c|c|c|c|}
\hline Exit slit (mm) & Aperture (mm) & $\begin{array}{l}\text { Time to Raise } \\
\text { at Fast Valve } \\
3 \times 10 \text { Torr mi } 11 \\
\end{array}$ & $\begin{array}{l}\text { Pressure } \\
\text { to } \\
\text { liseconds } \\
\end{array}$ & $\begin{array}{c}\text { Average } \\
\text { Velocity (m/msec) }\end{array}$ \\
\hline \multirow[t]{2}{*}{$0.2 \times 6$} & 15 & 87 & & 0.1 \\
\hline & $8 \times 9$ & 140 & & 0.06 \\
\hline $0.25 \times 8$. & 15 & 72 & $\because$ & 0.12 \\
\hline $8 \times 9$ & 15 & 24 & & 0.35 \\
\hline$\cdot$ & $8 \times 9$ & 34 & $\therefore$ & 0.25 \\
\hline 60 & none & 8.4 & & 1.0 \\
\hline
\end{tabular}

A summary of Peatman and Weiner's conclusions:

a. The velocity of the shock wave can be reduced by a factor of at least 3 ; depending upon the size of the exit slit. and aperture.

b. Flight time is unaffected for initial pressures of less than $3 \times 10^{-5}$ Torr.

c. Spacing between slit and conical disc of $25-30 \mathrm{~cm}$ is optimat.

d. Nonlinear geometries such as monochromators, mirror boxes, etc. and the volume of the system do not add to the delay tịme.

e. STit size is the most important factor in delay time.

f: Adding the conical disc improved the delay time between 40 and $70 \%$.

The designer should take into acount the considerable surface area in the acoustic delay line. Outgassing from this surface could adversely affect system pressure unless a vacuum pump is added. Because of the high impedance of an acoustic delay it can be used with vacuum pumps to provide differential pumping for certain classes of experiments.

1. Design of a Synchrotron Radition for Orsay's ACO Storage Ring: Lure, P.M. Guyon, C. Bepartex and G. More T (undated).

2. Protection Against Re-entry of Air into. Yacuum Installations, R. Jean and J. Rauss, LeVide, No. 111, May-June; 1964, Pp. 123-127, SLAC Translation-159.

3. Measurements in the Efficiency of Acoustic Delay Lines in View of Beam Lines for Synchrotron Radiation, H. Betz, P. Hofbauer, A. Heuberger, J. Vac. Sci. Tech Note 16 (3) May/June 1979.

4. Measurements ' of Shock Wave Flight. Times in Long Pipes, W. Peatman, and E:W. Weiner, BESSY, Technischer Bericht. 18/79, November 1979. 


\section{Appendix B}

B. NSLS Vacuum Standards

SLS-07.10-6-1 Tentative Standards of the American Vacuum Society (Only Table of Contents Provided) 
NATIONAL SYNCHROTRON LIGHT SOURCE

TECHNICAI SPECIFICATION

for

TENTATIVE STANDARDS OF THE AMERICAN VACUUM SOCIETY

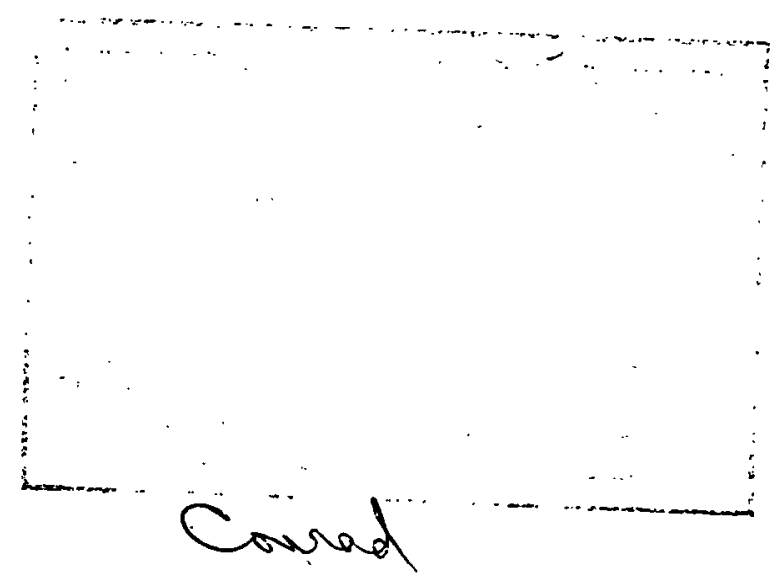

व०
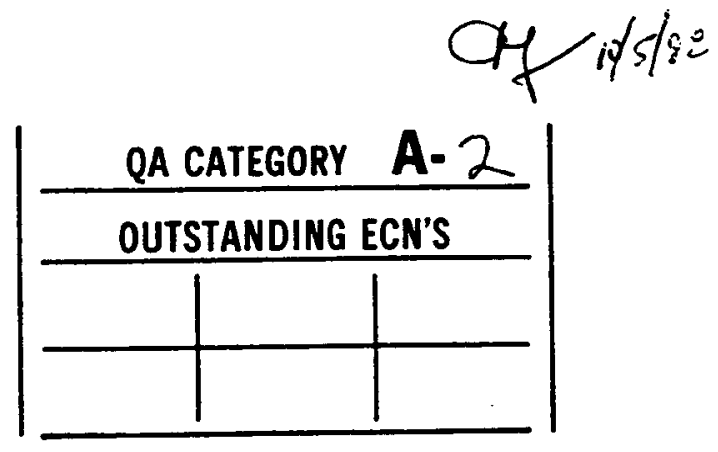

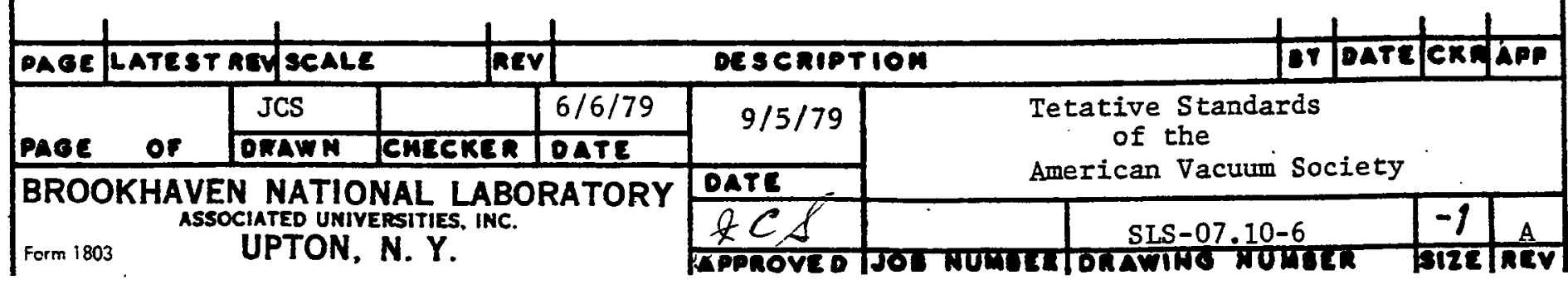


TENTATIVE STANDARDS OF THE AMERICAN VACUUM SOCIETY

JANUARY 1976

2.1 Calibration of Leak Detectors of the Mass Spectrometer Type.

2.2 Method for Vacuum Leak Calibration.

2.3 Procedure for Calibrating Gas Analyzers of the Mass Spectrometer Type.

3.1 Unbaked, Ungrooved Bol ted Vacuum Connection Flanges, Nominal Sizes 4 in. to 24 in.

3.2 Flanges Bakeable to $500^{\circ} \mathrm{C}$.

3.3 Method for Testing Flange Seals to $5000 \mathrm{C}$.

3.4 Dimensions for Unbaked Flanges, Light Series:

3.6 Procedure for Rating All-Metal Valves Bakeable to above $2500 \mathrm{C}$.

4.1 Procedure for Measuring Speed of 0 il Diffusion Pumps.

4.2 Procedure for Measuring Throughput of $0 i l$ Diffusion Pumps.

4.3 Procedure for Measuring the Forepressure Characteristics of Oil Diffusion Pumps.

4.4 Procedure for Measuring the Ultimate Pressure of 0il Diffusion Pumps.

4.5 Procedure for Measuring Backstreaming of $0 i l$ Diffusion Pumps.

4.6 Procedure for Measuring the Warmup and Cooldown Characteristics of 0 il Diffusion Pumps.

4.7 Procedure for Measuring the Ultimate Pressure of Pumps without Working Fluids.

4.8 Procedure for Measuring Speed of Pumps without Working Fluids.

4.10 Determining the Refrigerant Consumption and Temperature Characteristics of Baffles and Traps.

5.1 Measurament of Blank-off Pressure (Permanent Gases) of Positive Displacement Mechanical Vacuum Pumps.

5.2 Presentation of Pumping Speed Curves of Mechanical Pumps.

5.3 Method for Measuring Pumping Speed of Mechanical.Vacuum Pumps for Permanent Gases.

6.2 Procedure for Calibrating Vacuum Gauges of the Thermal Conductivity Type.

6.4 Procedure for Calibrating Hot Filament Ionization Gauges Against a Reference Manometer in the Range 10-2-10-5. Torr.

6.5 Procedures for the Calibration of Hot Filament Ionization Gauge Controls.

7.1. Graphic Symbols in Vacuum Technology.

9.1 Reporting of Outgassing Data.

9.2 Reporting of Thermal Degassing Data. 


\section{Appendix C}

C. NSLS Technical Specifications

SLS-07.11-7-1

SLS-07.12-1-1

Fast Valve Sensor

SLS-07.12-2-1

SLS-07.13-1-1

SLS-07.13-2-1

SLS-07.13-3-1

SLS-07.13-4-1

SLS-07.14-1-1

SLS-07.14-4-1

Cleaning Procedures for Vacuum Components and Hardware

Cleaning and Fabrication of Welded Bellows Assemblies

Thermister Gauge, Atmosphere to 1 Micron

Thermister Gauge, Atmosphere to 1 Micron Ion Gauge, Cold Cathode, $10^{-3}$ to $10^{-8}$ Torr Ion Gauge, Hot Filament, $10^{-4}$ to $10^{-11}$ Torr UHV Bakeable Flanges (Conflat)

Copper Gaskets for Conflat Flanges 

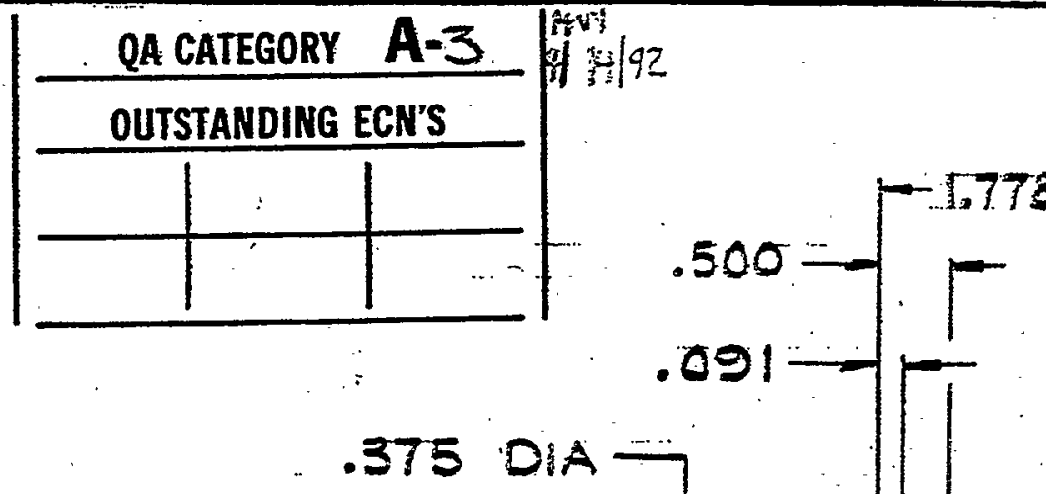

2.75 D.D. .650 DAA

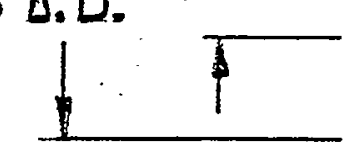

.500 DIA $=$
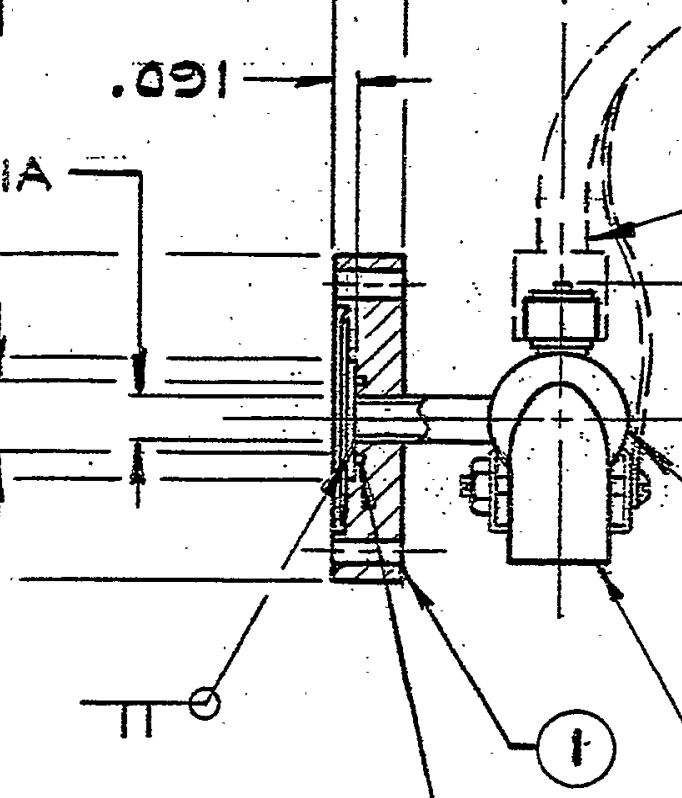

(4)

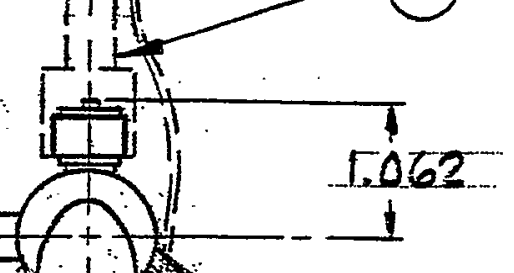

.047 WIDE $\times .062$ DEEP GROOVE

\section{MAT $T^{\prime}:$}

(1) - NON ROTATABLE CONFLAT FLANGE $23 / 40.0$. VARIAN MODEL NE 954-5077 (SHOW ABOVE) ALTERNATE:

NON ROTATABLE CONFLAT FLANGE $11 / 30.0$.

VARIAN MODEL NO 954-5136

(2) - $90^{\circ}$ MINIATURE VACION PUMP VARIAN MODEL NO $913-0041$

(3) 1000 GAUSS MAGNET VARIAN MODEL NO 913.0042

(4) - HIGH VOLTAGE CABLE VARIAN MODEL $\mathrm{N}=2 \mathrm{9} 4=0020$

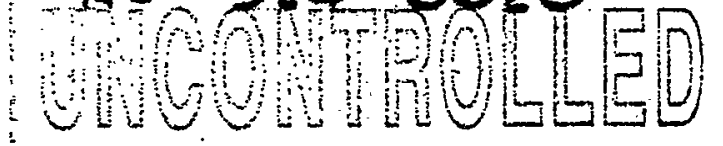

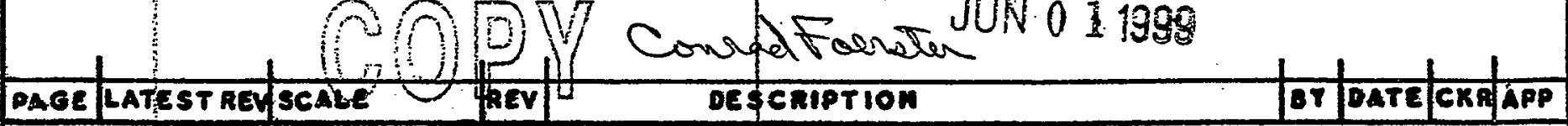

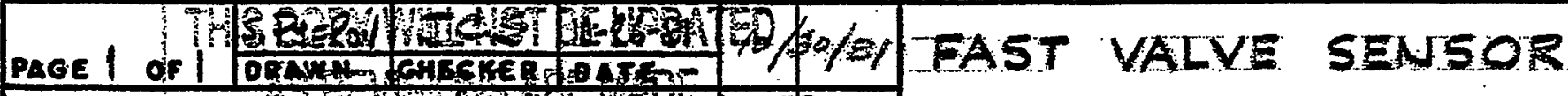
BROOKHAVEN WATTONAL LABORATOSYY OATE, Form $7803 \quad$ UPTON, N. Y. 


\section{BROOKHAVEN NATIONAL LABORATORY Associated Universities, Inc. \\ Upton, New York 11973}

SPECIFICATION FOR:

CLEANING VACUUM COMPONENTS AND HARDWARE

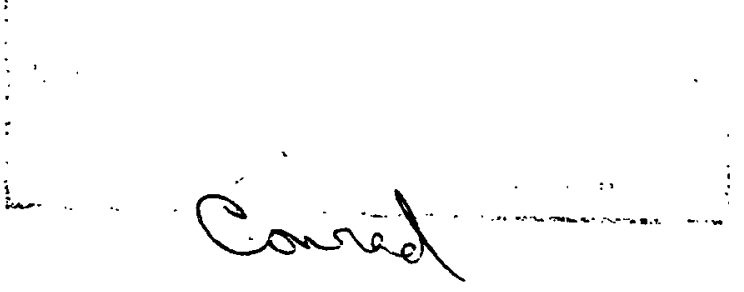

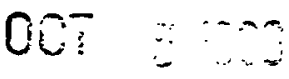

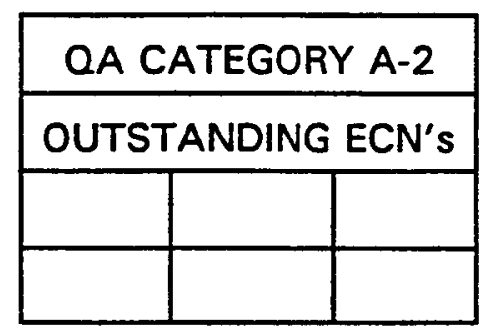

BROOKHAVEN NATIONAL LABORATORY ASSOCIATED UNIVERSITIES, INC. UPTON, N.Y.
CLEANING PROCEDURE FOR VACUUM COMPONENTS AND HARDWARE

\begin{tabular}{|c|c|c|c|} 
& SLS-07.12-1 & -1 & C \\
\hline JOB NUMBER & DRAWING NUMBER & SIZE & REV \\
\hline
\end{tabular}


REVISION CONTROL SHEET

\begin{tabular}{|c|c|c|c|c|c|}
\hline LETTER & DESCRIPTION & DATE & WRTTEN BY & APPROVED BY & TYPED BY \\
\hline A & First Issue & July 9, 1979 & RFC & J. C. Schuchman & \\
\hline B & & Jan. 1983 & RFC & J. C. Schuchman & \\
\hline C & $\begin{array}{l}\text { - Changed to numbering } \\
\text { format. } \\
\text {-Eliminated vapor } \\
\text { degreaser from all } \\
\text { procedures and added } \\
50 \% \mathrm{LPS}+50 \% \mathrm{H}_{2} \mathrm{O} \\
\text { degrease solution. } \\
\text {-Changed } 2 \text { minutes cold } \\
\text { water rinse to } 5 \text { minutes. } \\
\text {-Changed } 5 \text { minute } 360 \mathrm{~L} \\
\text { Okite etch to } 2 \text { minutes. } \\
\text {-Changed } 5 \text { to } 10 \text { minute } \\
\text { Hf-nitric pickel to } 5 \\
\text { minutes. } \\
\text {-Changed Desmut to } \\
\text { Alltone first } \\
\text {-Added } 5 \text { minute water } \\
\text { rinse for SS, Heavy scale } \\
\text {-Changed parts drying } \\
\text { procedure for all } \\
\text { processes. } \\
\text {-Changed Methanol rinse } \\
\text { to ethyl alcohol. } \\
\text { For all processes. }\end{array}$ & June 14, 1996 & C. Foerster & 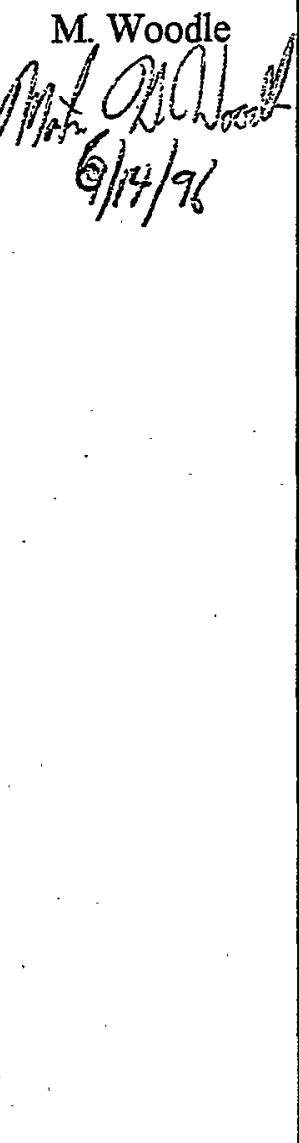 & L.J. Rogers \\
\hline
\end{tabular}

\begin{tabular}{|c|c|c|c|}
\hline & SLS-07.12-1 & -1 & C \\
\hline JOB NUMBER & DRAWING NUMBER & SIZE & REV \\
\hline
\end{tabular}




\section{TABLE OF CONTENTS}

1.0 Start-Up Procedure

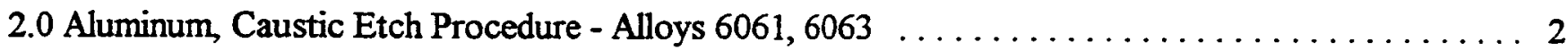

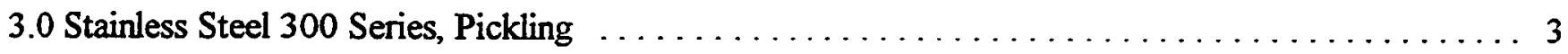

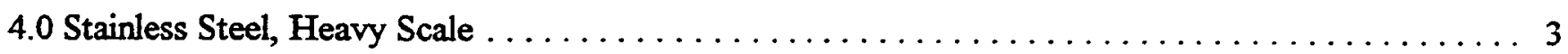

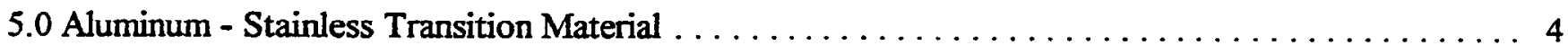

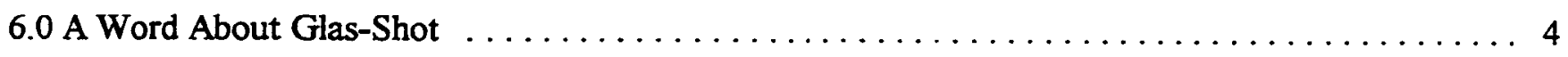

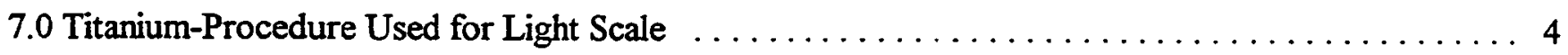

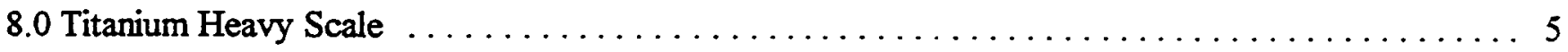

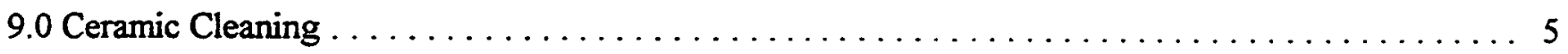

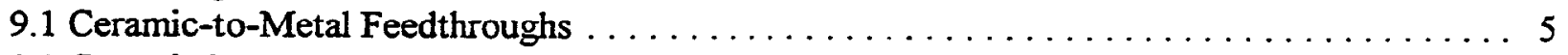

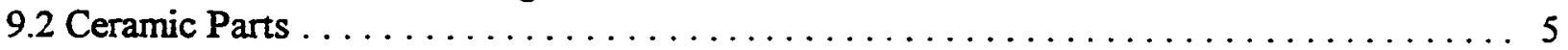

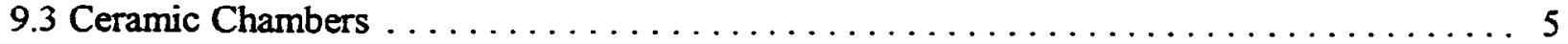

10.0 Copper Cleaning: . . . . . . . . . . . . . . . . . . . . . . . . . . . . . . . . . . . 6

10.1 Heavily Oxidized Copper . . . . . . . . . . . . . . . . . . . . . . . . . . . . . . 6

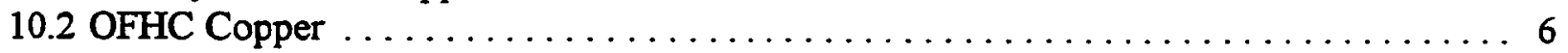

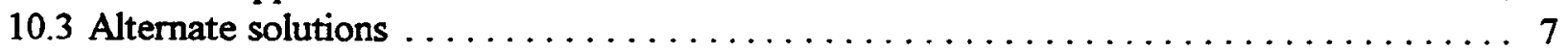

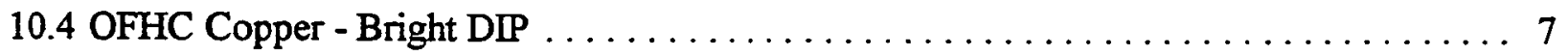

CLEANING PROCEDURES FOR VACUUM COMPONENTS AND HARDWARE

\begin{tabular}{|c|c|c|c|}
\hline & SLS-07.12-1 & -1 & C \\
\hline JOB NUMBER & DRAWING NUMBER & SIZE & REV \\
\hline
\end{tabular}




\section{$1.0 \quad$ Start Up Procedure}

\subsection{Switch on Oven}

1.2 Check that all tank heaters are on. Press "reset" if necessary. (Heaters are only shut off over weekends and/or holiday.).

1.3 Turn on deionized water pump and open valve all the way. When steady flow at outlet is achieved close valve so that stop is in vertical position. Switch on indicator lights. (Clean screen on water conditioner tank once a week.).

1.4 Turn on aerating compressor.

1.5 Plug in filter pump. Check gauge pressure, if 5 psi or greater, replace filters. Clean inlet screen daily.

1.6 Start-up "scrubber" by doing the following:

1.6.1 Close bypass valve.

1.6.2 Open valves V1 and V2.

1.6.3 Switch on pump.

Fill tank with water to just below the overflow while "scrubber" is operating. Check periodically during the day as evaporation (especially in warm weather) from system will occur. Level should not be allowed to fall below the halfway point.

1.7 Check that sump pumps are operating. If water is overflowing from sump reservoir a problem exists.

1.8 When tanks that are heated are up to temperature then remove covers. Open valves at water rinse tanks to give a small flow.

1.9 Open air valves at tanks.

1.10 Turn on $\mathrm{pH}$ controllers from "scrubber" and water rinse tanks.

1.11 Reverse procedure to shut down.

2.0 Aluminum, Caustic Etch Procedure, Alloys 6061, 6063

2.1 De-grease in $50 \%$ LPS, $50 \% \mathrm{H}_{2} \mathrm{O}$ solution for 15 minutes.

2.2 Soak in non-etch alkaline cleaner, Oakite 166 , for 5 minutes at $120^{\circ} \mathrm{F}$ to $150^{\circ} \mathrm{F}$, with air agitation.

2.3 Rinse in cold running tap water for 5 minutes, if water break appears repeat step 2.

2.4 Etch in $6 \%$ Oakite $360 \mathrm{~L}$ solution 2 minutes at $100^{\circ} \mathrm{F}$ to $110^{\circ} \mathrm{F}$, with air agitation.

2.5 Rinse in cold running tap water for 5 minutes.

2.6 De-smut at room temperature in Wyandotte Alutone for 5 minutes, with air agitation.

2.7 Rinse in cold running tap water for 5 minutes.

2.8 Rinse in hot, $160^{\circ} \mathrm{F}$; deionized water for 5 minutes, with air agitation (minimum resistivity $5,000,000 \Omega)$.

2.9 Dry Parts:

2.9.1 Ethyl alcohol USP (190 proof - $95 \%$ ) rinse (if desired).

2.9.2 Bake in oven at $250^{\circ} \mathrm{F}$.

\begin{tabular}{|c|c|c|c|}
\hline & SLS-07.12-1 & -1 & C \\
\hline JOB NUMBER & DRAWING NUMBER & SIZE & REV \\
\hline
\end{tabular}


2.10 Close all ports, or wrap entire part:

1st - lint-free paper

2nd - new aluminum foil.

2.11 Alternate Solutions for:

2.4 Etch in $20 \% \mathrm{~N}_{2} \mathrm{OH}$ by volume for 5 minutes at $100^{\circ} \mathrm{F}$ to $100^{\circ} \mathrm{F}$.

2.6 De-smut in room temperature solution of $30 \% \mathrm{HNO}_{3}$ by volume for 5 minutes.

3.0 Stainless Steel 300 Series, Pickling

3.1 De-grease in $50 \%$ LPS plus $50 \% \mathrm{H}_{2} \mathrm{O}$ solution for 15 minutes.

3.2 Soak in non-etch alkaline cleaner, Oakite 166 , for 5 minutes at $2^{\circ} \mathrm{F}$ to $150^{\circ} \mathrm{F}$, with air agitation.

3.3 Rinse in cold running tap water for 5 minutes. If water break appears repeat step 2.

3.4 Pickle in Hydrofluoric-Nitric acid solution, at room temperature $\left(70^{\circ} \mathrm{F}\right)$ for 5 minutes, with air agitation.

Hydrofluoric acid $\quad-33 \%$ by volume

Nitric acid, $42^{\circ}$ Baume $-33 \%$ by volume

Distilled water $\quad-33 \%$ by volume

Immersion time shall be sufficient to clean surface of scale and oxide. Care should be taken to avoid over-etching. Parts may be brushed with a stainless steel brush to facilitate oxide removal.

3.5 Rinse in cold running tap water;

3.5.1 De-smut in alutone for 2 minutes first, followed by $\mathrm{H}_{2} \mathrm{O}$ rinse ( 2 minutes).

3.6 Rinse in hot, $160^{\circ} \mathrm{F}$, deionized water for 5 minutes, with air agitation. (Minimum resistivity 500,000 $\Omega$.)

3.7 Dry Parts;

3.7.1 Ethyl Alcohol USP (190 proof - 95\%) rinse (if desired).

3.7.2 Bake in oven at $250^{\circ} \mathrm{F}$.

3.8 Close all ports, or wrap entire part:

1st - lint-free paper.

2nd - new aluminum foil.

4.0 Stainless Steel, Heavy Scale

For stainless steel parts that have heavy scale from Vacuum Deposition or Material fabrication the following procedure should be used:

4.1. De-grease in $50 \%$ LPS plus $50 \% \mathrm{H}_{2} \mathrm{O}$ solution for 15 minutes.

4.2 Water rinse for 5 minutes.

4.3 Blast with "Glass-Shot" Bead Blaster, until scaled surface is removed.

4.4 Proceed with procedure used for stainless steel, 300 series, pickling.

Page 3 of 7

BROOKHAVEN NATIONAL LABORATORY ASSOCIATED UNIVERSITIES, INC. UPTON, N.Y.

CLEANING PROCEDURES FOR VACUUM COMPONENTS AND HARDWARE

\begin{tabular}{|c|c|c|c|}
\hline & SLS-07.12-1 & -1 & $C$ \\
\hline JOB NUMBER & DRAWING NUMBER & SIZE & REV \\
\hline
\end{tabular}


5.0 Aluminum - Stainless Steel Transition Material

Clean in caustic etch solutions as aluminum part. As referenced on page 2.

6.0 A Word about Glas-shot

Glas-shot is an abrasive for surface treatment of metals by particular bombardment for the purposes of cold working, cleaning honing, polishing, preening or finishing. Unlike other abrasives, Glas-shot removes no base metal, leaves no embedment, will produce a matte finish. The effects of Glas-shot can be classed as mechanical surface reformations. National Synchrotron Light Source will be using Glasshot as a treatment for parts that are heavily scaled from vacuum deposition or material fabrication.

Glas-shot beads are manufactured of high grade, optical crown glass, soda lime type. High in silica content, they contain no lead and are resistant to atmospheric moisture, dilute acids and alkalies.

Annealed in the spherical shape for stress equalization, they resist wear and fracture ... exhibit high resilience and resistivity A minimum of $90 \%$ are true spheres and those with sharp or angular edges will not exceed $1 \%$. Glas-shot are crystal clear and free from deleterious surface films. No more than $2 \%$ show milkiness, scores or scratches. Bead sizes range from $0.0005^{\prime \prime}$, (MS-XL) to $0.0276^{\prime \prime}$ (MS-XPX).

7.0 Titanium - Procedure used for light scale.

7.1 De-grease in $50 \%$ LPS plus $50 \% \mathrm{H}_{2} \mathrm{O}$ solution for 15 minutes.

7.2 Soak in non-etch alkaline cleaner, Oakite 166 , for 5 minutes at $130^{\circ} \mathrm{F}$ to $150^{\circ} \mathrm{F}$, with air agitation.

7.3 Rinse in cold running tap water for 2 minutes. If water break appears repeat step 2.

7.4 Pickle in Hydrofluoric-Nitric acid solution, at room temperature $\left(70^{\circ} \mathrm{F}\right.$ ) for $15-30$ seconds with air agitation.

$48 \% \mathrm{HF} \quad-33 \%$ by volume

$42^{\circ}$ Baume $\mathrm{HNO}_{3} \quad-33 \%$ by volume

Deionized $\mathrm{H}_{2} \mathrm{O}-33 \%$ by volume

The above solution is used for light scale. The nitric acid content must not be allowed to drop, in order to avoid hydrogen embrittlement.

7.5 Rinse in cold running tap water for 2 minutes. Wipe with sponge.

7.6 Rinse in hot, $160^{\circ} \mathrm{F}$, deionized water for 2 minutes, with air agitation. (Minimum resistivity $500,000 \Omega$ ).

7.7 Dry parts:

7.7.1 Ethyl alcòhol USP (190 proof - 95\%) rinse (if desired).

7.7.2 Bake in oven at $250^{\circ} \mathrm{F}$.

7.8 Close all ports, or wrap entire part:

lst - lint free paper.

2nd - new aluminum foil.

\begin{tabular}{|c|c|c|c|c|}
\hline Page 4 of 7 & \multirow{2}{*}{\multicolumn{4}{|c|}{$\begin{array}{c}\text { CLEANING PROCEDURES FOR } \\
\text { VACUUM COMPONENTS AND HARDWARE }\end{array}$}} \\
\hline \multirow{3}{*}{$\begin{array}{l}\text { BROOKHAVEN NATIONAL LABORATORY } \\
\text { ASSOCIATED UNIVERSITIES, INC. } \\
\text { UPTON, N.Y. }\end{array}$} & & & & \\
\hline & & SLS-07.12-1 & -1 & C \\
\hline & JOB NUMBER & DRAWING NUMBER & SIZE & REV \\
\hline
\end{tabular}




\subsection{Titanium Heavy Scale}

For titanium parts that have tough milli-scale, the following procedure should be used:

8.1 De-grease $50 \%$ LPS plus $50 \% \mathrm{H}_{2} \mathrm{O}$ solution.

8.2 Cold water rinse for 5 minutes and wipe dry.

8.3 Blast with "Glas-shot" beam blaster, until scale is removed.

8.4 Proceed with procedure used for titanium, light scale.

\subsection{Ceramic Cleaning}

\subsection{Ceramic-to-Metal Feedthroughs}

The cracks and crevices usually present in ceramic-to-metal feedthrough present particular cleaning problems, in that there is a possibility of trapping the acid cleaning solution being used. Therefore, the standard cleaning procedure used to clean the Feedthroughs is as follows:

9.1.1 De-grease 50\% LPS plus $50 \% \mathrm{H}_{2} \mathrm{O}$ solution for 15 minutes. Place the Feedthrough on its side in a stainless steel basket.

9.1.2 Cold water rinse for 5 minutes.

9.1.3 D.I. water rinse for 5 minutes.

9.1.4 Oven dry at $150^{\circ} \mathrm{F}$ with air agitation.

9.2 Ceramics part used in the vacuum system as insulators, spacers, etc. must be chemically cleaned as follows:

9.2.1 De-grease $50 \%$ LPS plus $50 \% \mathrm{H}_{2} \mathrm{O}$ solution for 5 minutes.

9.2.2 Cold water rinse for 5 minutes.

9.2.3 Soak in non-etch alkaline cleaner, Oakite 166 , for 5 minutes at $130^{\circ} \mathrm{F}$ to $150^{\circ} \mathrm{F}$, with air agitation.

9.2.4 Rinse in cold running tap water for 5 minutes, if water break appears repeat Step 2.

9.2.5 Soak in $150^{\circ} \mathrm{F}$ deionized water for 1 hour (minimum resistivity $500,000 \Omega$ ).

9.2.6 Bake in oven at $250^{\circ} \mathrm{F}$.

9.2.7 Close all ports, or wrap entire part:

1 st - lint free paper.

2nd - new aluminum foil.

9.3 Removal of Coatings on Ceramic Chambers

9.3.1 De-grease for 5 minutes, followed by 5 minute water rinse.

9.3.2 Soak in non-etch cleaner for 5 minutes.

9.3.3 Rinse in water for 2 minutes.

9.3.4 Soak in $\mathrm{HF}-\mathrm{HNO}_{3}$ solution for 1 minute.

9.3.5 Rinse in water for at least 4 hours.

9.3.6 Brush off coating with stainless steel brush. Follow with deionized water for two minutes.

\begin{tabular}{|c|c|c|c|}
\hline & SLS-07.12-1 & -1 & $C$ \\
\hline JOB NUMBER & DRAWING NUMBER & SIZE & REV \\
\hline
\end{tabular}


10.0 Copper Cleaning

\subsection{Heavily Oxidized Copper}

On copper and copper alloys containing more that $85 \%$ copper, oxide films will contain a high percentage of cupruous oxide $\left(\mathrm{CU}_{2} \mathrm{O}\right)$ which is not easily removed by sulfuric acid pickles, and the addition of an oxidizing agent is desirable. Therefore, in cases such as described the following procedure will be used:

10.1.1 De-grease in $50 \%$ LPS plus $50 \% \mathrm{H}_{2} \mathrm{O}$ solution.

10.1.2 Soak in non-etch alkaline cleaner, Oakite 166, for 5 minutes

10.1.3 Rinse in cold running tap water for 2 minutes, if water break appears, repeat step 2.

10.1.4 Mat dipping - this solution produces a light mate finish on copper. Dip for 5 minutes in $10 \% \mathrm{H}_{2} \mathrm{SO}_{4}$ (by volume) or until oxide is removed $10 \%$ Hydrogen Peroxide (by volume) Curpic Sulfate $200_{\mathrm{g}}$ /liter solution at $110^{\circ} \mathrm{F}$.

10.1.5 Rinse in cold running tap water for 2 minutes.

10.1.6 If oxidation starts to from, rinse for 5 minutes in a drag out solution containing $85 \%$ deionized $\mathrm{H}_{2}$ Oor $15 \%$ Mat Dripping Solution described in 10.1.4.

10.1.7 Rinse in cold running tap water for 2 minutes.

10.1.8 Rinse in hot, $160^{\circ} \mathrm{F}$, deionized water for 2 minutes, with air agitation. (Minimum

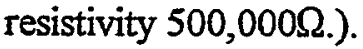

10.1.9 Dry Parts:

10.1.9.1 Electronic grade methanol rinse (if desired).

10.1.9.2 Bake in oven at $250^{\circ} \mathrm{F}$.

10.1.10 Close all ports, or wrap entire part:

1st - lint free paper.

2nd - new aluminum foil.

\subsection{OFHC Copper}

10.2.1. De-grease in $50 \%$ LPS plus $50 \% \mathrm{H}_{2} \mathrm{O}$ solution for 15 minutes.

10.2.2 Soak in non-etch alkaline cleaner, Oakite 166 , for 5 minutes at $130^{\circ} \mathrm{F}$ to $150^{\circ} \mathrm{F}$, with air agitation.

10.2.3 Rinse in cold running tap water for 2 minutes, if water break occurs repeat step 10.2.1.2.

10.2.4 Immerse in $50 \%$ (by volume) $\mathrm{HNO}_{3}$. solution for 5 minutes, solution at room temperature.

10.2.5 Rinse in cold running tap water for 2 minutes.

10.2.6 Repeat steps 4 \& 5, if requited.

10.2.7 Rinse in hot, $\left(160^{\circ} \mathrm{F}\right.$, deionized water for 2 minutes, with air agitation (Minimum resistivity $500,000 \Omega$.).

10.2.8 Dry Parts;

10.2.8.1 Ethyl alcohol USP (190 proof - $95 \%$ ) rinse (if desired).

10.2.8.2 Bake in oven at $250^{\circ} \mathrm{F}$.

Page 6 of 7

BROOKHAVEN NATIONAL LABORATORY ASSOCIATED UNIVERSITIES, INC. UPTON, N.Y.

CLEANING PROCEDURES FOR VACUUM COMPONENTS AND HARDWARE

\begin{tabular}{|c|c|c|c|}
\hline & SLS-07.12-1 & -1 & C \\
\hline JOB NUMBER & DRAWING NUMBER & SIZE & REV \\
\hline
\end{tabular}


10.2.9 Close all ports, or wrap entire part:

1 st - lint free paper.

2nd - new aluminum foil.

10.3 Alternate Solutions (Use this procedure)

10.3.1 Use Step 10.1.4 and Step 10.2.4

Use Oakite "Metal Sheen" at 35 to $50 \%$ by volume, room temperature.

Immersion time from 10 seconds to 2 minutes depending on the amount of stain and tarnish to be removed and surface finish desired.

\subsection{OFHC Copper - bright dip}

There are several "bright dips" available for copper. Care should be used when selecting a bright dip since some contain phosphoric acid and other materials which might compromise the vacuum.

The following solution will be used for bright dipping copper:

10.4.1 De-grease in 50\% LPS plus $50 \% \mathrm{H}_{2} \mathrm{O}$ solution for 5 minutes.

10.4.2 Soak in non-etch alkaline cleaner, Oakite 166 , for 5 minutes at $130^{\circ} \mathrm{F}$ to $150^{\circ} \mathrm{F}$, with air agitation.

10.4.3 Rinse in cold running tap water for 2 minutes, if water break appears, repeat step 2.

10.4.4 Dip in a solution of the following:

$\begin{array}{lll}\text { Deionized } \mathrm{H}_{2} \mathrm{O} & - & 2 \text { liters } \\ \mathrm{H}_{2} \mathrm{SO}_{4} & - & 1.7 \text { liters } \\ \mathrm{HNO}_{3} & - & 28^{\circ} \mathrm{ml} \text { (concentrated) } \\ \mathrm{HCl}_{3} & - & 10 \mathrm{ml} \text { (concentrated) } \\ \text { Dip for } 5 \text { minutes at room temperature. }\end{array}$

Dip for 5 minutes at room temperature.

10.4.5 Rinse in cold running tap water for 2 minutes.

10.4.6 Rinse in hot, $160^{\circ} \mathrm{F}$, deionized water, for 2 minutes, with air agitation. (Minimum resistivity 500,000 ohms.)

10.4.7 Dry parts

a. Ethyl alcohol USP (190 proof - $95 \%$ ) rinse (if desired).

b. Bake in oven at $250^{\circ} \mathrm{F}$.

10.4.8 Close all ports, or wrap entire part: 1st - lint free paper

2nd - new aluminum foil

\begin{tabular}{|c|c|c|c|}
\hline & SLS-07.12-1 & -1 & $C$ \\
\hline JOB NUMBER & DRAWING NUMBER & SIZE & REV \\
\hline
\end{tabular}


NATIONAI SYNCHROTRON LIGHT SOURCE

TECHNICAL SPECIFICATION

for

CLEANING AND FABRICATION

of

WELDED BELLOWS ASSEMBLIES

05! 5098

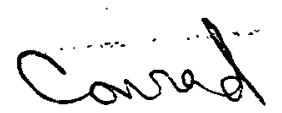

:

annd

\begin{tabular}{|c|c|c|c|c|c|c|c|c|c|c|}
\hline DAOE & LATEST REY SCALE & hev & & DESCRI & & & 27 & DATE & CKE & APP \\
\hline PAGE & JCS & & $6 / 18 / 79$ & $9 / 5 / 79$ & \multirow{2}{*}{\multicolumn{4}{|c|}{$\begin{array}{l}\text { Cleaning and Fabrication } \\
\text { of } \\
\text { Welded Bellows Assemblies }\end{array}$}} & & \\
\hline \multirow{2}{*}{\multicolumn{4}{|c|}{$\begin{array}{l}\text { BROOKHAVEN NATIONAL LABORATORY } \\
\text { ASSOCIATED UNIVERSITIES, INC. } \\
\text { UPTO i } 803\end{array}$}} & DATE & & & & & & \\
\hline & & & & $\frac{\text { ecd }}{\text { xponove }}$ & & $\begin{array}{r}\text { SIS-0 } \\
\text { OLATIS? }\end{array}$ & $\frac{7.12-2}{\text { र्रणाय }}$ & & \begin{tabular}{|c|}
-1 \\
$12 E$
\end{tabular} & $\frac{A}{\text { AEv }}$ \\
\hline
\end{tabular}


Introduction

The stringent requirements which must be met by all components incorporated in the NSIS vacuum system necessitate a thorough explanation of the appropriate manufacturing standards.

The welded stainless steel bellows in particular deserve special attention to detail because of their unusual construction. Hydrocarbon contamination of surfaces or particulate matter trapped in the crevices of welded bellows convolutions is for all practical purposes there to stay. Experience has shown that post-manufacturing chemical cleaning is of little value in removing such contamination. Bellows made with improperly handled or poorly cleaned diaphragms are rendered useless for our purpose.

The criteria for obtaining bellows which do meet the cleanliness requirements of the ultra high vacuum system is simply this:

1. Thoroughly chemically clean all component parts as specified.

2. Assemble and weld the parts without re-contaminating them.

Service Requirements

A11 bellows made to these standards must withstand bakeout to $250^{\circ} \mathrm{C}$ concurrent with the axial and offset stroke specified.

Deviations

No deviation from these specifications will be permitted without the prior approval of the NSIS.

Chemical Cleaning

Prior to assembly, all metal parts and fixtures must be thoroughly chemically cleaned. The following process is standard practice at NSIS and is provided here as a guide to successful cleaning.

End fittings shall be cleaned in the same manner as diaphragms. Handle with white gloves. Parts need only to be cleaned once, just prior to welding. By handling in a manner which does not re-contaminate them, they will remain in a clean state and not be cause for rejection.

1. Pieces shall be suspended on a stainless steel holding fixture in such a way that diaphragms or parts do not touch each other.

2. Degrease in trichloroethane vapor degreaser. If not available, parts may be cleaned in the ultrasonic tank using trichloroethane or freon TF:

3. Soak in non-etch alkaline cleaner, Oakite 166 , for 5 minutes at $130^{\circ} \mathrm{F}$ to $150^{\circ} \mathrm{F}$, with air agitation.

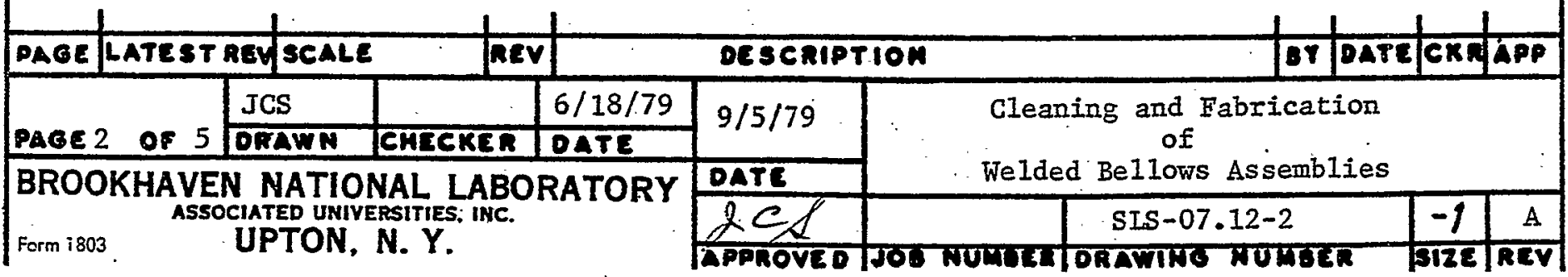


4. Rinse in cold running tap water for 2 minutes. If water break appears repeat step 2 .

5. Pickle in Hydro Fluoric-Nitric acid solution, at room temperature ( $70^{\circ} \mathrm{F}$ ) for 1 to 2 minutes, with air agitation.

$$
\begin{aligned}
& \text { Hydrofluoric acid } 48 \%-33 \% \text { by volume } \\
& \text { Nitric acid, } 42^{\circ} \text { Baume }-33 \% \text { by volume } \\
& \text { Distilled water }
\end{aligned}
$$

Immersion time shall be sufficient to clean surface of scale and oxide. Care should be taken to avoid overetching.

6. Rinse in cold running tap water for 2 minutes.

7. Rinse in hot, $160^{\circ} \mathrm{F}$, deioxized water for 2 minutes, with air agitation. (Minimum resistivity 5000,000 ohms).

8a. Electronic grade methanol rinse.

b. Blow dry with dry nitrogen gas, preferably taken from an evaporated liquid source. Dry, high purity $(99.99 \%)$ water pumped nitrogen bottled gas may also be used.

9. Close all ports, or wrap entire part: 1st - lint-free paper

2nd - new aluminum foil

Place part in polyethylene, non-static bag, pumpout and backfill with dry nitrogen and seal.

\section{Handling and Assembly}

When unwrapping cleaned diaphragms in preparation for welding, they shall only be handled by clean, white, nylon gloves. Gloved hands which touch cleansed parts must touch nothing else!

The welder must be alert at all times not to touch his face, clothing, tools, bench, stools, etc. Actuation of switches, adjustment of welding torch, etc. must be performed with gloves removed. Gloves which do come in contact shall be immediately replaced with a new pair. New gloves shall also be used at the beginning of each shift and following period breaks.

All those parts of the welding apparatus which come in contact with, or even close proximity to the diaphragms being welded, must be thoroughly cleaned and wiped down with approved solvent and the lint free tissue.

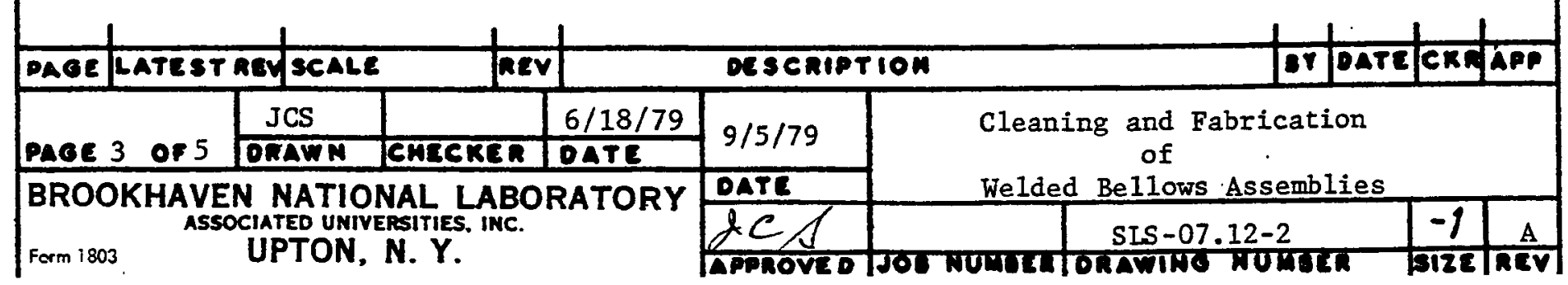


Trichloroethane or Freon $T F$ may be used. This will be followed by wiping down with another tissue using electronic grade methanol.

The welded convolution shall be re-wrapped in new tissue immediately. following welding and inspection: The handling criteria for assembly of the convolutions, inserting the spacer rings, welding the core and associated steps shall be the same as for welding the diaphragms, namely: using new gloves at the same intervals; gloved hands which touch the bellows parts touch nothing else; machinery which comes in contact with or close to the bellows shall be wiped down with the same solvent procedure as before. The copper spacer rings must be thoroughly cleaned to the same standards as the diaphragms with one exception: the Pickle/Passive step 5 is omitted and a copper cleaning solution such as: Enthone "Actane 36" or MacDermid Metex chemical polish - "BCB" substituted in its place. All other cleaning parameters remain the same. All handing, welding, and leak testing shall take place in a Clean Room which follows current vacuum industry practice for ultra high vacuum cleanliness.

Weld Quality and Workmanship

Unless otherwise approved, all welding shall be by tungsten inert gas (TIG) fusion process without the use of filler rod.

It is important to state that leak tightness alone is not the only criterion for the acceptability of weld quality. The appearance and workmanship of the welding is equally important. All weld bead shall be continuous and uniform in height and width.

Material Certification

Vendor shall furnish original source certifications: physical and chemical test reports, of all materials which are a part of the final assembly. In the case where these reports are not available, the vendor shall provide evidence that the materials being used are in fact those specified.

End Fittings

Al1 bellows end attachments such as collars, flanges, weld rings, etc., shall be made from solid stock material, either plate, sheet or forgings. No cast material will be acceptable. End fittings shall be free of any file marks, dents or scratches.

\section{Leak Testing}

Following welding," bellows shall be lèak tested using a mass spectrometer helium leak detector. Unwrapping, handling, and rewrapping of the bellows during leak testing shall also follow the previous glove restrictions: periodic glove changes; no contamination transfer, etc. Use of the leak detector including periodic maintenance shall conform to the manufacturer's recommendations. During testing, the helium nozzle must be directed at the gap between the spacer wires or chill rings inserted between each convolution so that the gas will enter the void between the convolutions. No indication of leakage is permitted when tested by a leak detector

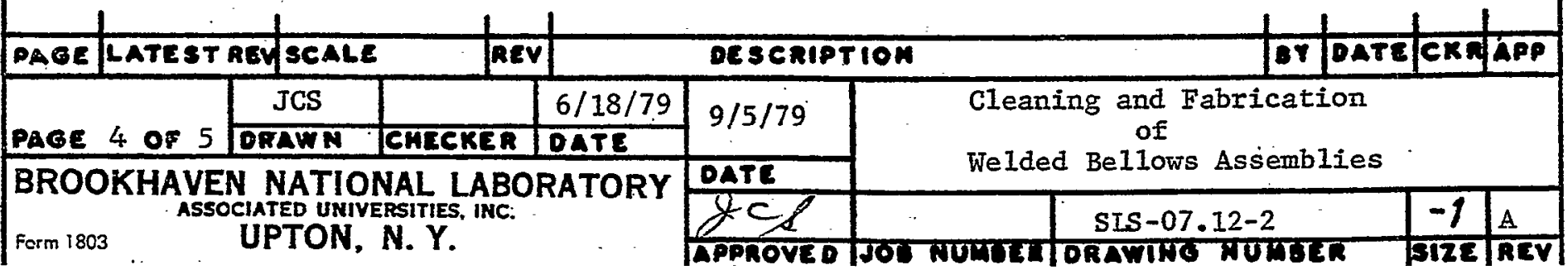


with a minimum helium sensitivity of $2 \times 10^{-10} \mathrm{std} \mathrm{cc} / \mathrm{sec}$ per division.

The helium leak detector shall not be situated within the clean room proper because of the contamination due to mechanical pump rubber belts and exhaust. The roughing pump used to evacuate the bellows prior to leak testing shall be "trapped" to prevent passage of oil vapors into the bellows.

The internal vacuum plumbing which joins the test plate, the leak detector and roughing pump shall be thoroughly cleaned with approved solvents prior to testing the first bellows.

0-rings or rubber flat stock used as a temporary seal on the ends of the bellows for the purpose of leak testing shall be new rubber, clean and dry. No lubricants or grease of any kind are permitted. Experience has shown that low durometer 0-rings or pure gum rubber sheet works satisfactorily if the seal loading is adequate.

\section{Shipment}

Each bellows which is accepted shall be completely wrapped with new aluminum foil immediately following leak testing. It will then be placed in a new polyethlene bag and the open end heat sealed. This package will then be placed in its own corrugated paper carton. Shipment of individually boxed bellows may be made in a larger corrugated cardboard carton.

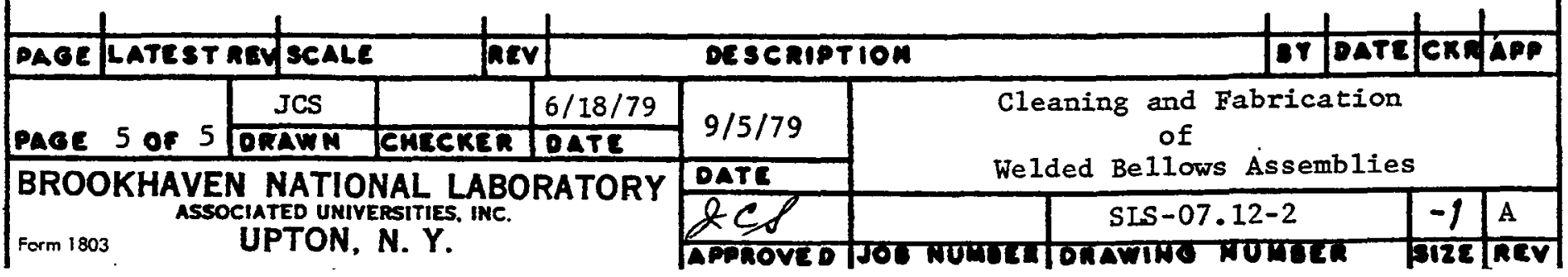




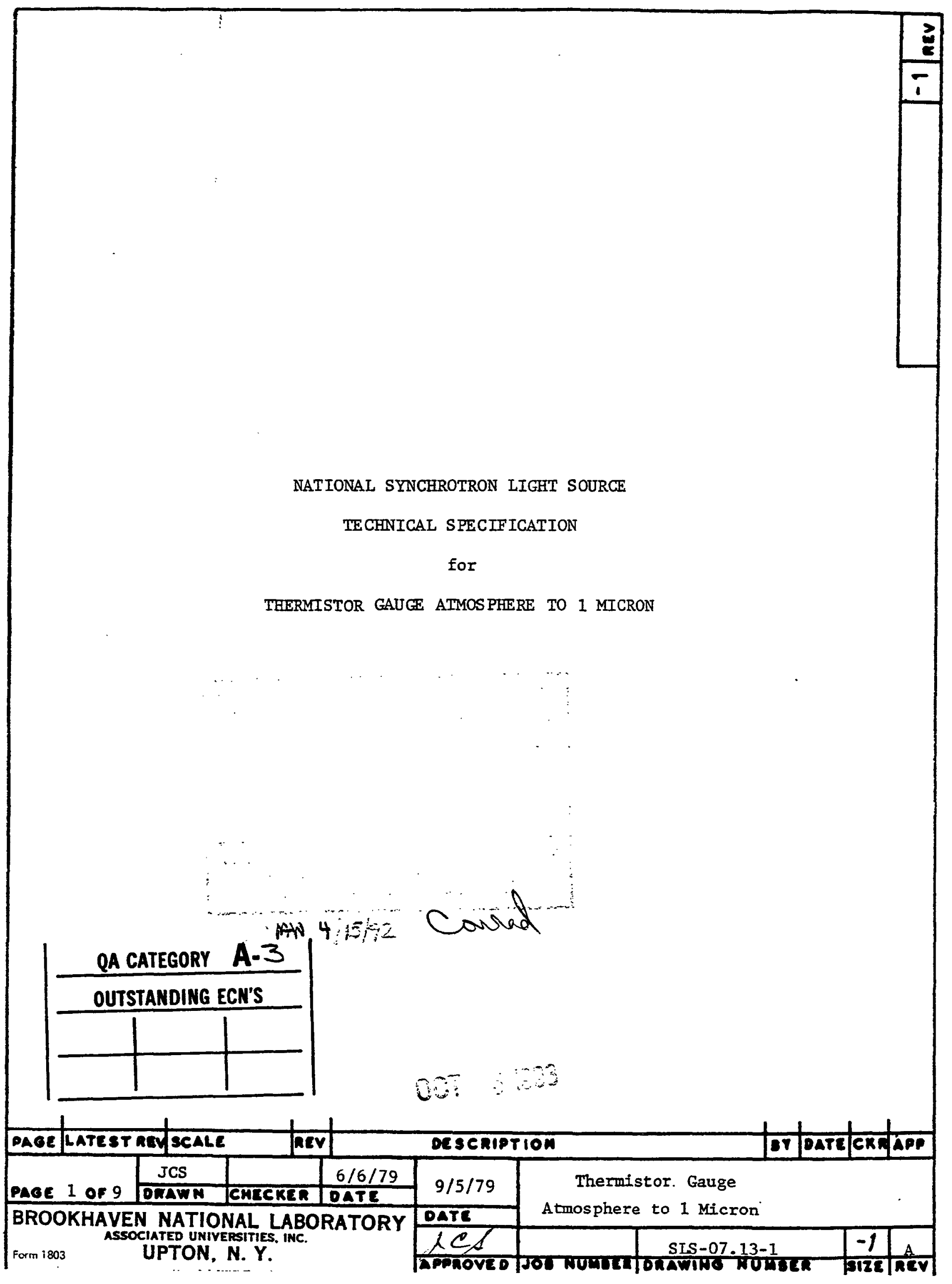




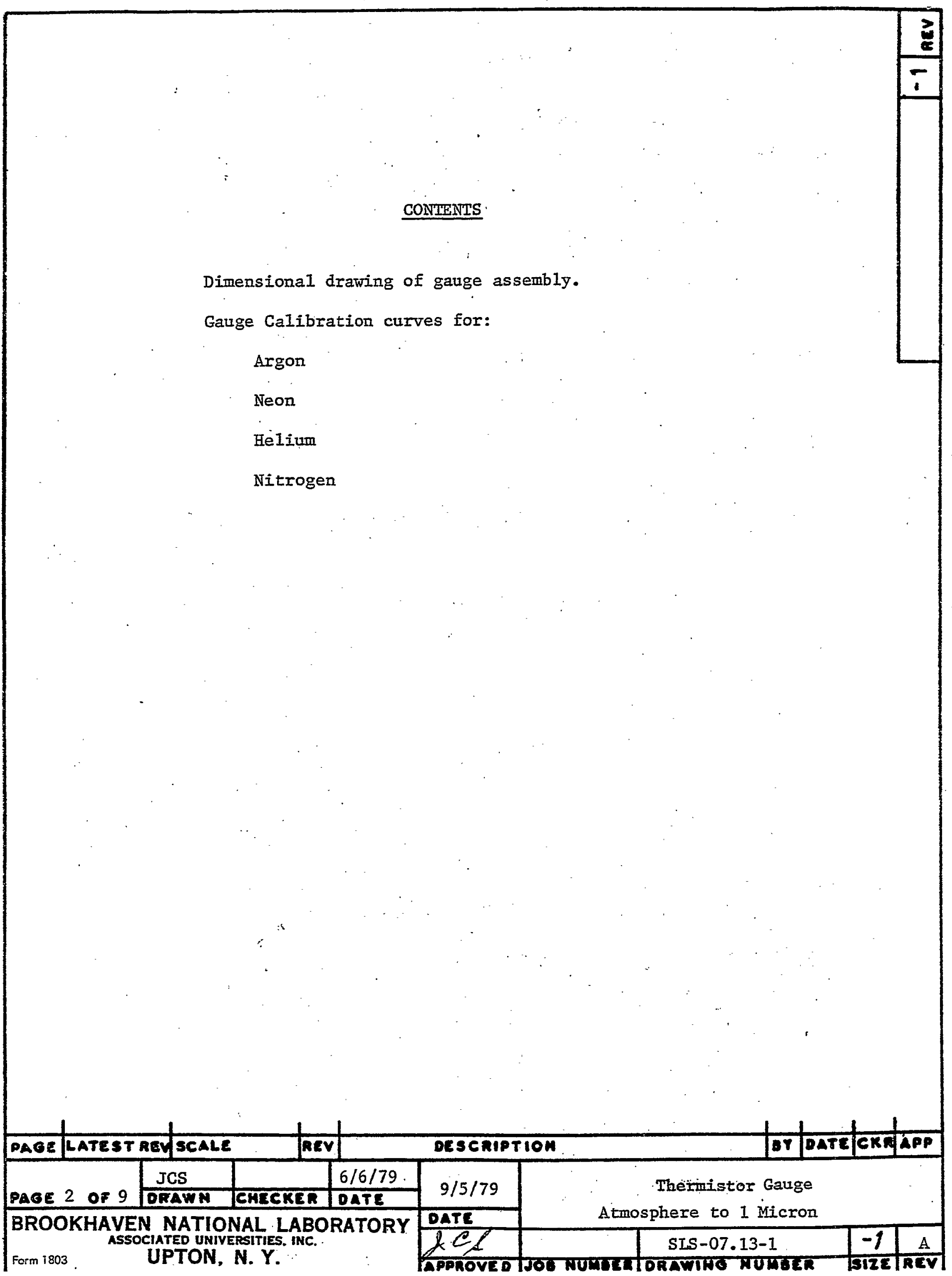




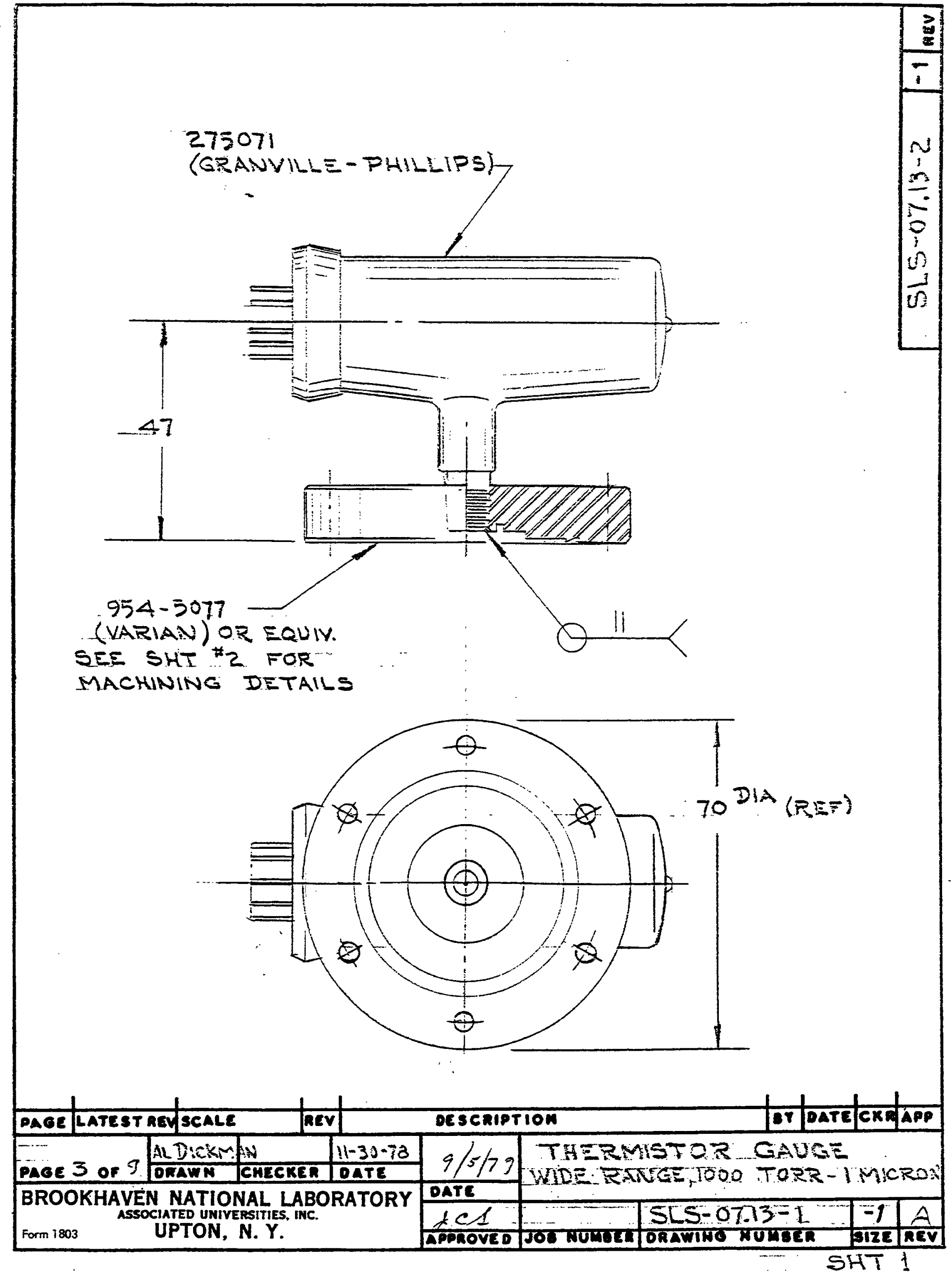




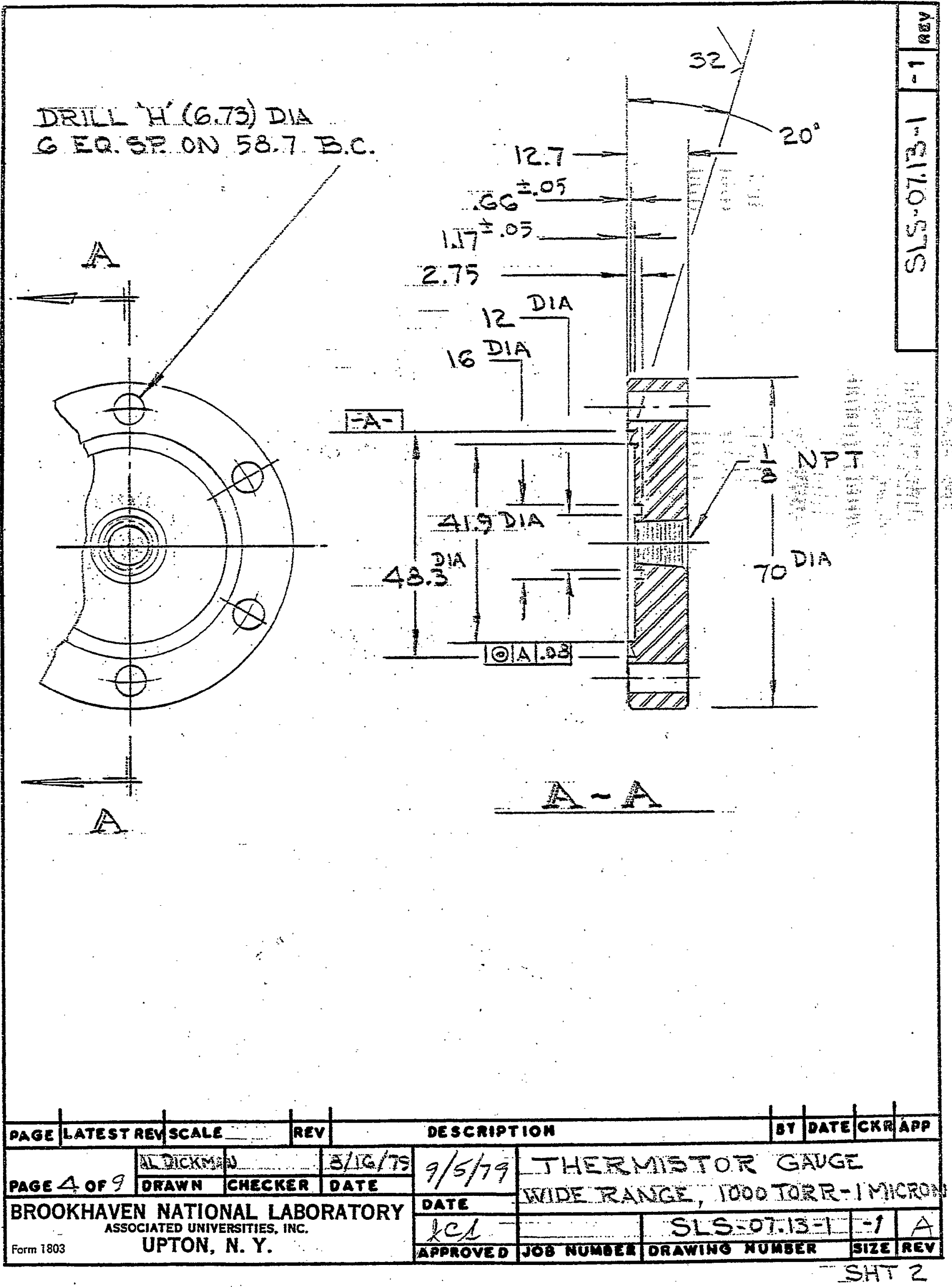




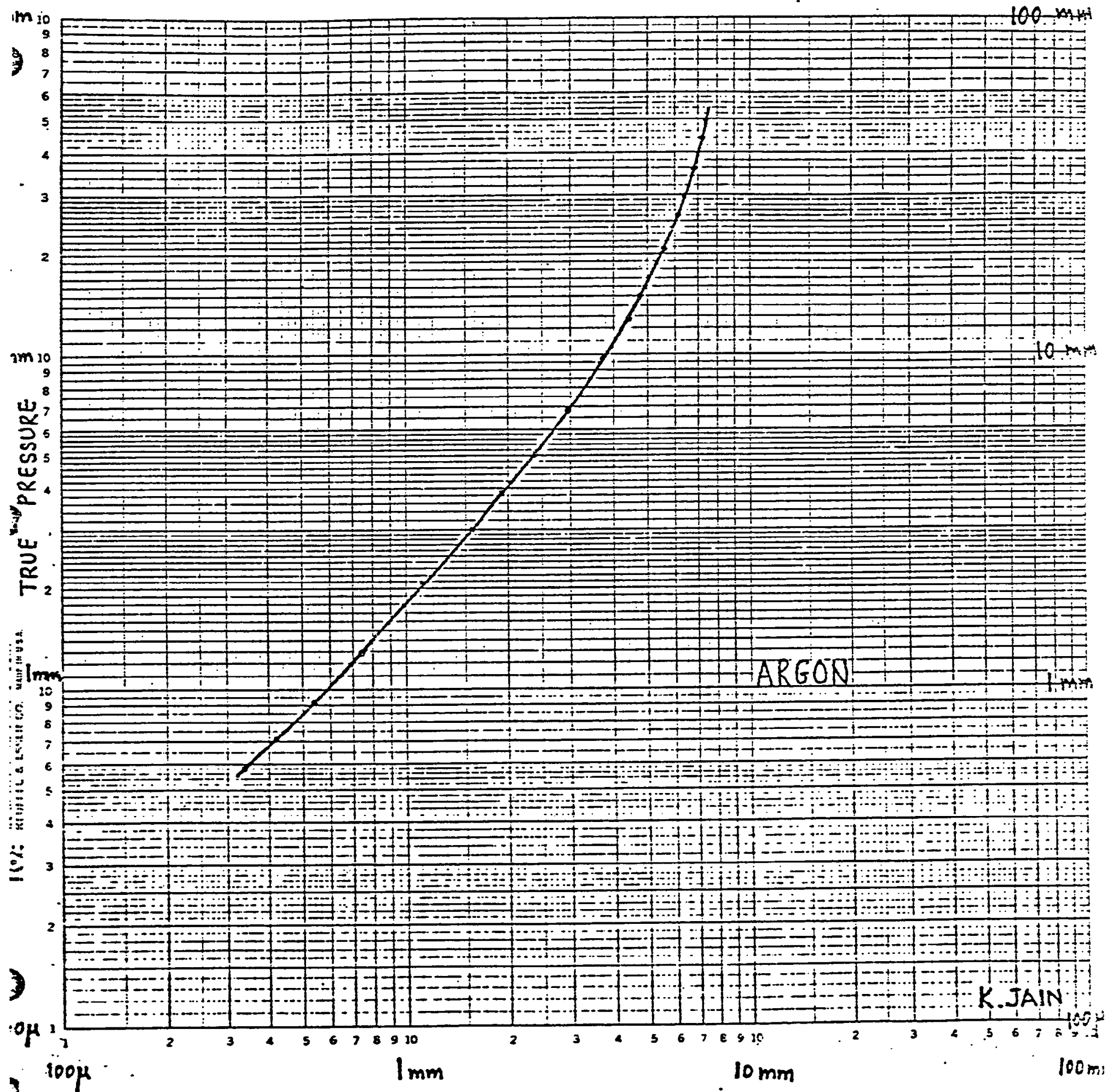

GP 275 READING 


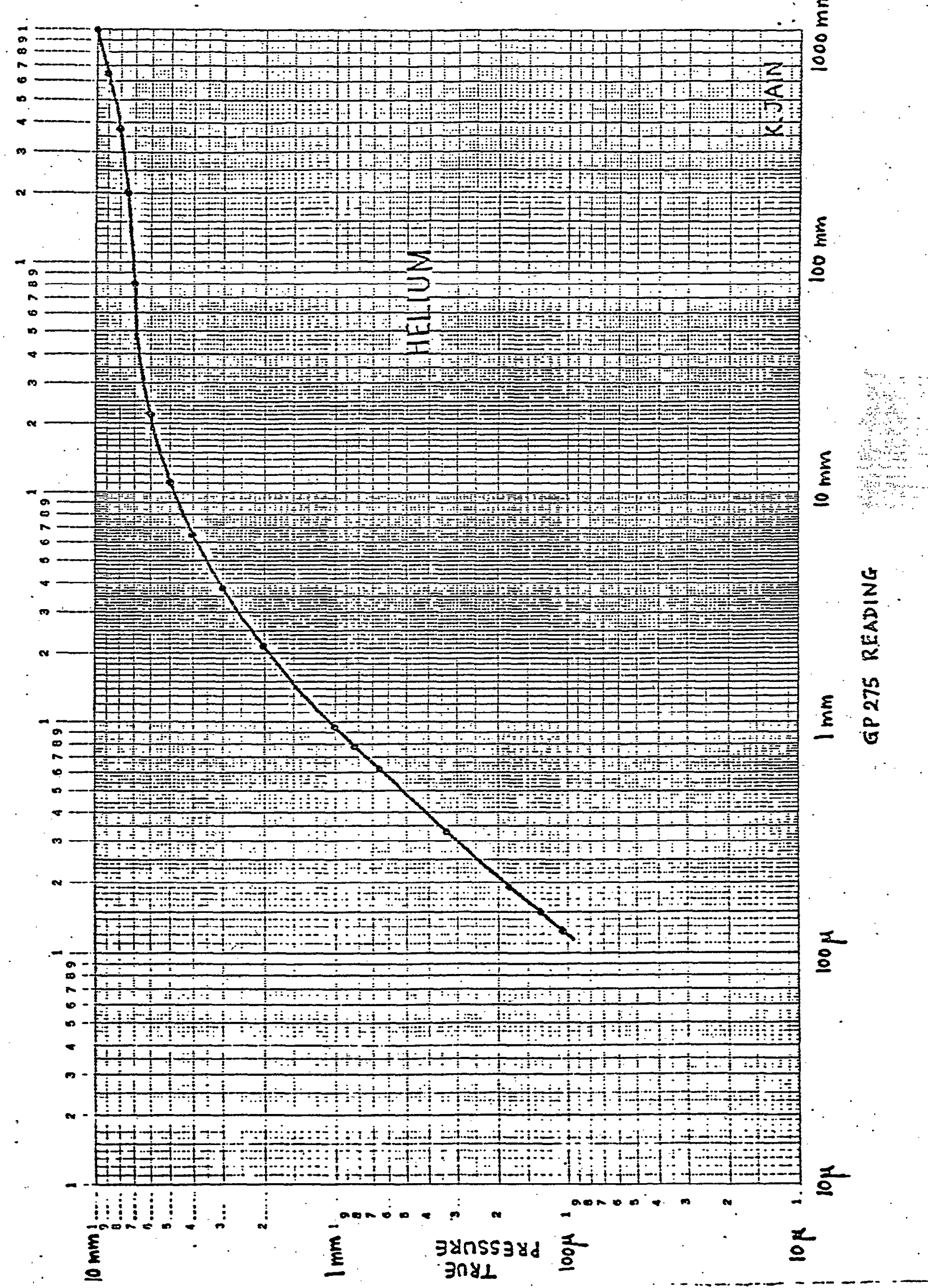



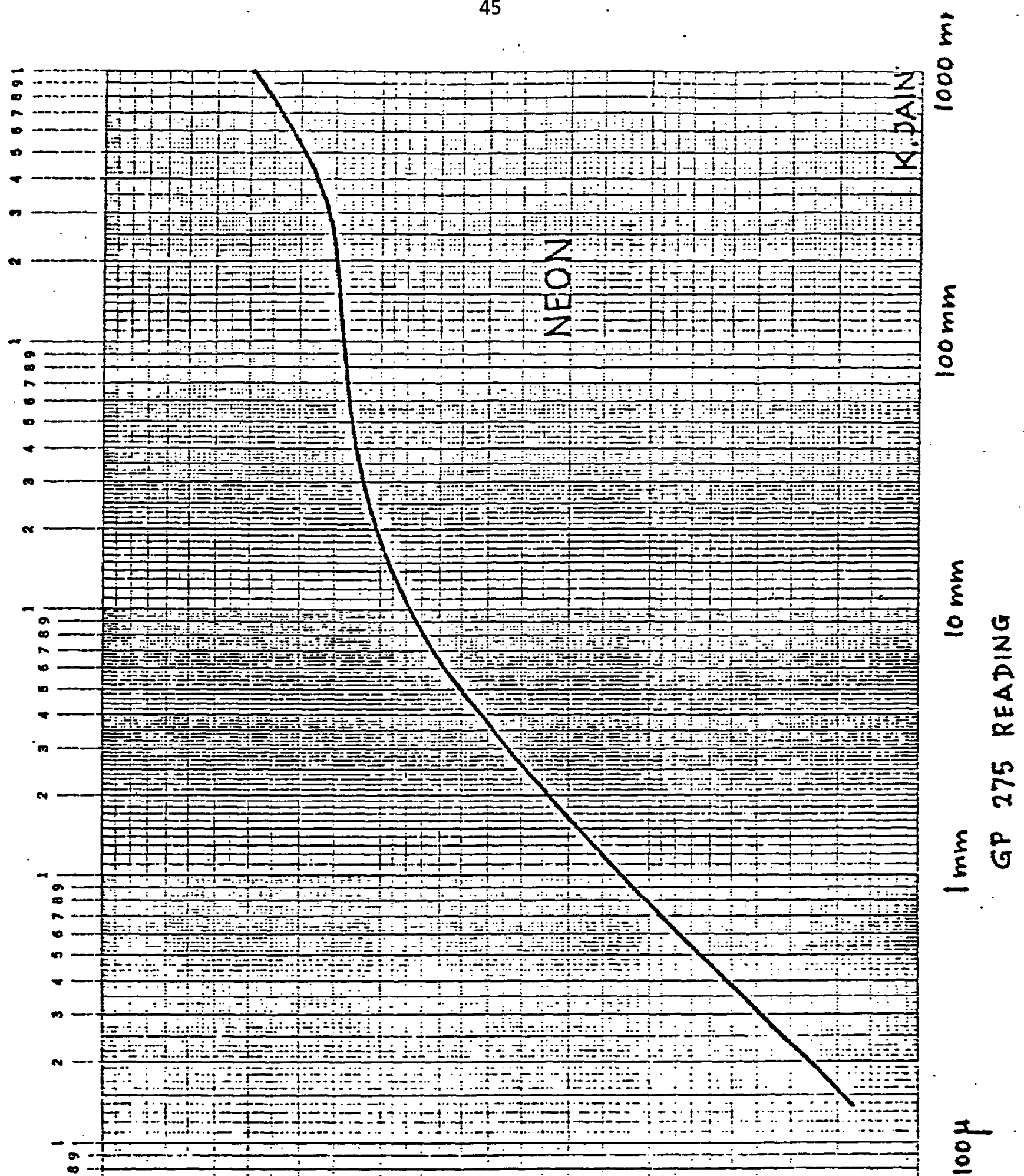

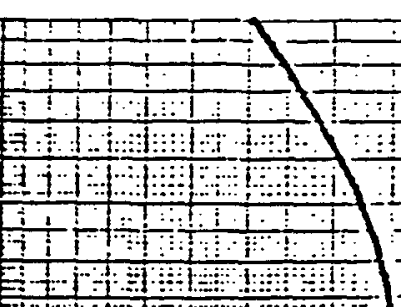

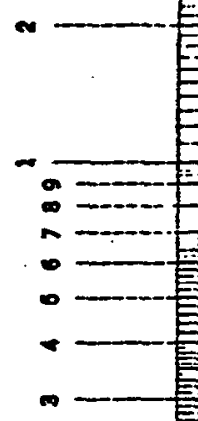

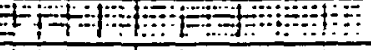

-

$19=1$

$\mathrm{H}=$

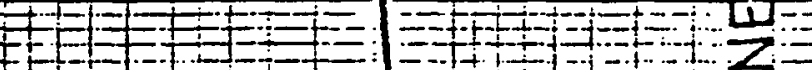

191000010

aftaf

$*$ *

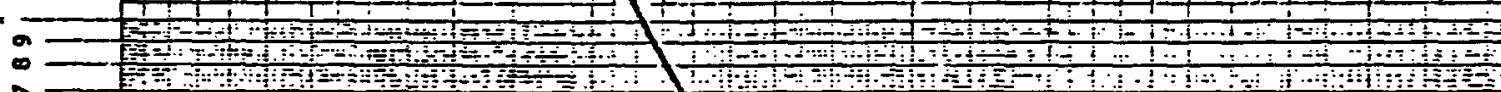

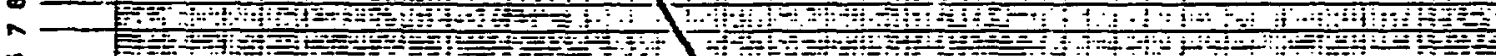

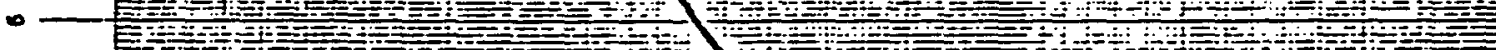

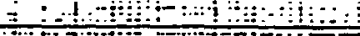

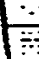

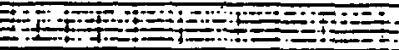

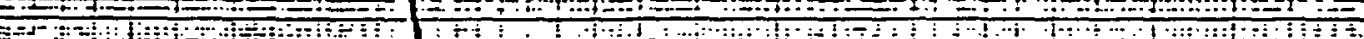
-

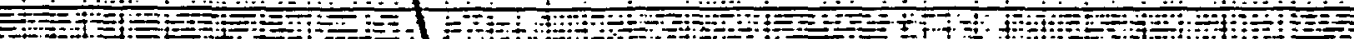

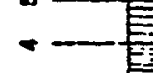

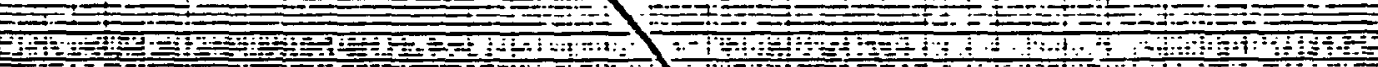

o -

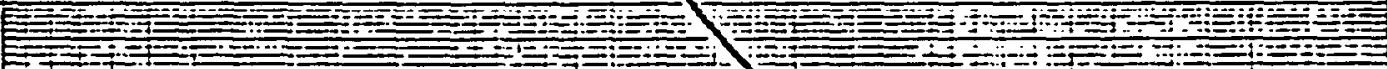

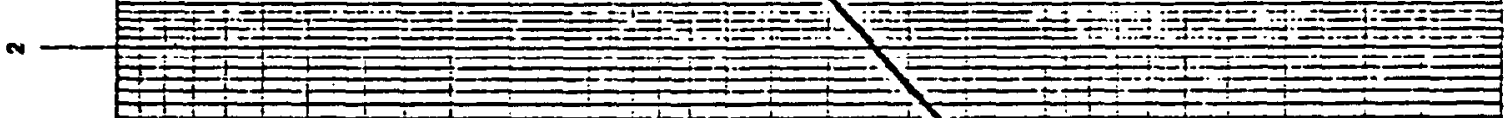

$+1+1+2$

on
$0=\frac{1}{5}$
$0-1$
$\infty$

$1+$

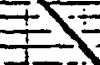

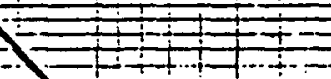

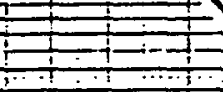

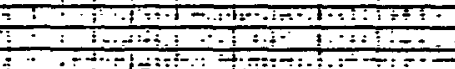

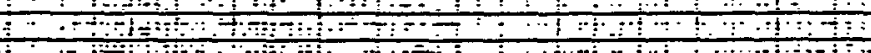

H

-

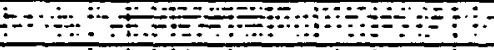

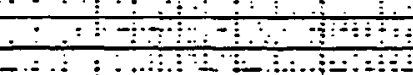

in

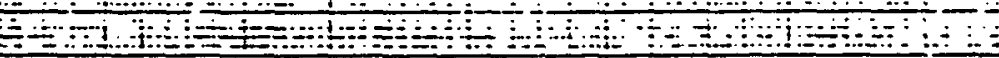

-

Ex

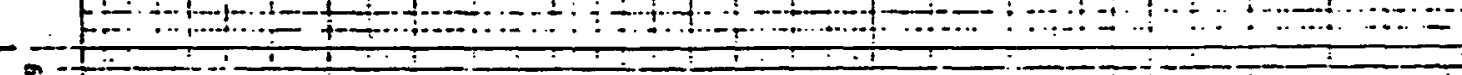

$\infty$

- -

$0-\frac{1}{t}$

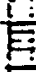

1

-

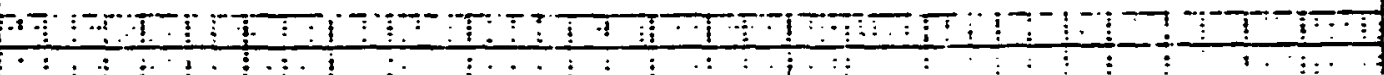

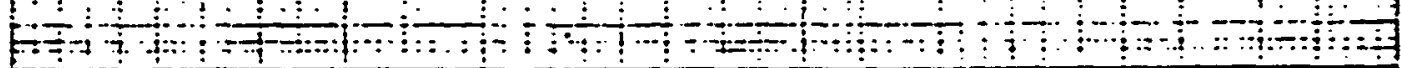

-

\begin{tabular}{ll}
0 \\
\hline
\end{tabular}

-

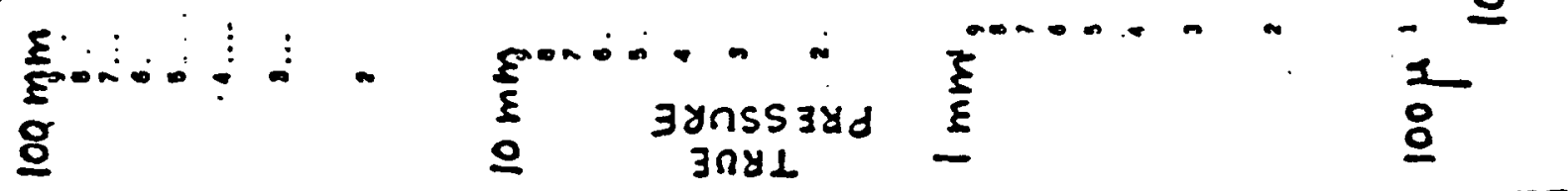




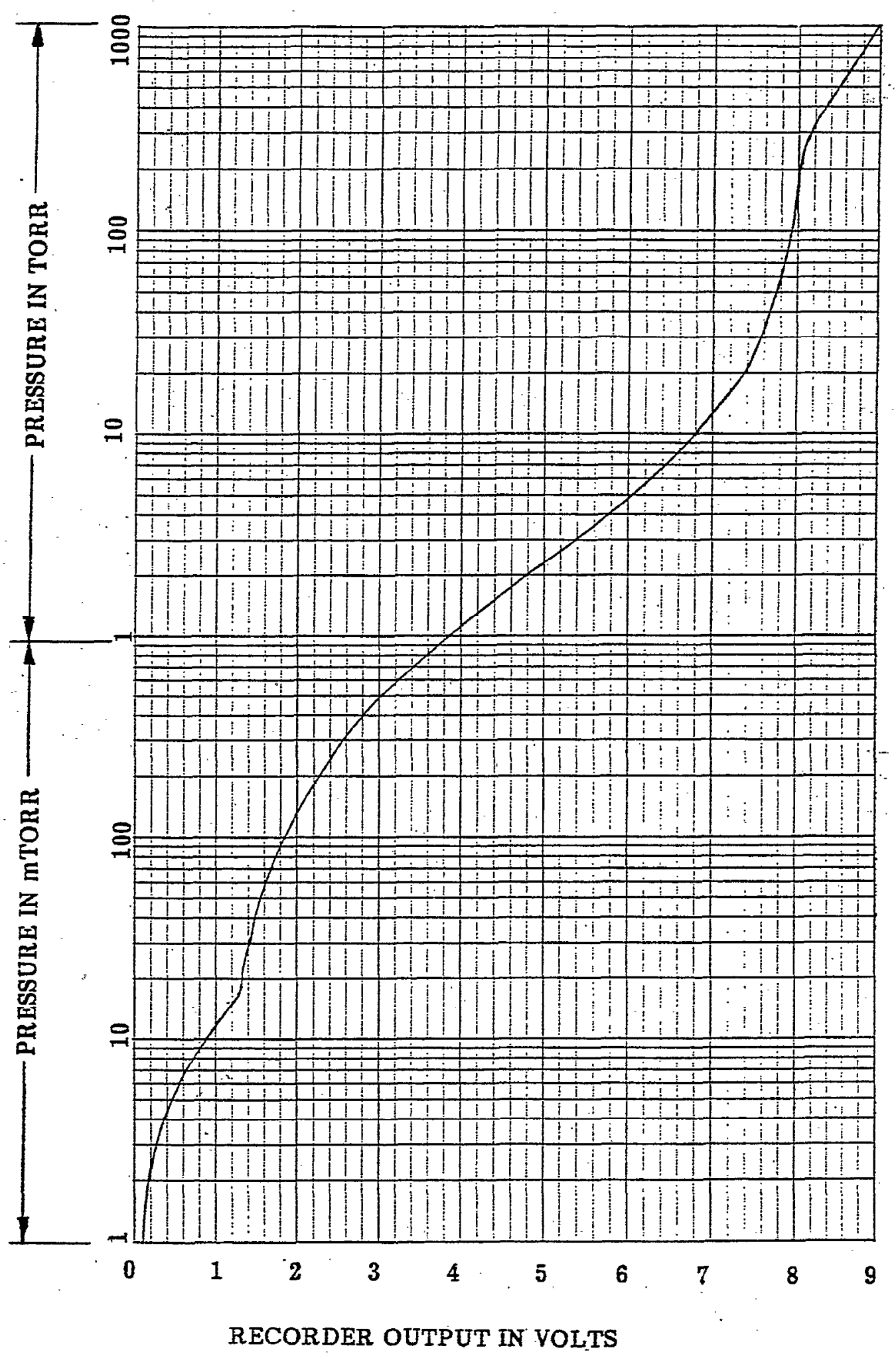




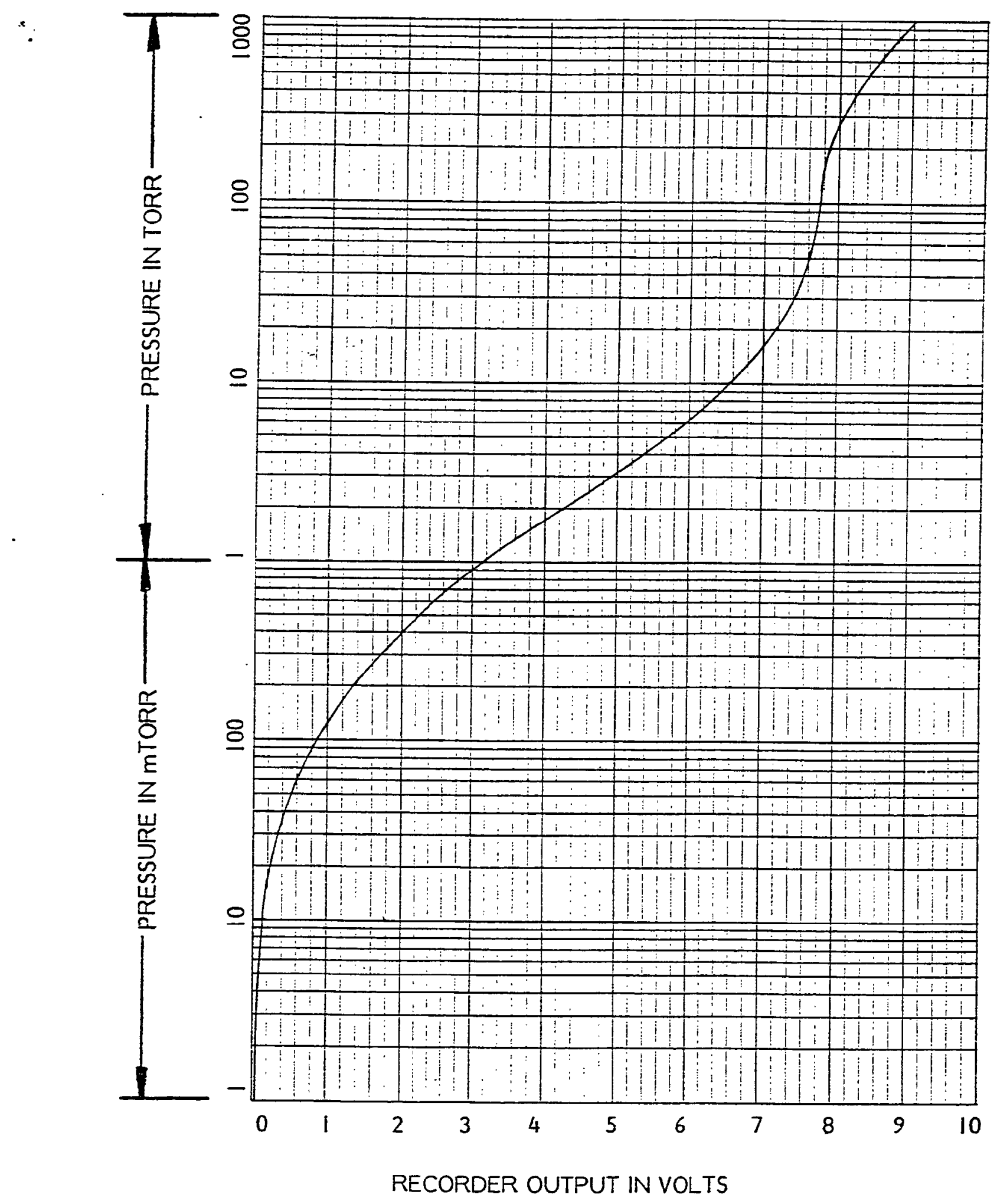

FIG. 4-5 NITROGEN PRESSURE VS. DIGITAL CONTROLLER RECORDER OUTPUT VOLTAGE 
NATIONAL SYNCHROTRON LIGHT SOURCE

TECHNICAL SPECIFICATION

for

THERMISTOR GAUGE ATMOSPHERE TO 1 MICRON
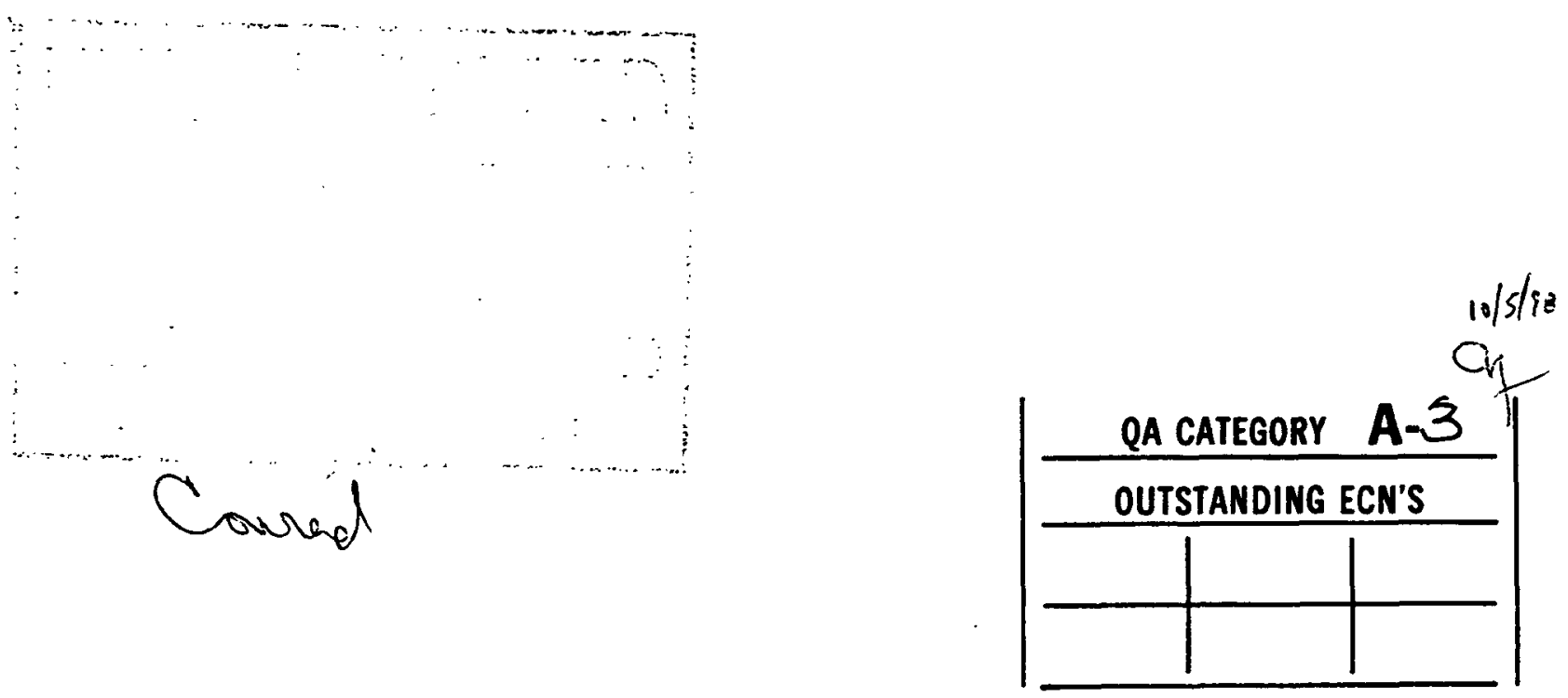

$$
907 \text { 30\% }
$$

\begin{tabular}{|c|c|c|c|c|c|c|c|c|c|c|}
\hline DAGE LATEST & AEY SCAl & ne & \multicolumn{3}{|c|}{ DESCRIPTION } & & BID & DATE & CRn & APP \\
\hline Pace 1 or 3 & $\frac{\text { JCS }}{\text { DraWM }}$ & CMECRER & $\frac{6 / 6 / 79}{\text { DATE }}$ & $9 / 5 / 79$ & \multirow{2}{*}{\multicolumn{6}{|c|}{$\begin{array}{l}\text { Thermistor Gauge } \\
\text { Atmosphere to } 1 \text { Micron }\end{array}$}} \\
\hline \multirow{2}{*}{\multicolumn{4}{|c|}{$\begin{array}{l}\text { BROOKHAVEN NATIONAL LABORATORY } \\
\text { ASSOCIATED UNIVERSITIES, INC. } \\
\text { UPTON, } \mathbf{N} \text {. Y. }\end{array}$}} & DATE & & & & & & \\
\hline & & & & $\& \subset A$ & & SLS-07. & $13-2$ & & -1 & $A$ \\
\hline
\end{tabular}




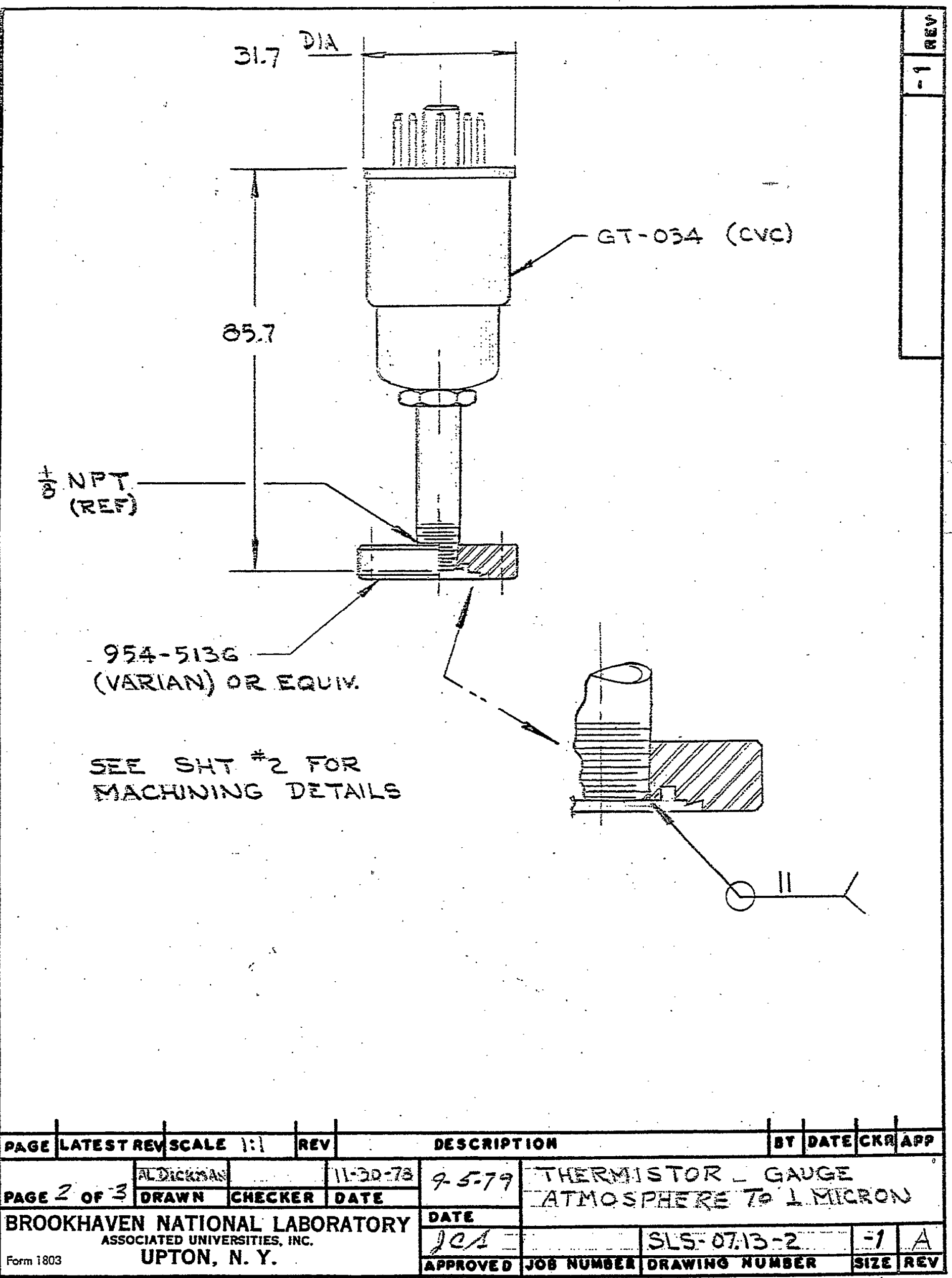


DRILI 17 (4.37) DIA

6. EQ.SP. ON 26.97 B.C.

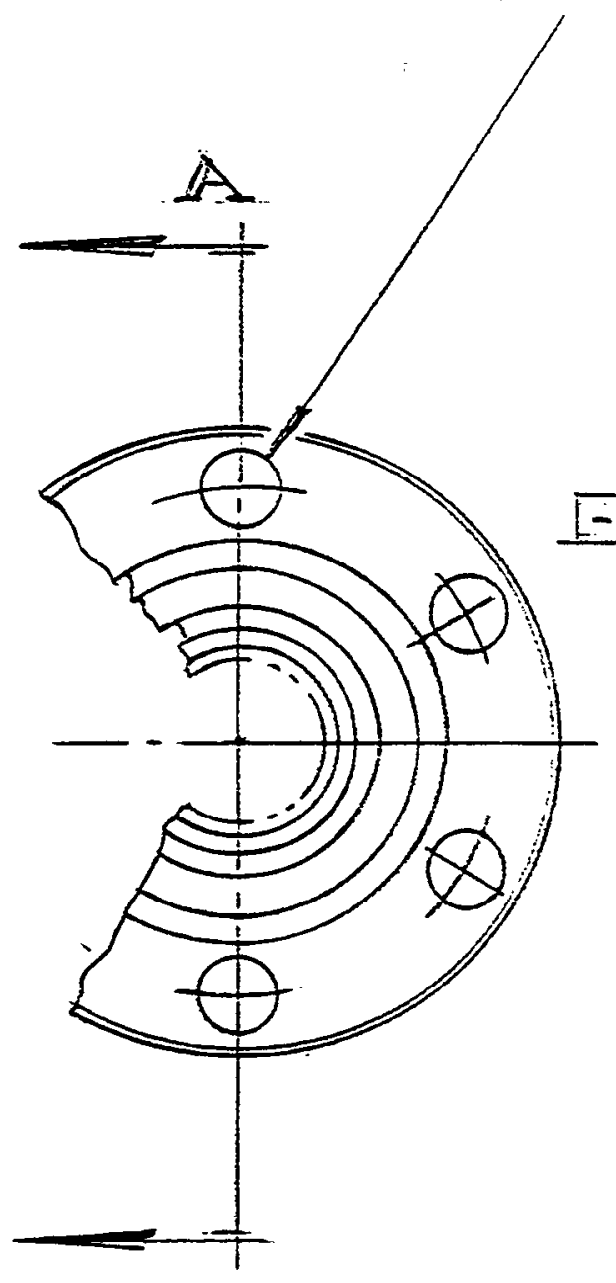

A

$$
327
$$

$20^{\circ}$

7.24

$.66^{ \pm .05}$

$1.17 \div .05$

2.75

$21.46^{ \pm .05}$

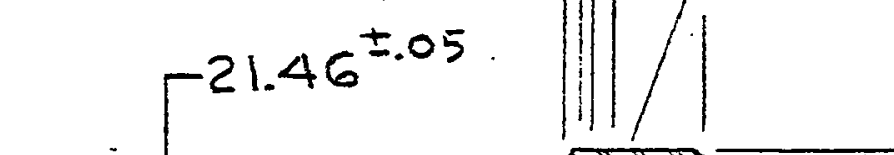

NOTE:-

1. SCALE 2:1

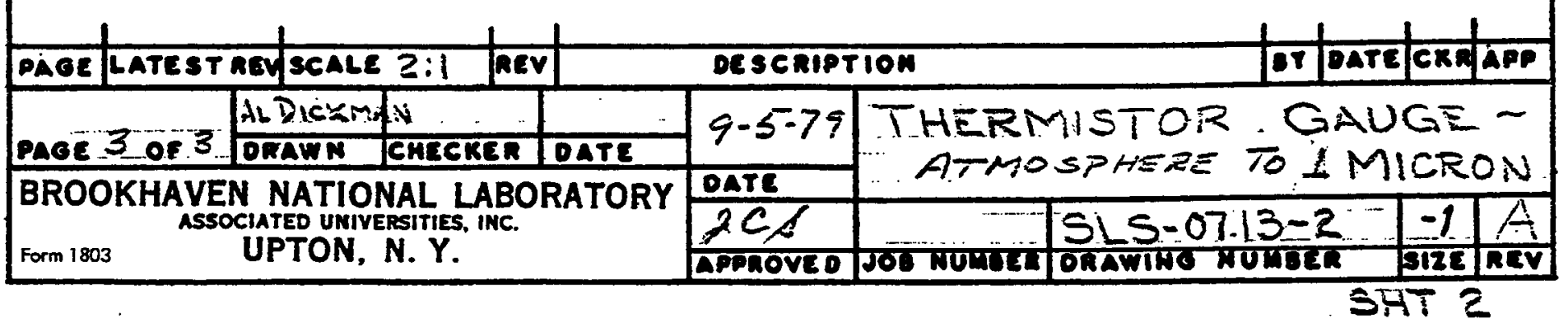


NATIONAL SYNCHROTRON IIGHT SOURCE

TECHNICAI SPECIFICATION

for

ION GAUGE - COLD GATHODE $10^{-3}$ TORR to $10^{-8}$ TORR

Din

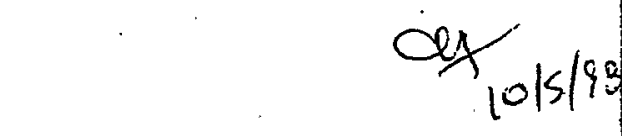

Anvad

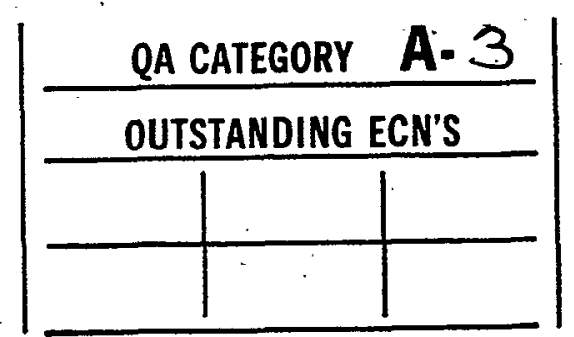

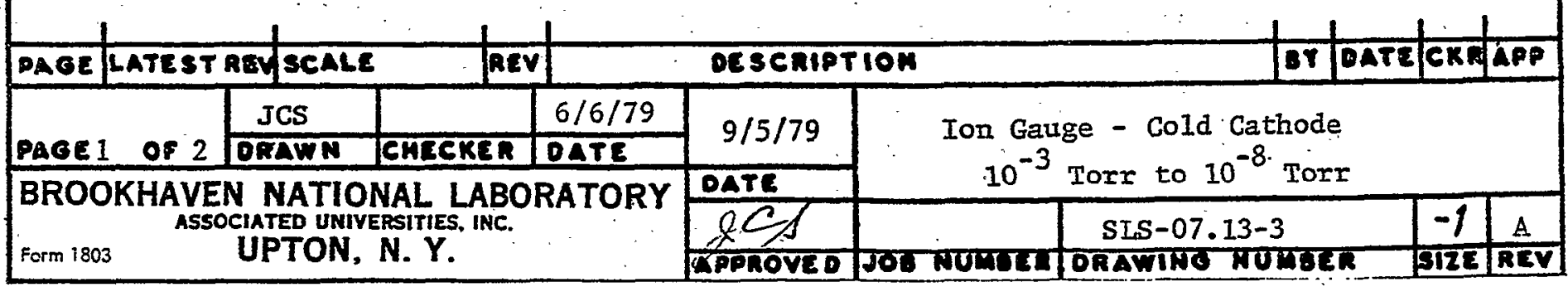




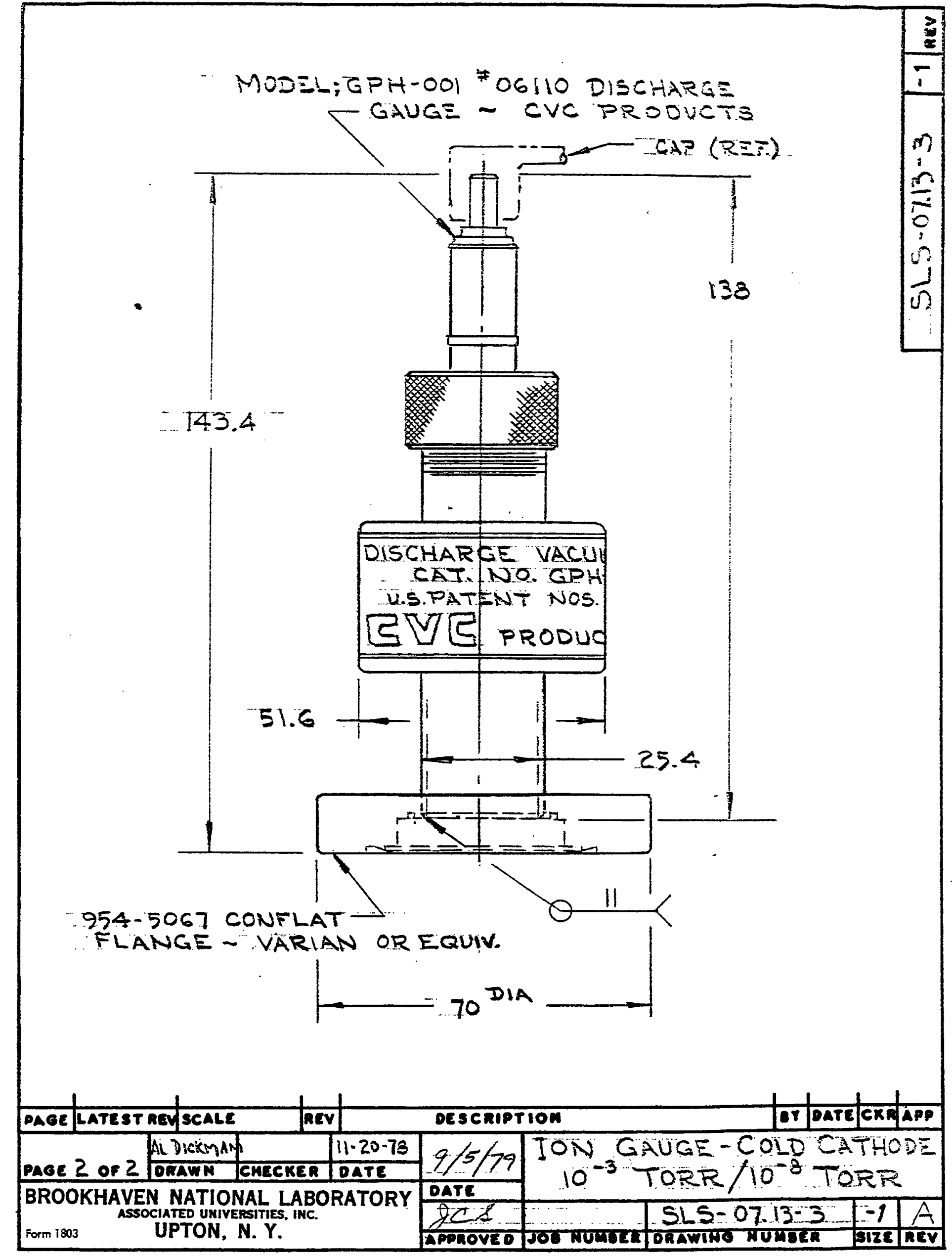


$\therefore$ 
NATIONAL SYNCHROTRON LIGHT SOURCE

TECHNICAL SPECIFICATION

for

ION GAUGE - HOT FIIAMENT $10^{-4}$ TORR to $10^{-11}$ TORR

Coured

rimis

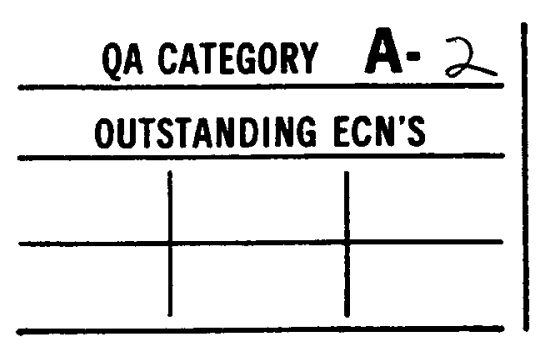

ids 190<smiles>CC1(C)CC1</smiles> 


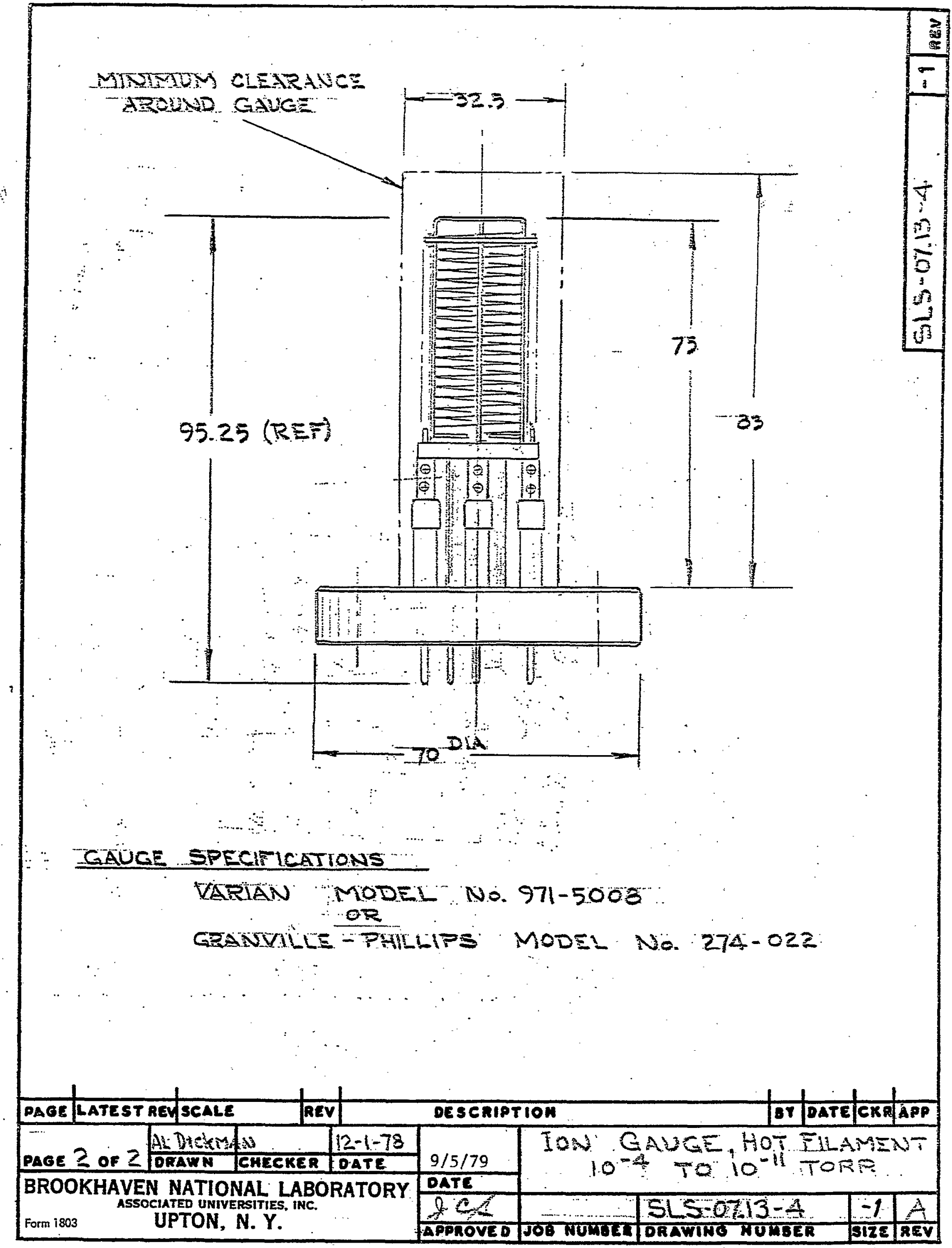


The following table hisis relative gauge sensitivitues for various gases. The vaiues are derived by empirical methods subsiantiateo - measurements reporteo in literature. The multiple values found in the table represent several difierent reterence: Th: ... le has been compiled and published by Robert L. Summers of Lewis Research Center. NASA Technicai Note TN D.52as. National Aeronauzic and Space Administration, Washington, D.C., June 19ą.

To convert readings from the ionization gauge control (normally calibrated for nitrogen) divide the indicated pressure by the number listed in the third column for the particular gas $\left(S / S_{n_{2}}\right)$.

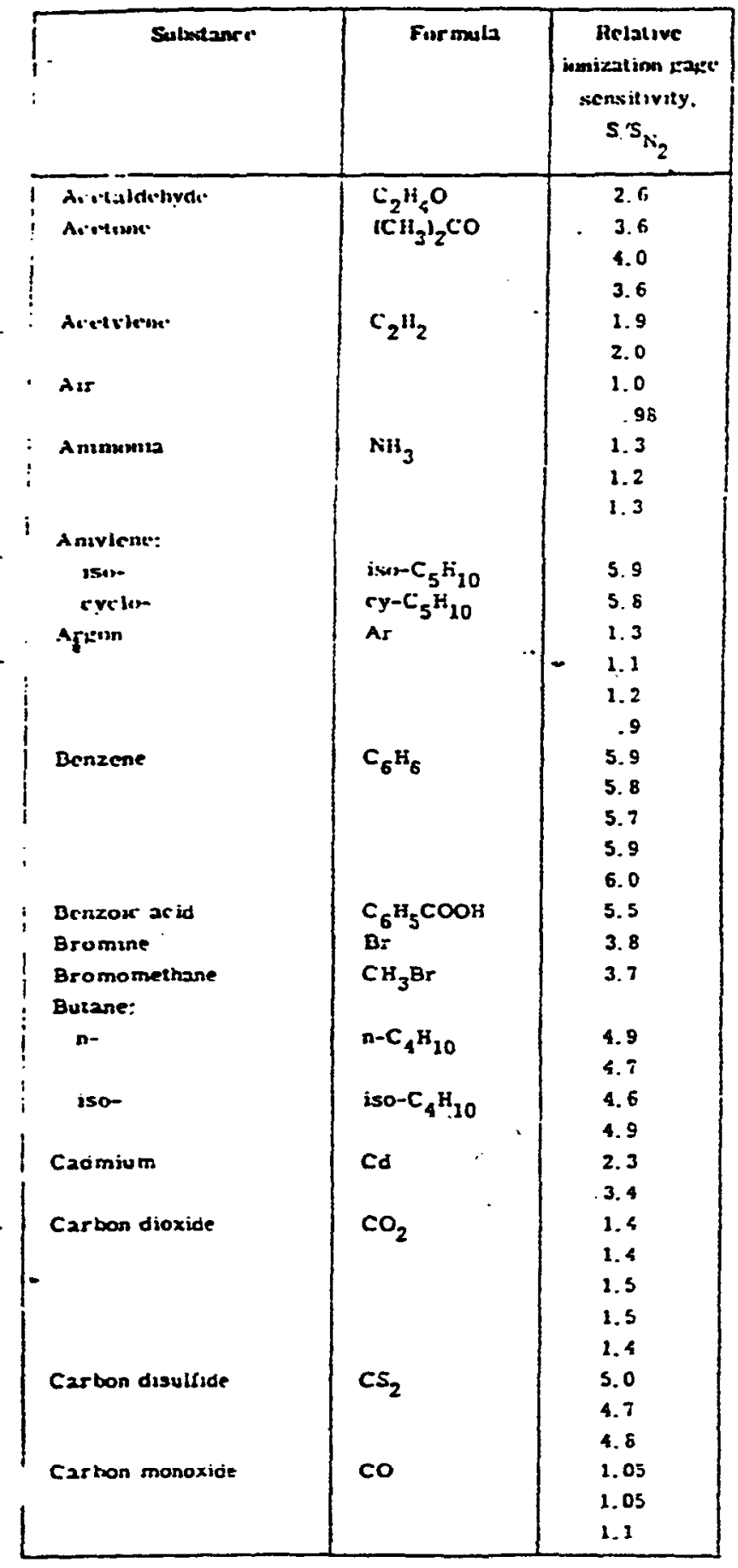

\begin{tabular}{|c|c|c|}
\hline Substance & Formula & $\begin{array}{l}\text { Rclative } \\
\text { fonizalinn gave } \\
\text { sensitivity. } \\
\text { S.'s } \mathrm{N}_{2}\end{array}$ \\
\hline Carbon tetrachloride & $\mathrm{CCl}_{4}$ & $\begin{array}{l}6.0 \\
6.3\end{array}$ \\
\hline Cesium & Cs & $\begin{array}{l}4.3 \\
2.0 \\
4.5\end{array}$ \\
\hline Chorise & $\mathrm{Cl}_{2}$ & $\begin{array}{l}.63 \\
2.6 \\
1.6\end{array}$ \\
\hline $\begin{array}{l}\text { Chlorobenzene } \\
\text { Chlorothane }\end{array}$ & $\begin{array}{l}\mathrm{C}_{6} \mathrm{H}_{5} \mathrm{Cl} \\
\mathrm{C}_{3} \mathrm{H}_{5} \mathrm{Cl}\end{array}$ & $\begin{array}{l}7.0 \\
4.0\end{array}$ \\
\hline CL:stolorm & $\mathrm{CHCl}_{3}$ & $\begin{array}{l}4.7 \\
4.6 \\
4.8\end{array}$ \\
\hline Chloromethane & $\mathrm{CH}_{3} \mathrm{Cl}$ & $\begin{array}{r}2.6 \\
3.2 \\
3.1\end{array}$ \\
\hline Cyanogen & $(\mathrm{CN})_{2}$ & $\begin{array}{l}2.8 \\
3.6 \\
2.7\end{array}$ \\
\hline Cyclohexylene & $\mathrm{C}_{6} \mathrm{~F}_{12}$ & $\begin{array}{l}7.9 \cdots \\
6.4\end{array}$ \\
\hline Deuterium & $D_{2}$ & $\begin{array}{l}.35 \\
.32\end{array}$ \\
\hline Dichiorodifloromethare & $\mathrm{CCl}_{2} \mathrm{~F}_{2}$ & $\begin{array}{l}2.7 \\
4.1\end{array}$ \\
\hline Diehloromethane & $\mathrm{CH}_{2} \mathrm{Cl}_{2}$ & 3.7 \\
\hline $\begin{array}{l}\text { Dus:trodonzene: } \\
\text { o- } \\
\text { n:- } \\
\text { p- }\end{array}$ & $\mathrm{C}_{6} \mathrm{H}_{4}\left(\mathrm{NO}_{2}\right)_{2}$ & $\begin{array}{l}7.8 \\
7.8 \\
7.8\end{array}$ \\
\hline Ethane & $C_{2} F_{6}$ & $\begin{array}{l}2.8 \\
2.8 \\
2.5\end{array}$ \\
\hline Ethanol & $\mathrm{C}_{2} \mathrm{H}_{5} \mathrm{OH}$ & $\begin{array}{l}3 . E \\
2,9\end{array}$ \\
\hline Einyl acetate & $\mathrm{CH}_{3} \mathrm{COOC}_{2} \mathrm{H}_{5}$ & 3.0 \\
\hline Etnyl ether & $\left(\mathrm{C}_{2} \mathrm{H}_{5}\right)_{2} \mathrm{O}$ & $\begin{array}{l}5.1 \\
5.1\end{array}$ \\
\hline Eihylene & $c_{2} r_{5}$ & $\begin{array}{c}2.3 \\
2.4 \\
2.2 \\
2.2102 .5\end{array}$ \\
\hline Ethylene oxlde & $\left(\mathrm{CH}_{2}\right)_{2} \mathrm{O}$ & 2.5 \\
\hline
\end{tabular}




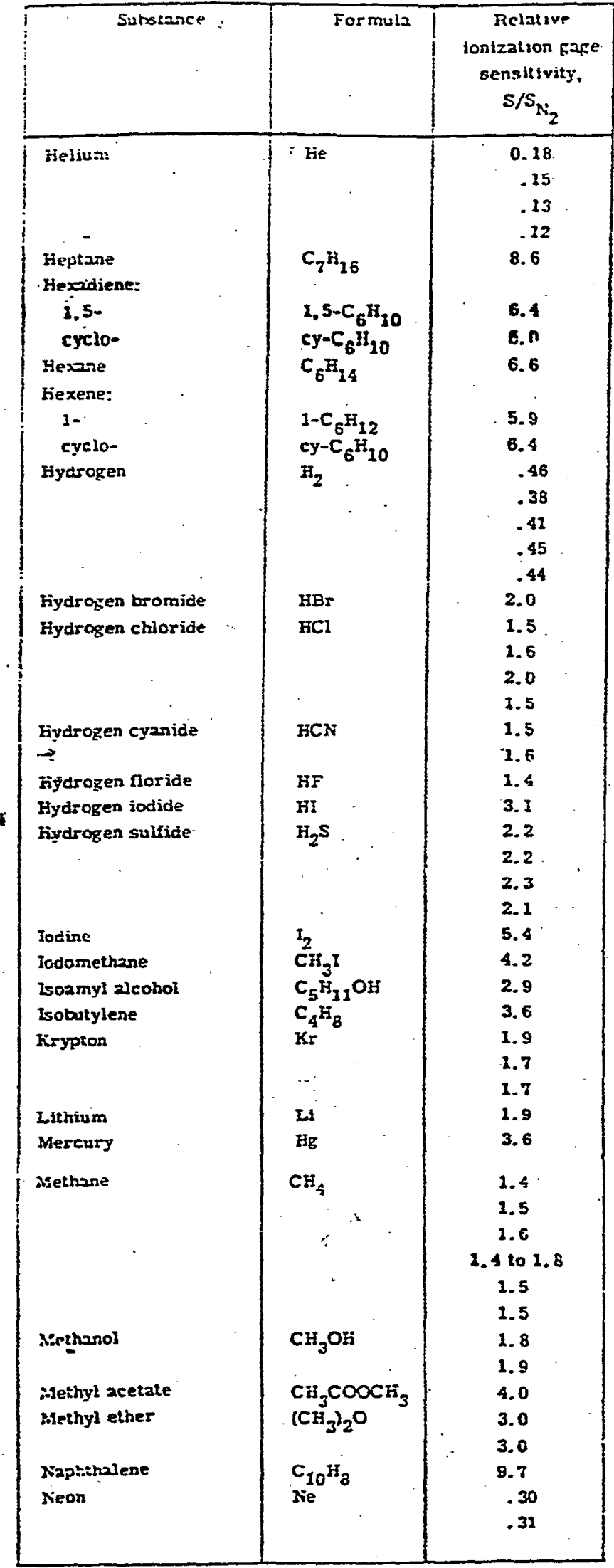

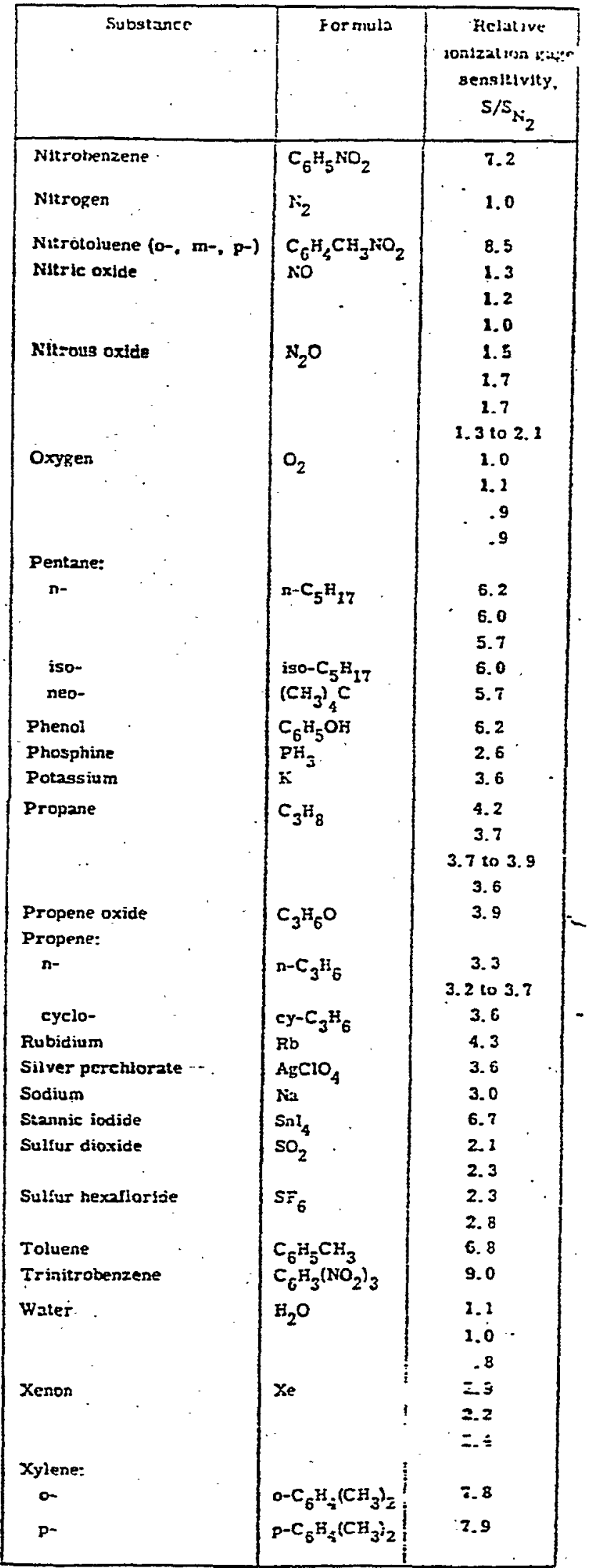




\section{BROOKHAVEN NATIONAL LABORATORY \\ Associated Universities, Inc. \\ Upton, New York 11973}

\section{Technical Specification}

for

UHV Bakeable Flanges

May 1997
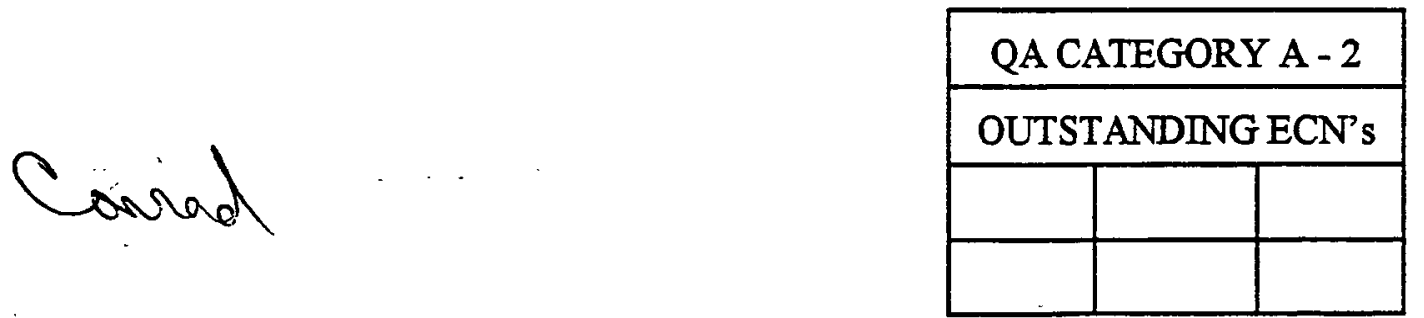

UHV Bakeable Flanges

BROOKHAVEN NATIONAL LABORATORY ASSOCIATED UNIVERSITIES, INC. UPTON, N.Y.

\begin{tabular}{|l|l|l|l|}
\hline SLS-07.14 & SLS-07.14-1 & -1 & D \\
\hline JOB NUMBER & DRAWING NUMBER & SIZE & REV \\
\hline
\end{tabular}


REVISION CONTROL SEEET

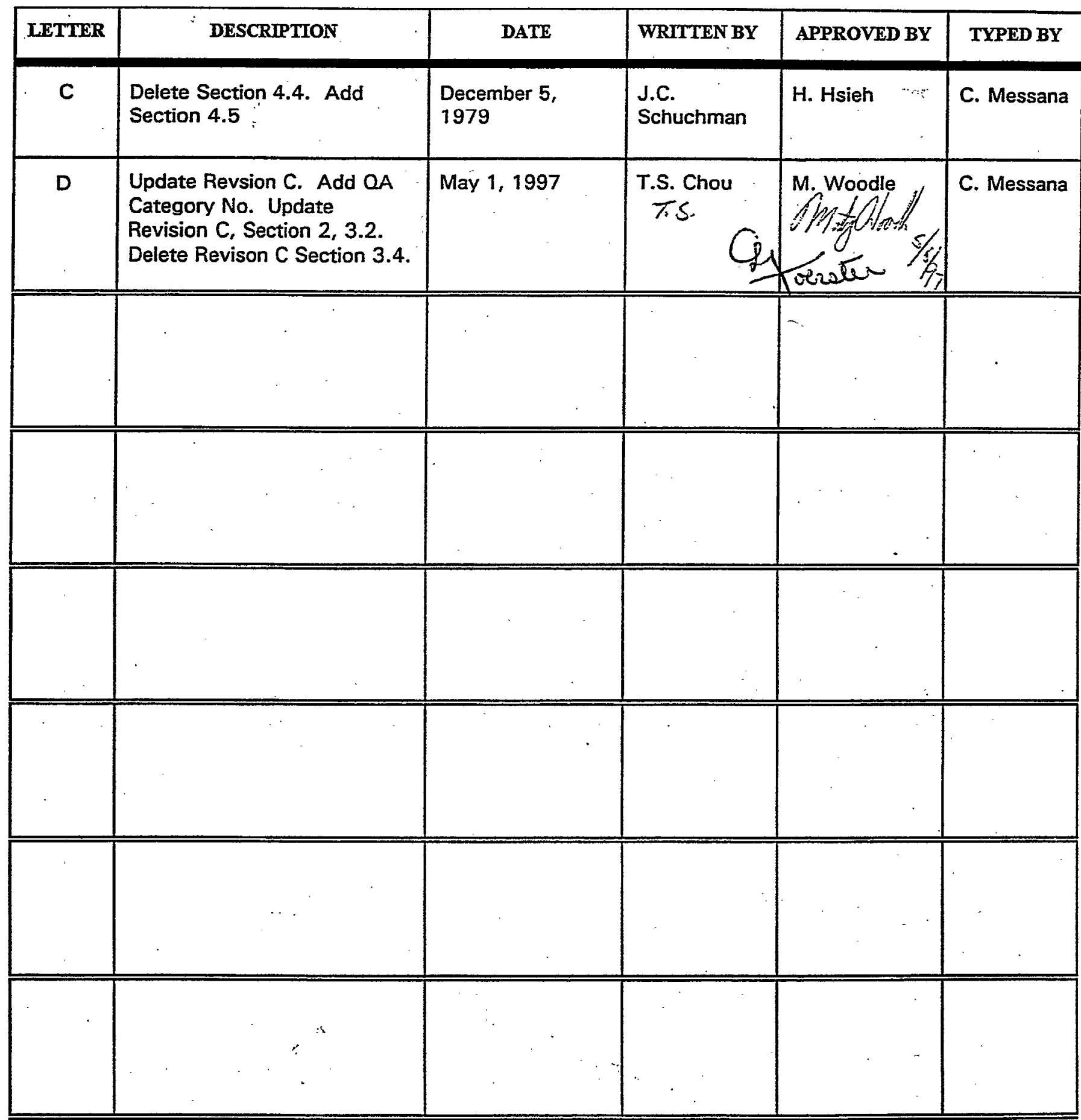

PAGE i

BROOKHAVEN NATIONAL LABORATORY ASSOCIATED UNIVERSITIES, INC.

Form 1803

\section{UHV Bakeable Flanges}

\begin{tabular}{|c|c|c|c|}
\hline SLS-07.14 & SLS-07.14-1 & -1 & D \\
\hline JOB NUMBER & DRAWING NUMBER & SIZE & REV \\
\hline
\end{tabular}




\section{INTRODUCTION}

This specification outlines the requirements of the Ultra High Vacuum (UHV) flanges for use on the National Synchrotron Light Source (NSLS) vacuum system.

The flange specified is the Conflat' flange, a patented design of Varian Associates and licensed by them to number of vacuum manufacturers for fabrication.

\section{APPLICABLE DOCUMENTS}

The applicable provisions of the following documents of issue in effect on the effective date of award shall become a part of this specification, to the extent specified herein.

1. AVS 3.2-1965 "Flanges Bakeable to $500^{\circ} \mathrm{C}$.

American Vacuum Society, 335E. 45th St., New York, N.Y. 10017

2. ASTM A-276-88a, "Standard Specification for Stainless and Heat-Resisting Steel Bars and Shapes."

3. ASTM A-484/A-484-88, "Standard Requirements for Stainless and Heat-Resisting Bars, Billets, and Forgings."

4. MIL-S-862B, "Steel - Billets, Corrosion Resisting: Reforging Application."

5. ASTM E-112, "Estimating the Average Grain Size of Metals."

6. ASTM E45-87, "Determining the Inclusion Content of Steel."

7. QQ-S-763E. "Steel Bars ..... Corrosion Resisting". Section 3.1 Materials, Section 3.4 Chemical Composition, Section 3.5 Mechanical Properties, Section 3.6 Macrostructure, Section 4.1

Responsibilities for Inspection, Section 4.2 Lot, Section 4.3 Sampling Procedure, Section 4.5.4 Intergranular Corrosion Test, Section 4.5.5 Rejection and Retest.

\section{REQUIREMENTS}

The proposed vendor must be able to substantiate his technical capability which qualify him to produce UHV flanges to this specification. One important factor is recent experience in successful production of quantities of UHV flanges. Other factors to be considered are Quality Assurance and Inspection operations and machine tool capabilities for producing a volume flow of flanges.

\subsection{Seal Design}

All flanges made to this specification shall be of the knife edge design (ConFlat) which uses a flat circular copper gasket ring to effect a leak tight, bakeable seal. Flanges are to be manufactured according to the Varian drawings which are provided as part of the license agreement.

${ }^{1}$ Conflat is a registered trademark of Varian Associates.

\begin{tabular}{|c|c|c|c|c|}
\hline Page 1 of 3 & \multicolumn{4}{|c|}{ UHV Bakeable Flanges } \\
\hline \multirow{3}{*}{$\begin{array}{l}\text { BROOKHAVEN NATIONAL LABORATORY } \\
\text { ASSOCIATED UNIVERSITIES, INC. } \\
\text { UPTON, N.Y. } \\
\text { Form } 1803 \quad \text { U }\end{array}$} & & & & \\
\hline & SLS-07.14 & SLS-07.14-1 & -1 & D \\
\hline & JOB NUMBER & DRAWING NUMBER & SIZE & REV \\
\hline
\end{tabular}




\subsection{Material}

All flange parts, certified Argon-Oxygen Decarburized (AOD), and Electro-Slag Remelted (ESR), AiSI type 304 stainless steel per the applicable sections of MIL-S-862B and QO-S-763E. Annealing temperatures of less than $1900^{\circ} \mathrm{F}$ are permitted but shall not in any way compromise the requirements of the intergranular corrosion test called for in QQ-S-763E.

\section{$3.3 \quad$ Forgings}

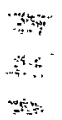

A. Flanges and flange parts which are required to be made from forgings must be formed by a process referred to as "Cross-Forging". This process is performed by hammer forging each piece triaxially at a "hot-cold work" temperature, approximately $1800^{\circ} \mathrm{F}$.

Billets from which forging blanks are cut have predominantly longitudinal metal flow due to drawing out to length in forging or rolling. In order to obtain finished flanges free from these potential leak paths the metal must receive $100 \%$ work and complete recrystallization to obtain the necessary fine grain structure.

The final operation for solid flanges and inserts is to hammer the plug into a Pocket Die (of larger diameter) causing the metal to re-flow outward and fill the die: : For rings to be used as retainers for rotatable inserts, the final operation is hammering into a ring die which produces the proper I.D. and O.D. and center punch out blank which is discarded.

- The finished forging should have at least a No. 3 grain size in the smaller flanges and no more than a No. 6 in larger sizes. Refer to ASTM E-112 for explanatory information.

B. Heat Treatment

Forged blanks shall be stress relief annealed at $1975^{\circ} \mathrm{F}$ prior to rough machining. Time at temperature and method of cooling depend on section thickness and shall be chosen to achieve optimum properties. Certification of heat treatment including time, temperature, and quench shall be provided at the request of the NSLS.

C. Machining

Following forging and heat treatment, each piece shall be rough machined using only "sulphur free" cutting fluids. The use of abrasive paper, buffing compounds or grinding wheels is prohibited in any finishing operation.

D. Hardness

All flanges must be certified to be a minimum hardness of Rockwell B 80 throughout. Typically, flanges should all be in the range of Rockwell B-85 to 90 which is the most desirable. The maximum hardness allowable is Rockwell B-95.

\section{E. Permeability}

In the annealed condition the magnetic permeability of each forging shall not exceed 1.05 at 200 Oersted, (air equal to 1.00). Magnetic permeability of austenitic stainless steel is a

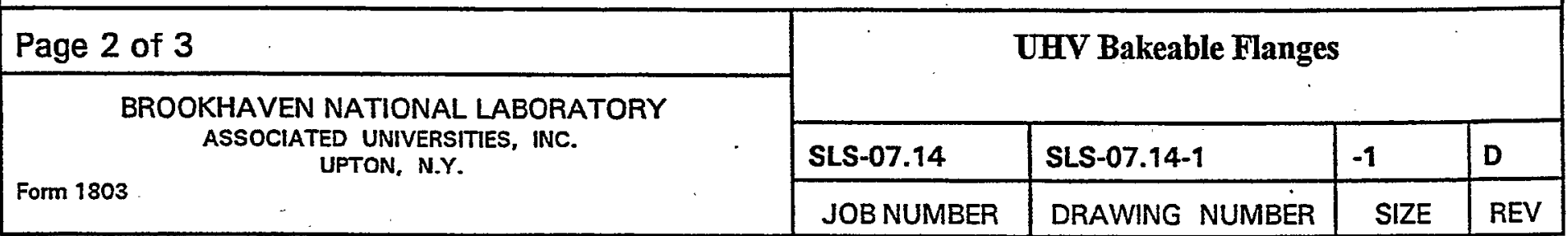


function of the amount of free ferrite present in the alloy. The maximum ferrite allowed shall be $1.5 \%$. Any flange which when tested indicates ferrite exceeding $1.5 \%$ shall be rejected.

F. Cleaning and Handling

Prior to final inspection each flange shall be chemically cleaned by vapor degreasing in tricholorethane or BNL approved substitute, followed by an alkaline soak cleaner, a thorough tap water rinse and drying with warm, oil-free air or dry nitrogen. Movement of finished flanges from machining to cleaning and inspection shall be within protective handling containers made specifically for this purpose.

\subsection{Finishing Bar Stock Flanges.}

Final machining, cleaning and handling of flanges made from bar stock shall follow the same requirements as for forged flanges.

\section{FINAL ACCEPTANCE}

Final acceptance of all flanges shall take place following delivery to, and inspection and testing by NSLS.

\subsection{Pre-Award Inspection}

NSLS reserves the right to send representatives to prospective vendor's plant prior to award for the purpose of inspecting the manufacturing facilities and reviewing the quality assurance organization. Vendor shall be prepared to respond to inquiries regarding the information provided in Section 4.1 and such other sections of the specification pertinent to determining the qualifications of the prospective vendor.

\subsection{Source Inspection}

A designated NSLS representative shall be permitted to witness any or all of the test and inspection provisions herein required. When so requested, the vendor shall notify NSLS 48 hours prior to the performance of a given test of inspection. In addition, NSLS reserves the right to inspect any process of procurement of manufacturing pertaining to these flanges including forgings which may be made by a sub-contractor.

\subsection{Flange Inspection}

In addition to the requirements of other sections, all flanges after being chemically cleaned, shall be $100 \%$ visually inspected for defects in surface finish and damage to the seal surface.

\subsection{Certification and Compliance}

If the certifications specified in Section 3.2 are not available, then an original certification by the vendor (seller), stating that the flanges supplied meet this specification, will be acceptable.

\begin{tabular}{|c|l|l|c|c|}
\hline Page 3 of 3 & \multicolumn{3}{|c|}{ UHV Bakeable Flanges } \\
\hline $\begin{array}{c}\text { BROOKHAVEN NATIONAL LABORATORY } \\
\text { ASSOCIATED UNIVERSIIIES, INC. } \\
\text { UPTON. N.Y. }\end{array}$ & SLS-07.14 & SLS-07.14-1 & -1 & D \\
\cline { 2 - 6 } Form $1803 \quad$ & JOB NUMBER & DRAWING NUMBER & SIZE & REV \\
\hline
\end{tabular}


NATIONAL SYNCHROTRON LIGHT SOURCE

TECHNICAL SPECIFICATION

for

COPPER GASKETS FOR CONFLAT FLANGES
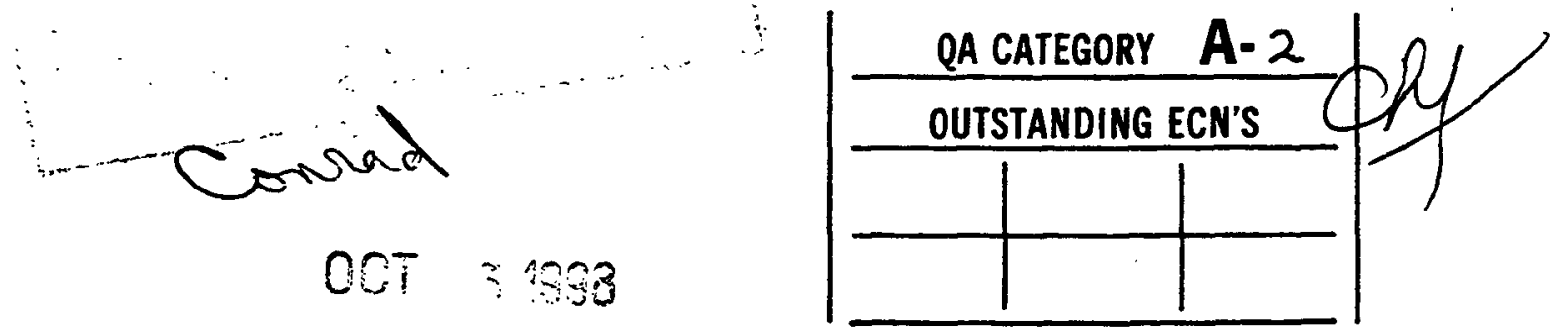

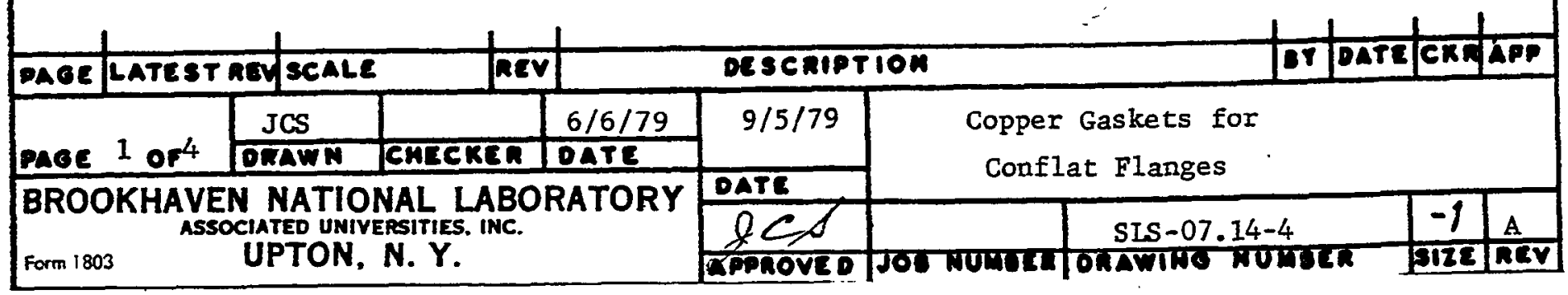




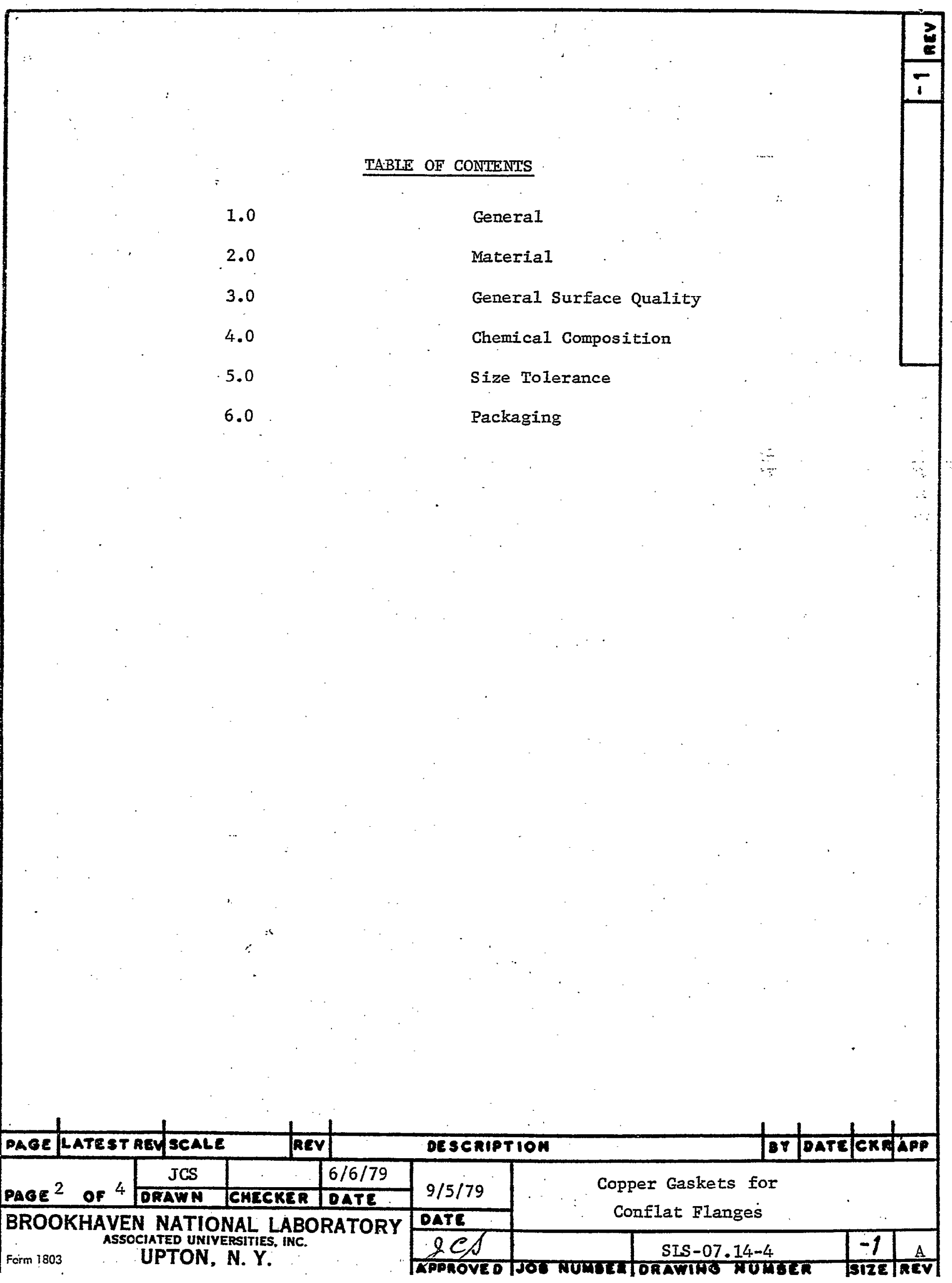


1.0 Genera1

1.1 This specification describes the copper gasket that is to be used with the UHV Conflat* flanges.

\subsection{Material}

2.1 Material to be electronic grade certified oxygen-free high conducting (OFHC) copper. (Copper alloy 非101 Oxygen free electronic).

\subsection{General Surface Quality}

3.1 All surfaces shall be uniformly bright and free from excessive cracks, folds, die marks, laps seams, pits, galls, blisters, and foreign contamination. In general, all defects which exceed $2 \%$ of the stock thickness or 0.020 inch, whichever is smaller, shall be deemed excessive. Additionally, the following shall apply to the specific forms indicated:

3.2 Electrical Resistivity - The electrical resistivity of specimens when annealed at $500^{\circ} \mathrm{C}$ for 30 minutes in a hydrogen or other reducing atmosphere shall not exceed $0.15176 \mathrm{ohm}-\mathrm{g} / \mathrm{m}^{2}$ at $20^{\circ} \mathrm{C}$ corresponding to a conductivity of not less than 101 percent International Annealed Copper Standard in accordance with ASTM method B 193, Test for Resistivity of Electrical Conductor Materials.

\subsection{Temper}

OFHC Copper

$1 / 4$ - hard
Typical Rockwe 11 Hardness

F-Scale $30 \mathrm{~T}-\mathrm{Scale}$
Typical

Yield Strength

at $1 / 2 \%$ - PSI 30,000

\subsection{Chemical Composition}

4.1 Chemical Limits - The material shall conform to the following chemical composition or refiner's certified analysis:

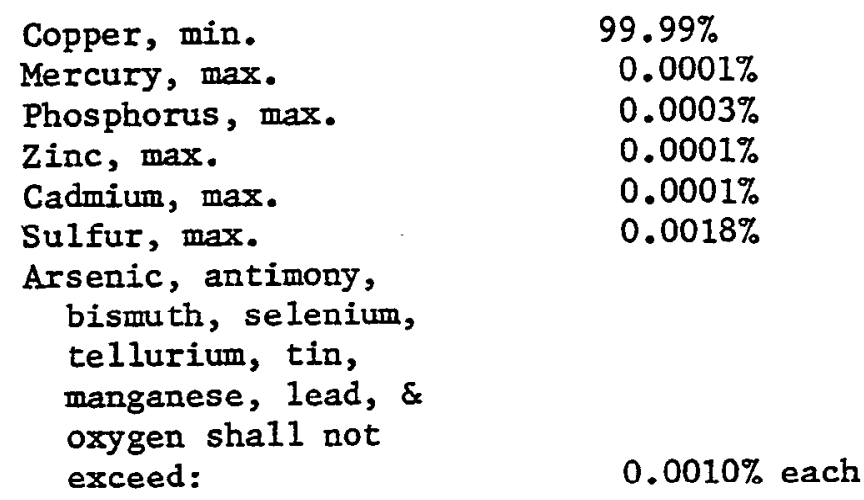

* Registered trademark of Varian Associates.

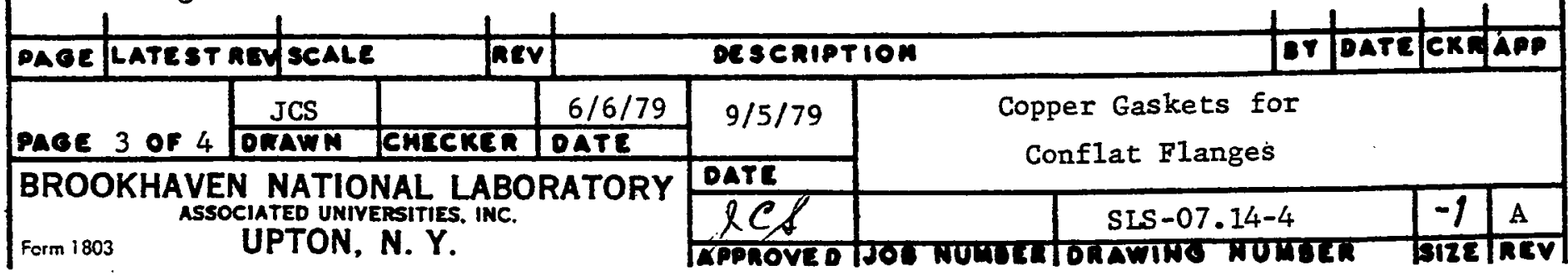


Copper shall be determined by difference of "Impurity Total" from 100\%. "Impurity Total" is defined as the sum of silver, sulfur, lead, tin, bismuth, arsenic, antimony, 'iron, nickel, mercury, zinc, phosphorus, selenium, tellurium, manganese, cadium, oxygen.

\subsection{Size Tolerance}

953-5070 for Mini ConFlat Flanges

953-5014 for $23 / 4^{n}$ O.D. ConFlat Flanges

953-50/3 for $33 / 8^{\prime \prime} 0 . D$. ConFlat Flanges

953-5015 for 43" O.D. ConFlat Flanges

953-5016 for 6" O.D. ConFlat Flanges

953-5017 for 8" 0.D. ConFlat Flanges
Thickness

$.080 \pm .0035$

$.080 \pm .0035$

$.080 \pm .0035$

$.080 \pm .0035$

$.080 \div 0035$

$.080 \pm 0035$

$$
\text { O.D. }
$$

I.D.

$.838 \pm .001$

$1.895 \pm .001$

$2.423 \pm .001$

$3.243 \pm .001$

4.7431.001

$6.743 \pm .001$
$.640 \pm .003$

$1.451 \pm .003$

$2.010 \pm .003$

$2.506 \pm .003$

$4.006 \pm .003$

$6.007 \pm .003$

\subsection{Packaging}

6.1 All gaskets shall be packaged with protective material to prevent damage and contamination during shipment.

Additionally, each gasket shall be individually foil packaged and heat sealed to insure contaminate free shelf life.

NOTE: The standard Varian copper gasket meets this specification.

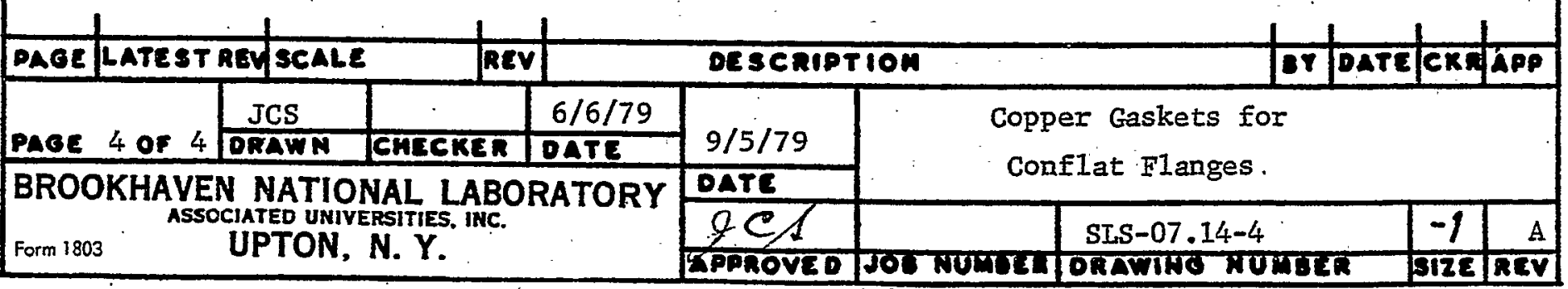




\section{Appendix D}

D. NSLS Procedures

SLS-07.19-12-1

SLS-07.19-4-1
Vacuum Procedure to Open VUV or X-ray Beam Line Front End Valve

Baking Out VUV or X-ray Storage Ring 
InsTs National Symchrotron light Source

BROOKHAVEN NATIONAL LABORATORY

No:

SLS07-19-12-

Date: $6 / 25 / 26$

Rev.: $"$ B

Page 1 of 3

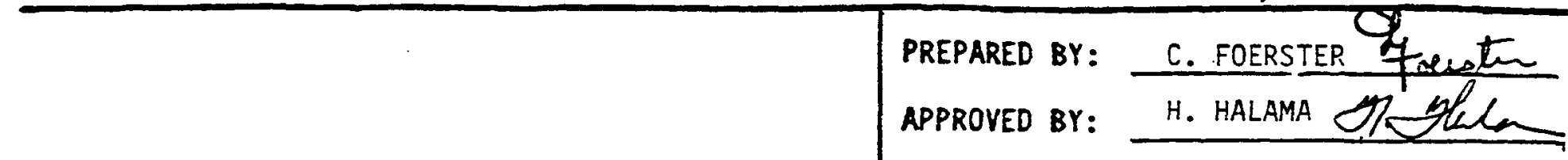

VACUUM PROCEDURE*

TO

OPEN VUV OR X-RAY FRONT END VALVE

TO RING
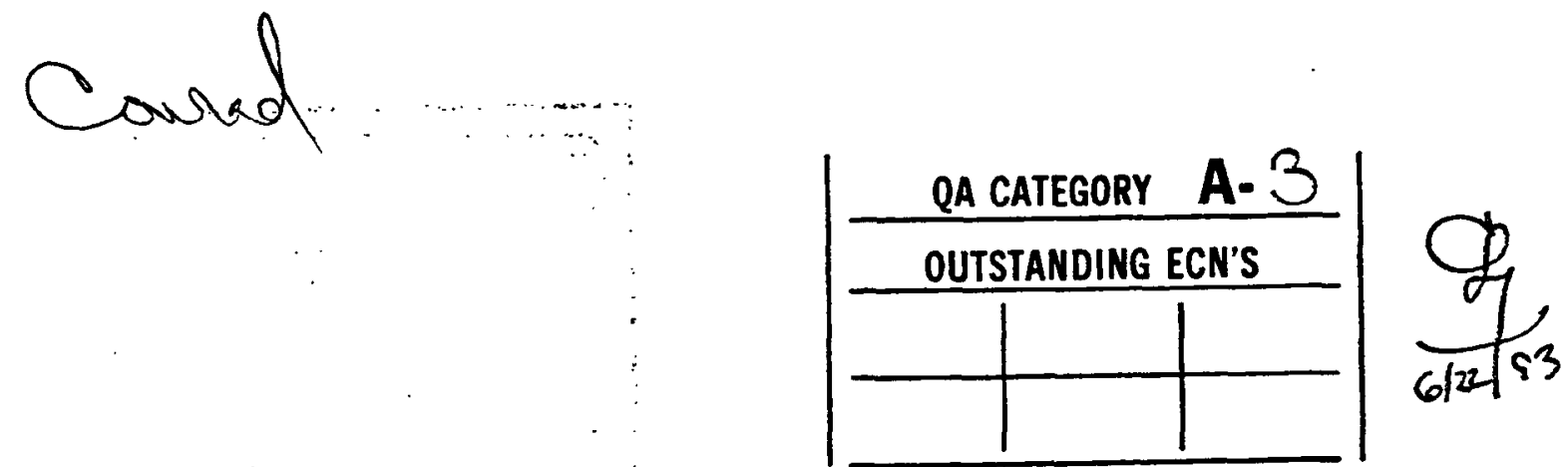

OC:

\begin{tabular}{|l|l|l|l|}
\hline P.EV. & $B / B$ & $B$ \\
\hline
\end{tabular}

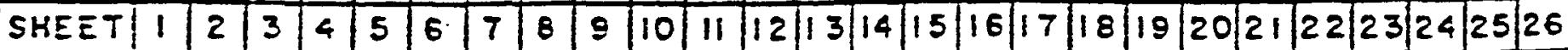


1. Scope

Procedure to allow beam lines to be opened to ring with minimum negative effects.

2. Documentation, Materials, and Equipment

2.1 "Policy for NSLS utilization by Participating Research Teams".

2.2 "Requirements and Guidelines for NSLS Experimental Beam Line Vacuum Systems" BNL 28073. Note: Memo 3/11/85 discontinue use of fomblin oil and grease.

2.3 Calibration factors for ionization gauge (IG) and RGA parent peaks.

2.4 RGA system.

2.5 Nude I.G. and controller.

2.6 SLS-07.19-4-1 Vacuum procedure for baking out WUV or X-ray ring.

3. Special Instructions

3.1 To open front end valve to ring the following vacuum requirements must be met.

a. Instrument tee I.G. must indicate $2 \times 10^{-9}$ Torr or less after correcting for calibration factor.

b. The RGA scan must indicate the predominant gas component to be hydrogen and it must be a minimum of $60 \%$ of the total pressure.

c. There-shall be no evidence of leaks (external, virtual, etc.) in the system, air or other.

d. High masses, greater than 28 shal1 be less than $10 \%$ of the total pressure.

e. Hydrocárbons, fluorocarbons, and other gas components indicated at mass locations $38,41,43,45$ and greater shall total less than $1 \times 10^{-11}$ Torr.

f. If instrument tee I.G. indicates $9 \times 10^{-10}$ Torr or less then a $R G A$ scan is not required $(b, c, d, e)$ to open.

3.2 Any exception to 3.1 must be approved by C. Foerster or H. Halama. 


\section{Setup}

4.1 Beam line vacuum systems which are valved to front end vacuum shall be constructed of materials and techniques as outlined in 2.1 and 2.2

4.2 System components should be vacuum baked and conditioned using 2.6 Vacuum Procedure as a guide. Conditioning must include $\mathrm{ArO}_{2}$ glow discharge cleaning of surfaces which will be subject to beam induced desorption.

4.3 Ion gauge and RGA should be degassed after system conditioning and a minimum of 48 hours prior to system evaluation for front end valve opening.

4.4 Opening of front end to ring valve for first light may only be performed during low beam current operation. Some low beam conditioning is required to prevent excessive pressure. Vacuum group should aiways be notified and represented.

\section{Procedure}

5.1 Record I.G. reading from instrument tee attached to beam line side of front end to be opened.

5.2 If gauge reading is acceptable, run RGA scan on $10^{-9}$ and $10^{-11}$ ranges. RGA must be degassed and "stabilized" prior to this operation.

a. Multiplier to be set to farday cup reading on mass 28 (calibration).

b. Record on upper right of scan

1. Date and time

2. Front end number

3. Valve status

4. Ion gauge reading

5. RGA total pressure readings

c. Record scale next to each mass scan

5.3 If scans are acceptable per 3.1, vacuum permission is given to open valve.

5.4 If scans are not acceptable, Vacuum Group will advise corrective action.

5.5 When valve is opened monitor pressure and rescan RGA with beam in front end.

a. Record beam current and beam life on scan. 
. . T 
IIsT) National Synchrotron Light Source

BROOKHAVEN NATIONAL LABORATORY
No:

SLS-07.19-4-1 Date: 1/30/85 Rev.: 5 Page 1 of 7

PREPARED BY: J.C. Schuchman APPROVED BY: C. Foerster folnth

VACUUM PROCEDURE

FOR

BAKING OUT VUV OR X-RAY STORAGE RING
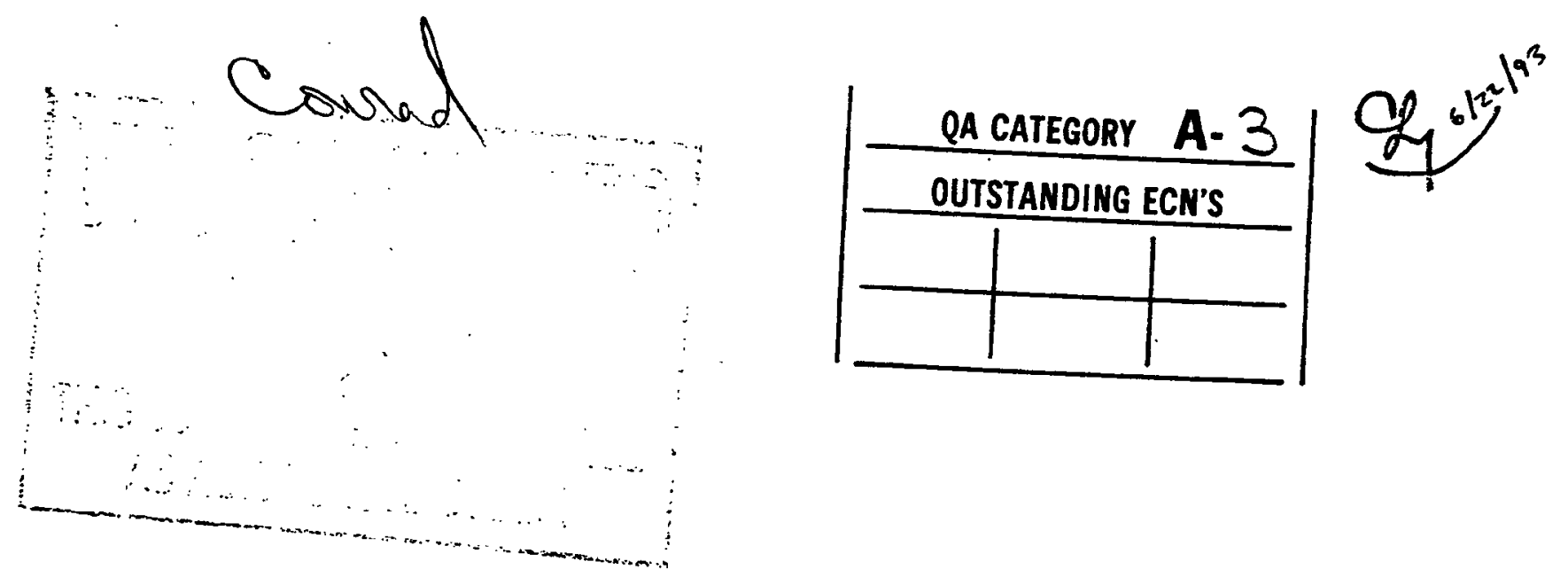

\begin{tabular}{|c|c|c|c|c|c|c|c|c|c|c|c|c|c|c|c|c|c|c|c|c|c|c|c|c|c|c|}
\hline REV. & $B$ & $A$ & B & B & $B$ & $B$ & A & & & & & & & & & & & & & & & & . & & & \\
\hline SHEET! & 1 & 2 & 3 & 4 & 5 & 6 & 7 & 8 & 9 & 10 & 11 & 12 & 13 & 14 & 15 & 161 & 17 & 18 & 19 & 20 & 21 & 22 & 23 & $\mid 24$ & 1751 & 6 \\
\hline
\end{tabular}




\section{Scope}

This bakeout procedure encompasses the nitrogen purge, pump down, leak test, bakeout, and conditioning of all pumps, gauges, and residual gas analyzers in the VUV or X-Ray storage ring.

\section{Equipment and Materials}

2.1 Liquid nitrogen boil off supply

2.2 Megasorb pumping station

2.3 Liquid nitrogen

2.4 Turbomolecular pumping station

2.5 HeTium Teak detector

2.6 Helium supply

2.7 Helium calibrated leak

2.8. Flexible bellows line

2.9 White gloves

\section{Set-Up}

3.1 Drain water from chamber and al1 TSP pumps.

3.2 Start-up leak detector and calibrate to manufacturers specification. Record sensitivity.

3.3 Connect megasorb pumping station to ring roughing valve using

- flexible bellows line (wear white gloves). Charge cryosorption pump with liquid nitrogen.

3.4 Connect turbomolecular pumping (TMP) station to ring roughing valve using flexible bellows line, (wear white gloves). Start TMP.

3.5 Connect leak detector to foreline of turbomolecular pumping station.

3.6 Switch on eryosorption roughing pump. 
4.0 Procedure

* See Fig. 1 for sequence and approximate vacuum bake conditiong cycle.

4.1 Pre-bakeout leak test:

a. Pumpdown ring with megasorb pump. Carbon vane pump is turned on and system is pumped for 20 minutes. Stage one is used to pump the system down to 500 microns. Valve off stage one, and valve in stage two. Pump to 5 microns.

b. When ring pressure reaches 5 microns valve in turbomolecular pump and valve off megasorb pump.

c. When ring pressure is equal to or less than $10^{-5}$ Torr leak check ring.

4.2 Venting with liquid nitrogen boil off:

a. Connect copper venting line to vent valve. Before connecting, bakeout line with heating tape for one hour at $125^{\circ} \mathrm{C}$. Purge line with nitrogen during bakeout.

b. Slowly open vent valve and vent ring. Vent at a rate comparable to pumpdown rate to avoid stirring up particulate matter and causing undue stresses on chamber.

4.3 Nitrogen Purge and Bakeout Start:

a. Start purging ring with nitrogen boil off before starting bake out cycle. Turn on purge gas manifold heater to raise the nitrogen gas temperature to $125^{\circ} \mathrm{C}$ at a flow rate of $53 \mathrm{ft} / \mathrm{hr}$. Turn on all ring pump and chamber heaters when starting to purge. Bake aluminum chamber at $125^{\circ} \mathrm{C}$ and the stainless steel parts up to $250^{\circ} \mathrm{C}$. Continue to purge for one hour.

b. Valve off purge gas. Start pump down with megasorb pump. Carbon vane pump is first valved in for about 20 minutes. Stage one is then used to pump down to 500 microns. At 500 microns valve off stage one and pump to 5 microns with stage two.

c. At 5 microns valve off the megasorb pump and valve in the turbomolecular pump. (This pump had been previously started at the same time as the megasorb, but had been left valved off from the ring.) 
4.4 -Leak Test at Bake Temperature

When ring pressure is equal to or less than $10^{-5}$ Torr, leak check ring. Test per procedure.

\subsection{Glow. Discharge Condition Ring}

a. Set up Argon Oxygen (90-10) gas on bleed valve adjacent to magnet section to be conditioned. Purge inlet.

b. Set up protected turbo pumping system on opposite end from bleed, of magnet section to be conditioned.

c. Connect power supply to D.I. pump anode in conditioning section. Insure proper electrical grounding.

d. Set up mass spec. system to monitor gases pumped during conditioning.

e. Adjust bleed valve for a pressure of $20 \mathrm{~m}$ Torr in the section.

f. Turn on and adjust power supply for negative 400 VDC. Next, adjust bleed gas for a current of $300 \mathrm{~mA}$. Run for ten minutes.

g. With supply off, reset for positive voltage. Turn on and adjust current to $300 \mathrm{~mA}$. Run for 20 minutes.

h. Run $M / S$ scan at start and finish of positive conditioning.

i. Repeat 4.5 a through $i$. For sections of ring to be conditioned.

j. RF cavity to be conditioned per procedure when required. 


\section{6 - ISP Conditioning:}

When the pressure is equal to or less than $10^{-5}$ Torr condition all Titanium Sublimination Pumps (TSP). Each of the four filaments in the pump is individually degassed at 20 amps for five minutes. At the end of the five minute degas cycle, each filament is run up to 50 amps for 30 seconds then back to zero. After conditioning, the system should be left connected to filament \#1. Record conditioning of each filament in VuV vacuum log book.

\subsection{DIP Conditioning:}

With pressure equal to or less than $10^{-5}$ Torr condition all Distributed Ion Pumps (DIP's). Dipole magnets must be on for DIP conditioning. The ring ion gauges must be turned on for this conditioning. The dipole magnets are first turned on, then the DIP's are switched on one at a time. Each pump is turned on for 45 seconds and the ion gauge pressure observed. The pressure will rise quite high when the pump is first turned on, but will decrease with each switching on of the pump. Continue this procedure until the pressure no longer increases. Turn off dipole magnets after conditioning the DIP's. Measure pump leakage current with no magnetic field. If pump currents are equal to or greater than $1 \times 10^{-11}$ Torr equivalent pressure, "spark-knock" pumps. Record all leakage currents in VuV vacuum $\log$ book.

4.8 SIP Conditioning:

Condition all SIP's following the procedure described in section 4.7 above for DIP's.

4.9 When the DIP's and SIP's are conditioned as outlined, the cryopump connected to the ring is introduced into the system. The cryopump must have been previously conditioned, cooled down and ready for operation.

4.10 DIP's and SIP's are turned on one at a time for a final condition check. All DIP's and SIP's are turned off at conclusion of this step. 
4.11 - One TI filament in each cartridge is flashed at $50 \mathrm{~A}$ for $2 \mathrm{~min}$. The filament chosen should follow in numerical sequence, if \#1 is broken use filament \#2. All the Ti pumps in the ring are flashed in this fashion. Care must be taken to bring up each filament to $50 \mathrm{~A}$ slowly.

4.12 Both RGA's and IG's are degassed. Discretion is exercised and if there is a large pressure increase, the degas is terminated until pressure returns to a safe level, then repeated. The IG's are gradually degassed to $40 . \mathrm{W} \max$. This process is continued for a 20 min. period. The RGA controllers incorporate an automatic degass ramping circuit. After degassing the $I G$ and $V G$ mass spectrometers are left on.

4.13 The cryopump is valved off and the ring leak checked.

4.14 After the leak check, the bake is terminated (36-48 $\mathrm{hr}$. bakeout) and the cryopump is valved in to the system.

4.15 Al1 the SIP's are turned on. When the pressure reads equal to or less than $10^{-8}$ Torr the TMP's are valved off.

4.16 Approximately.24 hours after terminating the bakeout the Ti pumps are flashed for the last time follow the procedure as outlined in Step 4.11.

4.17 The pressure is monitored with the IG gauges until equilibrium is achieved. 
FIGURE 1.

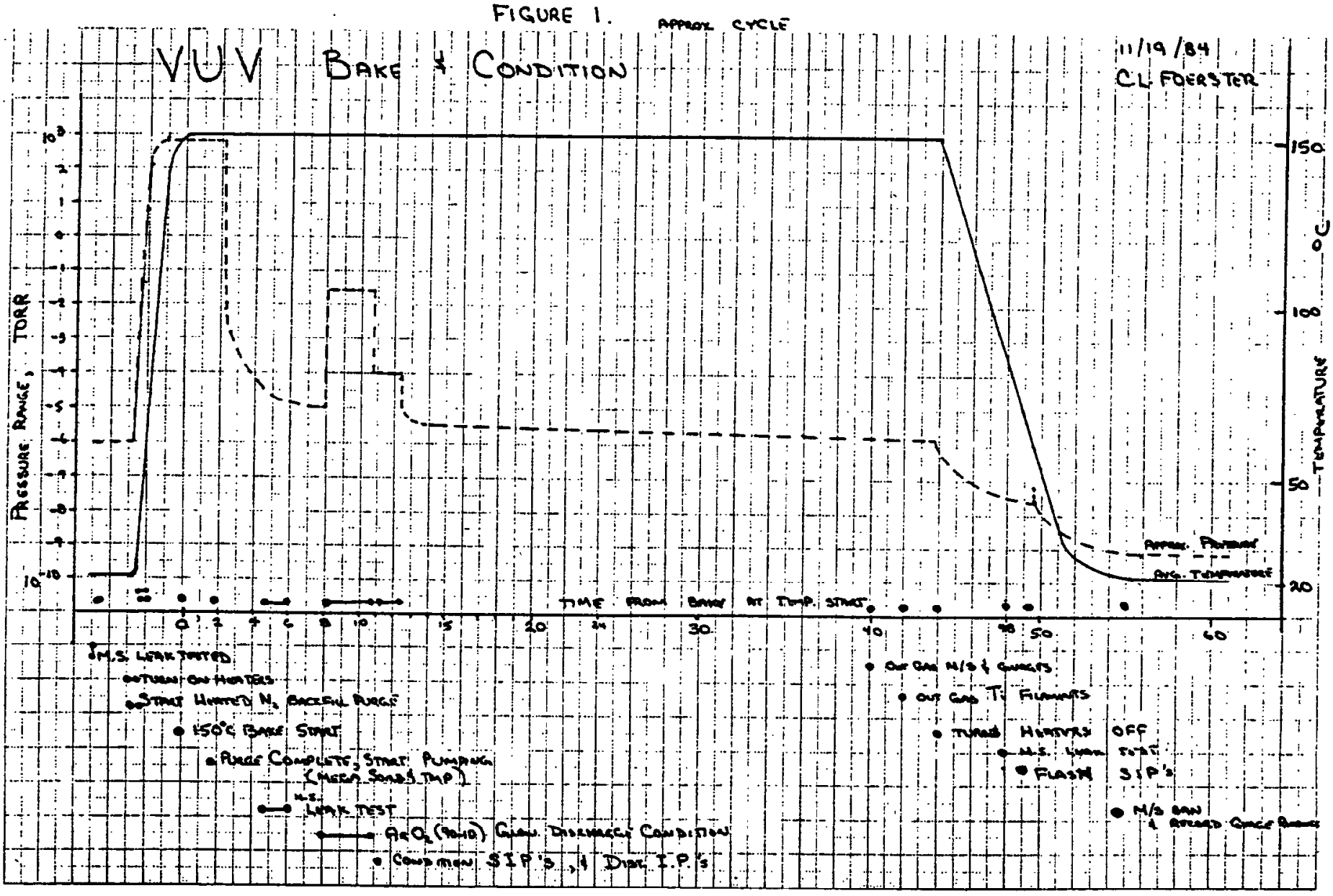


InsT National Synchrotron Light Source

BROOKHAVEN NATIONAL LABORATORY

SLS-07.19-4-1

Date: $1 / 30 / 85$

Rev.:

Page 1 of 7

PREPARED BY: J.C. Schuchman

APPROVED BY: C. Foerster $/$ fouth

VACUUM PROCEDURE

FOR

BAKING OUT VUV OR X-RAY STORAGE RING
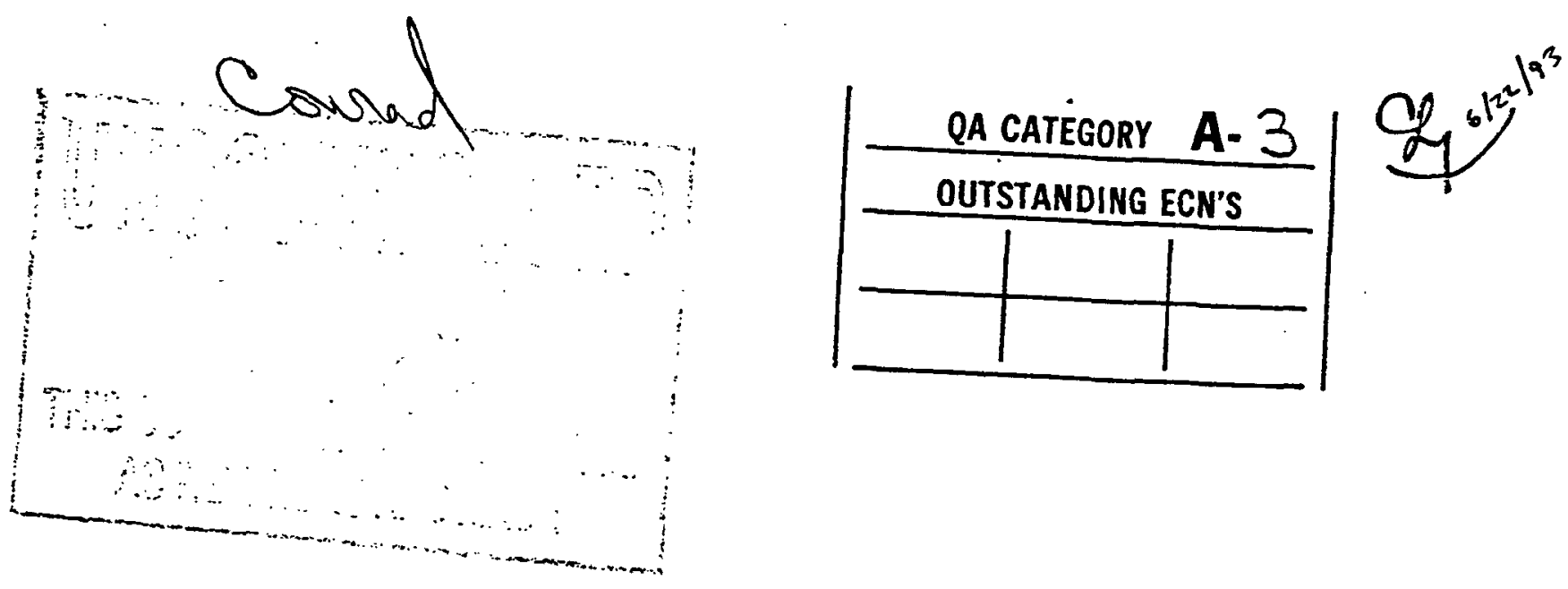

\section{6}

\begin{tabular}{|c|c|c|c|c|c|c|c|c|c|c|c|c|c|c|c|c|c|c|c|c|c|c|c|c|}
\hline REV. & $B$ & A & B & B & $B$ & B & A & & & & & & & & & & & & & & & & & \\
\hline$E \overline{E T}$ & 1 & 2 & 3 & 4 & 5 & 6 & 7 & 8 & 9 & 10 & 11 & 12 & 13 & 14 & 15 & 16 & 17 & 18 & 19 & 20 & 21 & 22 & 23 & \begin{tabular}{|l|l|l|}
24 & 25 \\
\end{tabular} \\
\hline
\end{tabular}




\section{Scope.}

This bakeout procedure encompasses the nitrogen purge, pump down, Teak test, bakeout, and conditioning of all pumps, gauges, and residual gas analyzers in the VUV or $X$-Ray storage ring.

\section{Equipment and Materials}

2.1 Liquid nitrogen boil off supply

2.2 Megasorb pumping station

2.3 Liquid nitrogen

2.4 Turbomolecular pumping station

2.5 Helium leak detector

2.6 Helium supply

2.7 Helium calibrated leak

2.8 Flexible bellows line

$2.9^{\circ}$ White gloves

\section{Set-Up}

3.1 Drain water from chamber and all TSP pumps.

3.2 Start-up leak detector and calibrate to manufacturers specification. Record sensitivity.

3.3 Connect megasorb pumping station to ring roughing valve using

- flexible bellows line (wear white gloves). Charge cryosorption pump with liquid nitrogen.

3.4 Connect turbomolecular pumping (TMP) station to ring roughing valve using flexible bellows line, (wear white gloves). Start TMP.

3.5 Connect leak detector to foreline of turbomolecular pumping station.

3.6 Switch on cryosorption roughing pump. 
4.0 Procedure

* See Fig. 1 for sequence and approximate vacuum bake conditiong cycle.

4.1 Pre-bakeout leak test:

a. Pumpdown ring with megasorb pump. Carbon vane pump is turned on and system is pumped for 20 minutes. Stage one is used to pump the system down to 500 microns. Valve off stage one, and valve in stage two. Pump to 5 microns.

b. When ring pressure reaches 5 microns valve in turbomolecular pump and valve off megasorb pump.

c. When ring pressure is equal to or less than $10^{-5}$ Torr leak check ring.

4.2 Venting with liquid nitrogen boil off:

a. Connect copper venting line to vent vaive. Before connecting, bakeout line with heating tape for one hour at $125^{\circ} \mathrm{C}$. Purge line with nitrogen during bakeout.

b. Slowly open vent valve and vent ring. Vent at a rate comparable to pumpdown rate to avoid stirring up particulate matter and causing undue stresses on chamber.

4.3 Nitrogen Purge and Bakeout Start:

a. Start purging ring with nitrogen boil off before starting bake out cycle. Turn on purge gas manifold heater to raise the nitrogen gas temperature to $125^{\circ} \mathrm{C}$ at a flow rate of $53 \mathrm{ft} / \mathrm{hr}$. Turn on all ring pump and chamber heaters when starting to purge. Bake aluminum chamber at $125^{\circ} \mathrm{C}$ and the stainless steel parts up to $250^{\circ} \mathrm{C}$. Continue to purge for one hour.

b. Valve off purge gas. Start pump down with megasorb pump. Carbon vane pump is first valved in for about 20 minutes. Stage one is then used to pump down to 500 microns. At 500 microns valve off stage one and pump to 5 microns with stage two.

c. At 5 microns valve off the megasorb pump and valve in the turbomolecular pump. (This pump had been previously started at the same time as the megasorb, but had been left valved off from the ring.) 
4.4 -Leak Test at Bake Temperature

When ring pressure is equal to or less than $10^{-5}$ Torr, leak check

ring. Test per procedure.

\subsection{Glow Discharge Condition Ring}

a. Set up Argon Oxygen (90-10) gas on bleed valve adjacent to magnet section to be conditioned. Purge inlet.

b. Set up protected turbo. pumping system on opposite end from bleed, of magnet section to be conditioned.

c. Connect power supply to D.I. pump anode in conditioning section. Insure proper electrical grounding.

d. Set up mass spec. system to monitor gases pumped during conditioning.

e. Adjust bleed valve for a pressure of $20 \mathrm{~m}$ Torr in the section.

f. Turn on and adjust power supply for negative 400 VDC. Next, adjust bleed gas for a current of $300 \mathrm{~mA}$. Run for ten minutes.

g. With supply off, reset for positive voltage. Turn on and adjust current to $300 \mathrm{~mA}$. Run for 20 minutes.

h. Run M/S scan at start and finish of positive conditioning.

i. Repeat 4.5 a through $i$. For sections of ring to be conditioned.

j. RF cavity to be conditioned per procedure when required. 


\section{6 . ISP Conditioning:}

When the pressure is equal to or less than $10^{-5}$ Torr condition all Titanium Sublimination Pumps (TSP). Each of the four filaments in the pump is individually degassed at 20 amps for five minutes. At the end of the five minute degas cycle, each filament is run up to 50 amps for 30 seconds then back to zero. After conditioning, the system should be left connected to filament \#1. Record conditioning of each filament in VuV vacuum log book.

\subsection{DIP Conditioning:}

With pressure equal to or less than $10^{-5}$ Torr condition all Distributed Ion Pumps (DIP's). Dipole magnets must be on for DIP conditioning. The ring ion gauges must be turned on for this conditioning. The dipole magnets are first turned on, then the DIP's are switched on one at a time. Each pump is turned on for 45 seconds and the ion gauge pressure observed. The pressure will rise quite high when the pump is first turned on, but will decrease with each switching on of the pump. Continue this procedure until the pressure no longer increases. Turn off dipole magnets after conditioning the DIP's. Measure pump leakage current with no magnetic field. If pump currents are equal to or greater than $1 \times 10^{-11}$ Torr equivalent pressure, "spark-knock" pumps. Record all leakage currents in VUV vacuum log book.

4.8 SIP Conditioning:

Condition all SIP's following the procedure described in section 4.7 above for DIP's.

4.9 When the DIP's and SIP's are conditioned as outlined, the cryopump connected to the ring is introduced into the system. The cryopump must have been previously conditioned, cooled down and ready for operation.

4.10 DIP's and SIP's are turned on one at a time for a final condition check. All DIP's and SIP's are turned off at conclusion of this step. 
4.11. One $T I$ filament in each cartridge is flashed at $50 \mathrm{~A}$ for $2 \mathrm{~min}$. The filament chosen should follow in numerical sequence, if \#1 is broken use filament \#2. All the Ti pumps in the ring are flashed in this fashion. Care must be taken to bring up each filament to $50 \mathrm{~A}$ slowly:

4.12 Both RGA's and IG's are degassed. Discretion is exercised and if there is a large pressure increase, the degas is terminated until pressure returns to a safe level, then repeated. The IG's are gradually degassed to $40 \mathrm{~W}$ max. This process is continued for a 20 min. period. - The RGA controllers incorporate an automatic degass ramping circuit. After degassing the IG and VG mass spectrometers are left on.

4.13 The cryopump is valved off and the ring leak checked.

4.14 After the leak check, the bake is terminated (36-48 $\mathrm{hr}$. bakeout) and the cryopump is valved in to the system.

4.15 All the SIP's are turned on. When the pressure reads equal to or less than $10^{-8}$ Torr the TMP's are valved off.

4.16 Approximately 24 hours after terminating the bakeout the Ti pumps are flashed for the last time follow the procedure as outlined in Step 4.11 .

4.17 The pressure is monitored with the IG gauges until equilibrium is achieved. 
ACUUM PROCEDURE FOR BAKING OUT VUV OR X-RAY STORAGE RING No. SLS-07.19-4-1
Date: $\frac{1 / 30 / 85}{A}$
Rev.: $\frac{A}{7 \text { of } 7}$
Page

Figure 1

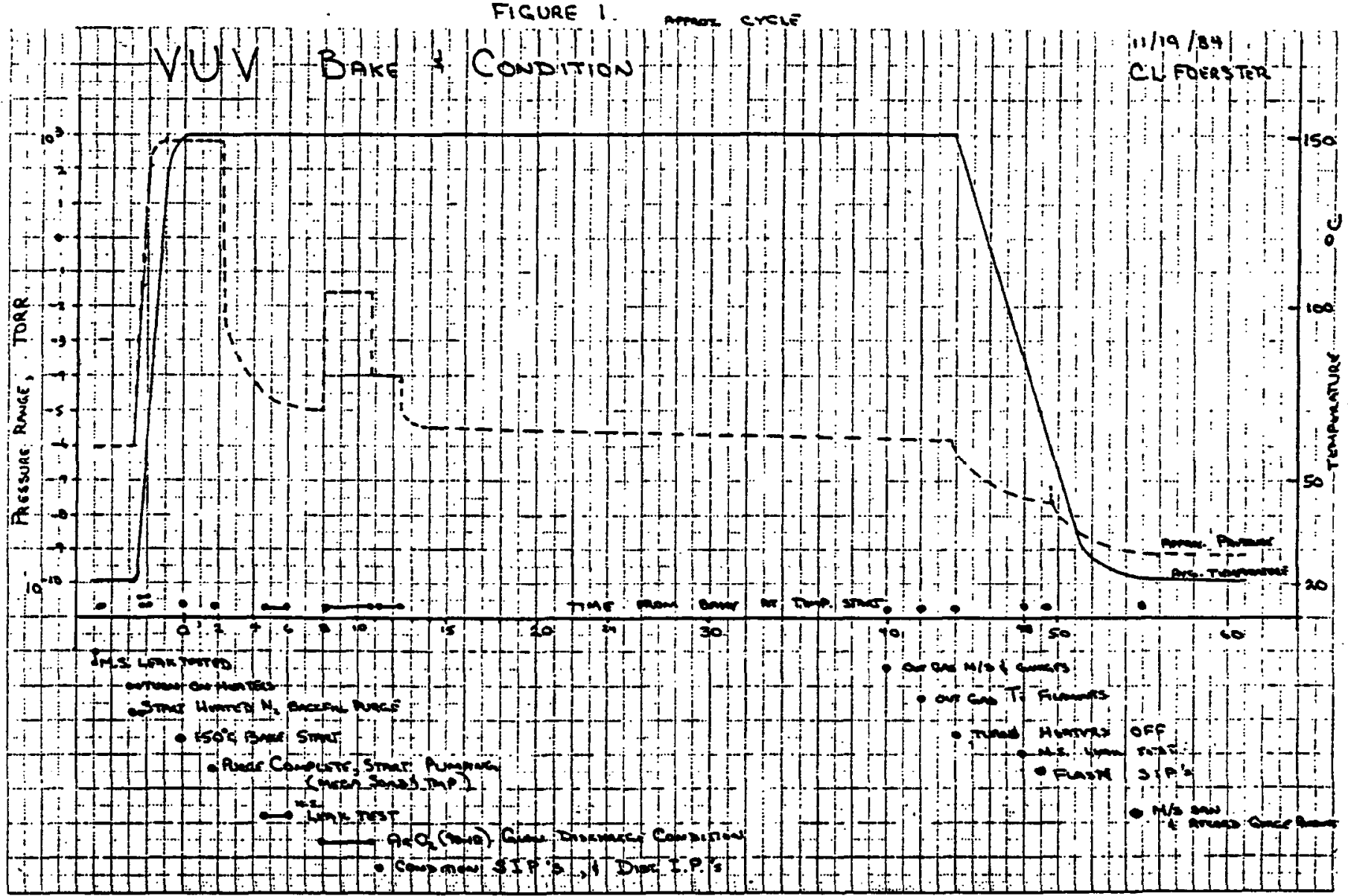


IISTS National Synchrotron Light Source

BROOKHAVEN NATIONAL LABORATORY

No:

$$
\begin{aligned}
& \text { SLS07-19-12-1 } \\
& \text { Date: } 6 / 25 / 26 \\
& \text { Rev.: } \frac{B}{109+3} \\
& \text { Page } 100
\end{aligned}
$$

\section{PREPARED BY: c. FOERSTER f finest \\ APPROVED BY: H. HALAMA MT GleL}

\section{VACUUM PROCEDURE*}

TO

OPEN VUV OR X-RAY FRONT END VALVE

TO RING
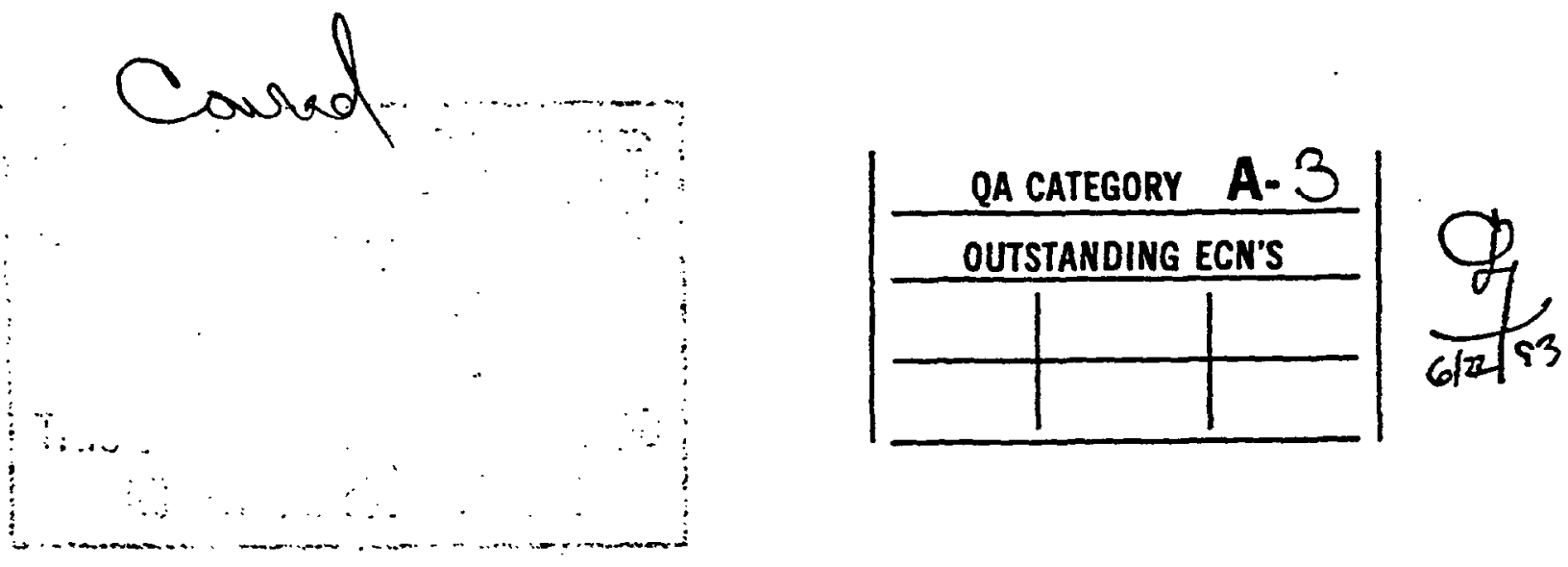

GOT

\begin{tabular}{|l|l|l|l|l|l|l|l|l|l|l|l|l|l|l|l|l|l|l|l|l|l|l|l|l|l|}
\hline PEV. & B & $B$ & $B$ & & & & & & & & & & & & & & & & & & & & & & \\
\hline SHEET|11 & 2 & 3 & 4 & 5 & 6 & 7 & 8 & 9 & 10 & 11 & 12 & 13 & 14 & 15 & 16 & 17 & 18 & 19 & 20 & 21 & 22 & 23 & 24 & 25 & 26 \\
\hline
\end{tabular}




\section{Scope}

Procedure to allow beam lines to be opened to ring with minimum negative effects.

2. Documentation, Materials, and Equipment

2.1 "Policy for NSLS utilization by Participating Research Teams" :

2.2 "Requirements and Guidelines for NSLS Experimental Beam Line Vacuum Systems" BNL 28073. Note: Memo 3/11/85 discontinue use of fomblin oil and grease.

2.3 Calibration factors for ionization gauge (IG) and RGA parent peaks.

2.4 RGA system.

2.5 Nude I.G. and controller.

2.6. SLS-07.19-4-I Vacuum procedure for baking out VúV or $X$-ray ring.

\section{Speciar Instructions}

3.1 To open front end valve to ring the following vacuum requirements must be met.

a. Instrument tee I.G. must indicate $2 \times 10^{-9}$ Torr or less after correcting for calibration factor.

b. The RGA scan must indicate the predominant gas component to be hydrogen and it must be a minimum of $60 \%$ of the total pressure.

c. There shall be no evidence of leaks (external, virtual, etc.) in the system, air or other.

d. High masses, greater than 28 shall be less than $10 \%$ of the total pressure.

e. Hydrocarbons, fluorocarbons, and other gas components indicated at mass locations $38,41,43,45$ and greater shall total less than $1 \times 10^{-11}$ Torr.

f. If instrument tee I.G. indicates $9 \times 10^{-10}$ Torr or less then a $R G A$ scan is not required $(b, c, d, e)$ to open.

\subsection{Any exception to 3.1 must be approved by C. Foerster or H. Hajama.}


4. Setup

4.1 -Beam line vacuum systems which are valved to front end vacuum shall be constructed of materials and techniques as outlined in 2.1 and 2.2

4.2 System components should be vacuum baked and conditioned using 2.6 Vacuum Procedure as a guide. Conditioning must include $\mathrm{ArO}_{2}$ glow discharge cleaning of surfaces which will be subject to beam induced desorption.

4.3 Ion gauge and RGA should be degassed after system conditioning and a minimum of 48 hours prior to system evaluation for front end valve opening.

4.4 Opening of front end to ring valve for first light may only be performed during low beam current operation. Some low beam conditioning is required to prevent excessive pressure. Vacuum group should always be notified and represented.

\section{Procedure}

5.1 Record I.G. reading from instrument tee attached to beam line side of front end to be opened.

5.2 If gauge reading is acceptable, run RGA scan on $10^{-9}$ and $10^{-11}$ ranges. RGA must be degassed and "stabilized" prior to this operation.

a. Multiplier to be set to farday cup reading on mass 28 (calibration).

b. Record on upper right of scan,

1. Date and time

2. Front end number

3. Valve status

4. Ion gauge' reading

5. RGA total pressure readings

c. Record scale next to each mass scan

5.3 If scans are acceptable per 3.1 , vacuum permission is given to open valve.

5.4 If scans are not acceptable, Vacuum Group will advise corrective action.

5.5 When valve is opened monitor pressure and rescan RGA with beam in front end.

a. Record beam current and beam life on scan. 
